Universidad de Lima

Facultad de Ingeniería Industrial

Carrera de Ingeniería Industrial

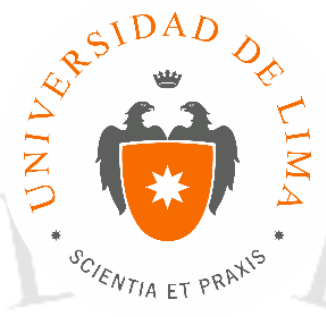

\title{
ESTUDIO DE MEJORA DEL PROCESO DE PRODUCCIÓN DE MAYONESA DE LA
}

\section{EMPRESA ALIEX}

Trabajo de investigación para optar el título profesional de Ingeniero Industrial

Silvia del Pilar Cacho Meza

20090154

Asesor

Carlos Chirinos

Lima - Perú

Noviembre de 2016 


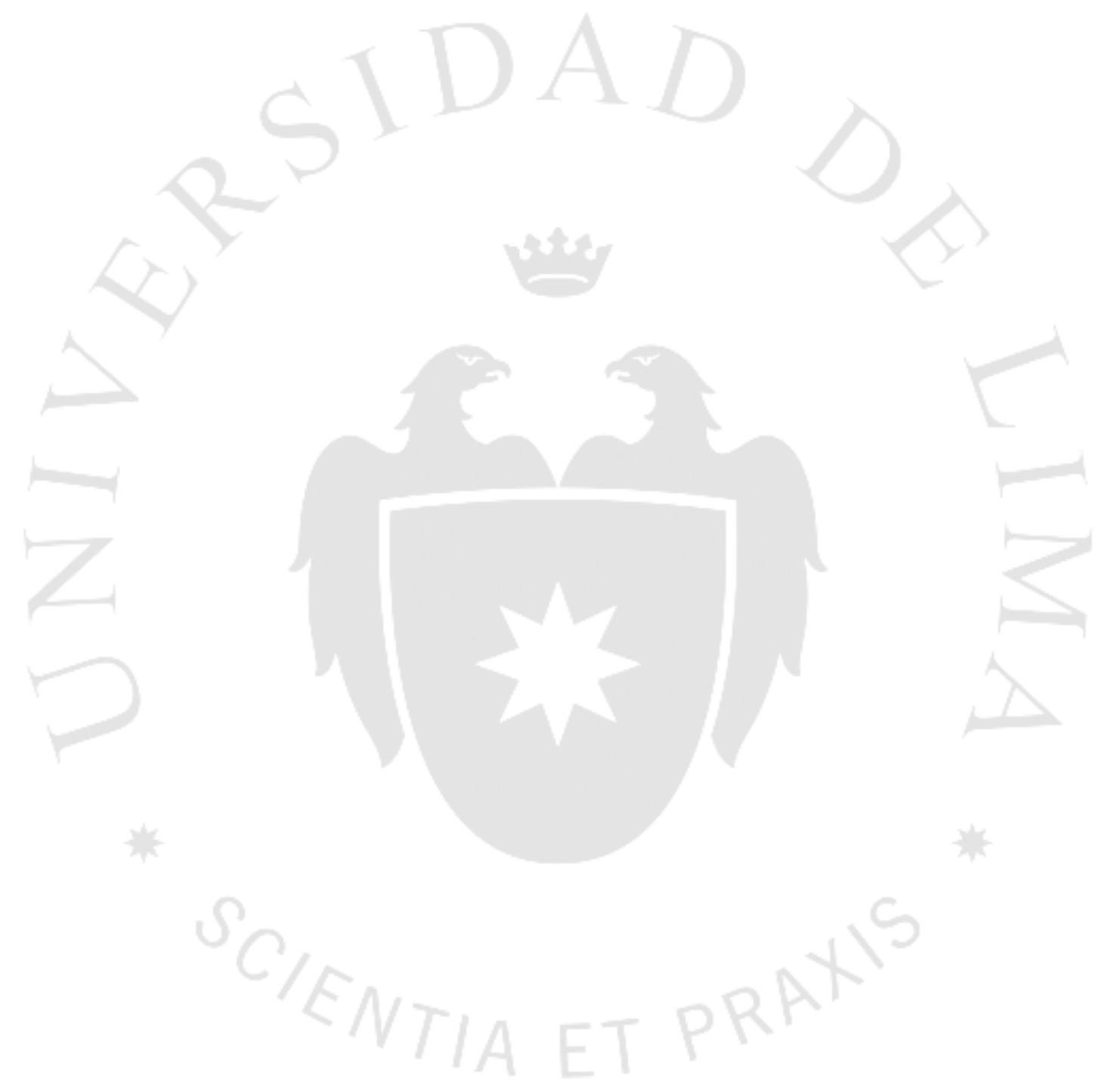




\title{
ESTUDIO DE MEJORA DEL PROCESO DE
} PRODUCCIÓN DE MAYONESA DE LA

\author{
EMPRESA ALIEX
}




\section{TABLA DE CONTENIDO}

RESUMEN EJECUTIVO .............................................

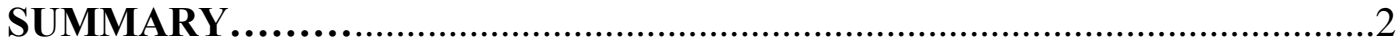

CAPÍTULO I: CONSIDERACIONES GENERALES DE LA

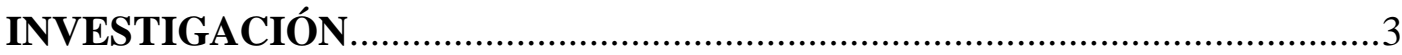

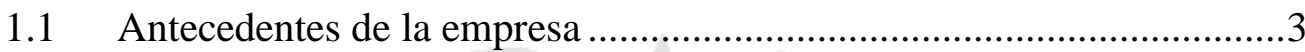

1.1.1 Breve descripción de la empresa y reseña histórica .............................3

1.1.2 Descripción de los productos o servicios ofrecidos ..............................5

1.1.3 Descripción del mercado objetivo de la empresa.....................11

1.1.4 Estrategia general de la empresa...............................12

1.2 Objetivos de la investigación (general y específicos)................13

1.3 Alcance y limitaciones de la investigación.........................14

1.4 Justificación de la investigación..................................14

1.5 Hipótesis de la investigación..................................15

1.6 Marco referencial de la investigación...............................15

1.7 Marco conceptual.............................................16

\section{CAPÍTULO II: ANALISIS SITUACIONAL DE LA EMPRESA Y SELECCIÓN}

DEL SISTEMA O PROCESO A SER MEJORADO ......................... 18

2.1 Análisis Externo de la Empresa..................................18

2.1.1 Análisis del entorno global......................................18

2.1.2 Análisis del entorno competitivo y del mercado........................19

2.1.3 Identificación y evaluación de las oportunidades y amenazas del

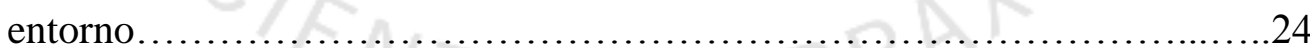

2.2 Análisis Interno de la empresa....................................25

2.2.1 Análisis del direccionamiento estratégico de la empresa..............25

2.2.2 Análisis de la organización y estructura organizacional...............27

2.2.3 Identificación y descripción general de los procesos claves............29

2.2.4 Análisis de los indicadores generales de desempeño de los procesos claves (metas, resultados actuales, tendencias, brechas)....................32 
2.2.5 Determinación de posibles oportunidades de mejora..................37

2.2.6 Selección del sistema o proceso a mejorar...........................38

\section{CAPÍTULO III: DIAGNOSTICO DEL SISTEMA O PROCESO DE ESTUDIO}

3.1 Análisis del sistema o proceso objeto de estudio .44

3.1.1 Caracterización detallada del sistema o proceso objeto de estudio

3.1.2 Análisis de los indicadores generales de desempeño de los procesos claves (metas, resultados actuales, tendencias, brechas)...................48

3.2 Determinación de las causas raíz de los problemas hallados .55

3.2.1 Análisis de los factores que influyen favoreciendo o limitando los resultados actuales

3.2.2 Identificación y evaluación de las fortalezas y debilidades de la empresa.

\section{CAPÍTULO IV: DETERMINACION DE LA PROPUESTA DE SOLUCION61}

4.1 Planteamiento de alternativas de solución a la problemática encontrada...61

4.2 Selección de alternativas de solución. .65

4.2.1 Determinación y ponderación de criterios evaluación de las

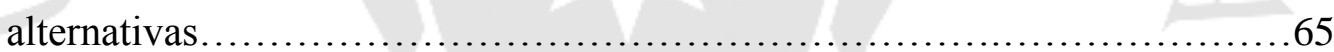

4.2.2 Evaluación cualitativa y cuantitativa de alternativas de solución.......66

4.2.3 Priorización y programación de soluciones seleccionadas................72

\section{CAPÍTULO V: DESARROLLO Y PLANIFICACION DE LAS SOLUCIONES}

5.1 Ingeniería de la solución .73

5.2 Planificación de la implementación de la solución. .95

5.2.1 Determinación de objetivos y metas...............................95

5.2.2 Presupuesto general requerido para la ejecución de la solución.........98

5.2.3 Cronograma de implementación de la solución. .99 


\section{CAPÍTULO VI: EVALUACIÓN DE LA SOLUCIÓN Y BENEFICIOS}

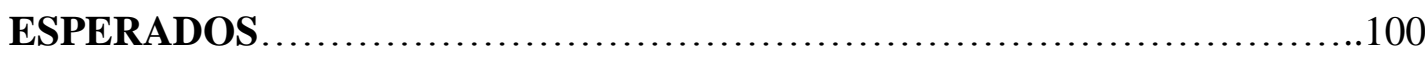

6.1 Evaluación económica financiera de la solución........................100

6.2 Determinación de escenarios que afectarían la solución..................101

6.3 Análisis del impacto social y ambiental de la solución....................104

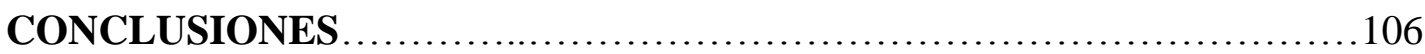

RECOMENDACIONES ............................................... 107

REFERENCIAS .......................................................... 108

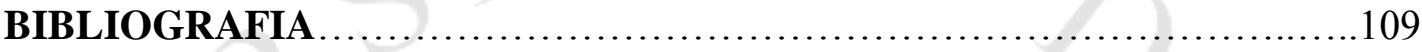

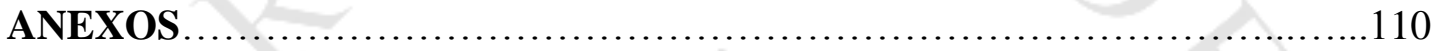




\section{ÍNDICE DE TABLAS}

Tabla 1.1: Listado de productos de ALIEX ............................................................ 6

Tabla 1.2: Valoración de aspectos de niveles de productos de ALIEX …..................... 10

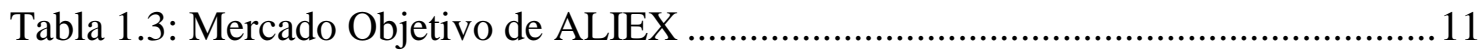

Tabla 1.4: Tipo de Estrategias generales de ALIEX .................................................. 13

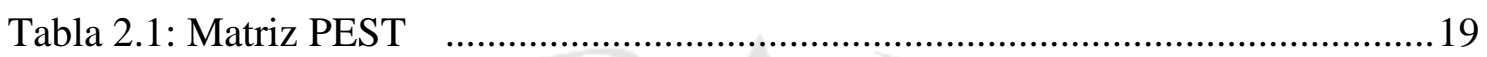

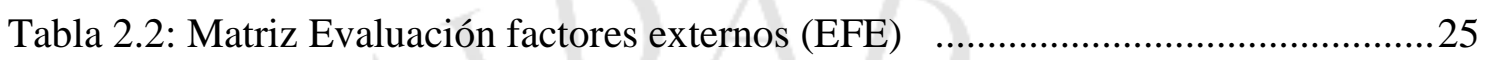

Tabla 2.3: Elementos de la visión de ALIEX …......................................................26

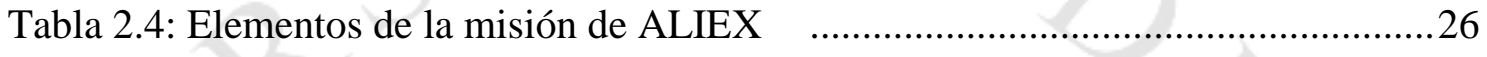

Tabla 2.5: Historial crecimiento ventas totales de ALIEX …......................................... 33

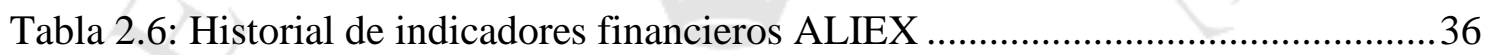

Tabla 2.7: Costo (S/.) incurridos por productos devueltos ........................................ 36

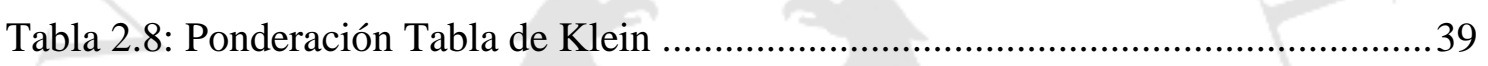

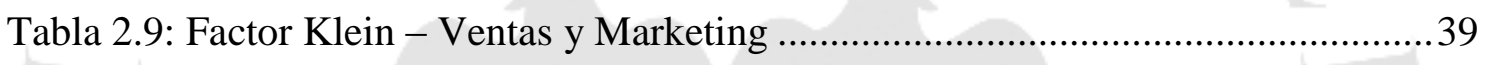

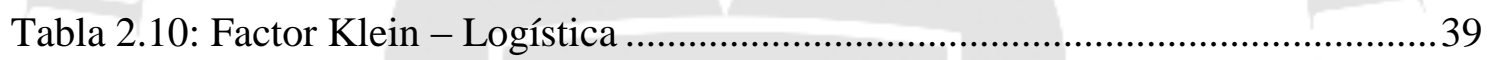

Tabla 2.11: Factor Klein - Aseguramiento de la calidad .......................................... 40

Tabla 2.12: Factor Klein - Recursos Humanos ........................................................... 40

Tabla 2.13: Factor Klein - Finanzas y Contabilidad ............................................... 40

Tabla 2.14: Factor Klein - Producción ................................................................... 41

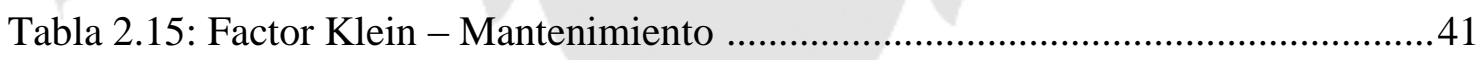

Tabla 2.16: Ponderación desempeño de procesos ....................................................... 41

Tabla 2.17: Ventas Totales históricas de Mayonesa en soles por tipo de formato .........43

Tabla 2.18: Crecimiento de ventas mayonesa en sachets de $10 \mathrm{gr}$.............................43

Tabla 3.1: Evolutivo del indicador utilización de licuadora en porcentaje (HNP/HBP) 48

Tabla 3.2: Evolutivo del indicador Productividad Mano de Obra (Kg/HH) - Licuado .. 50

Tabla 3.3: Evolutivo del indicador utilización de envasadora de 10 gr en porcentaje ...52

Tabla 3.4: Evolutivo del indicador productividad de mano de obra (Cajas/HH) -

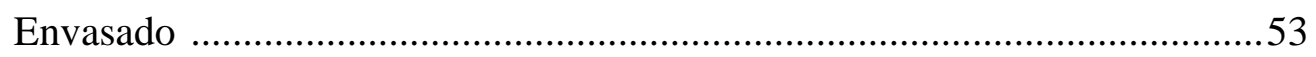

Tabla 3.5: Causas raíces de problemas identificados ..................................................58

Tabla 3.6: Matriz de evaluación de factores internos (EFI) .......................................... 60

Tabla 4.1: Pesos de criterios y escalas de calificación ...................................................61

Tabla 4.2: Matriz de selección de causas principales .....................................................62 
Tabla 4.3: Ranking de causas

Tabla 4.4: Escala de calificación y pesos de criterios para la elección de soluciones ....66

Tabla 4.5: Alternativas de solución para la causa 2 ...................................................66

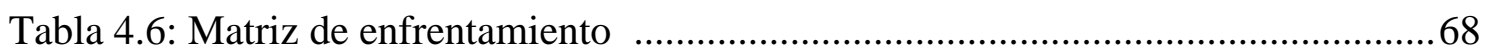

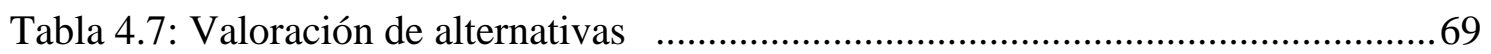

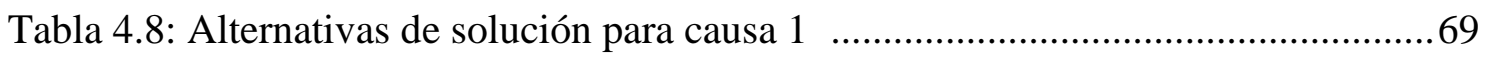

Tabla 4.9: Alternativas de solución para causa 4 ..................................................... 70

Tabla 4.10: Matriz de enfrentamiento - Soluciones propuestas $\quad$..................................72

Tabla 5.1: Pronóstico de ventas en cajas x 252 sachets de 10 gr ….............................76

Tabla 5.2: Lista de materiales (BOM) para semielaborado de $100 \mathrm{Kg}$ de Mayonesa .... 77

Tabla 5.3: Listado de materiales (BOM) del Producto terminado (Cajas de 252 sachets)

Tabla 5.4: Plantilla de un MRP I (Plan de requerimiento de materiales) ...................... 79

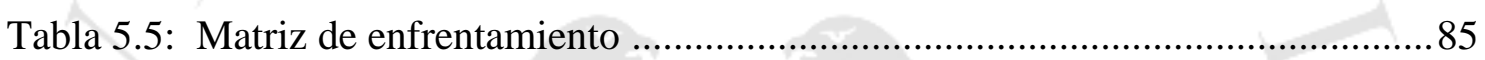

Tabla 5.6: Matriz de selección para la Valoración de alternativas ……........................85

Tabla 5.7: Relación de máquinas del área de mayonesa ...............................................91

Tabla 5.8: Plantilla de una orden de trabajo de mantenimiento ...................................93

Tabla 5.9: Histórico de Venta en soles de Mayonesa ......................................................96

Tabla 5.10: Venta en Cajas por 252 sachets de 10gr de mayonesa del $2015 \quad$..............96

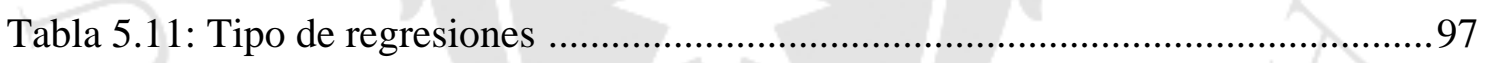

Tabla 5.12: Pronóstico de Venta en cajas de 252 sachets de 10 gr para los próximos 12

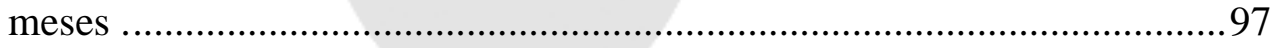

Tabla 5.13: Cajas de 252 sachets de 10 gr. adicionales a vender ..................................98

Tabla 5.14: Presupuesto en soles de las soluciones propuestas ....................................98

Tabla 5.15: Cronograma de implementación de las soluciones ....................................99

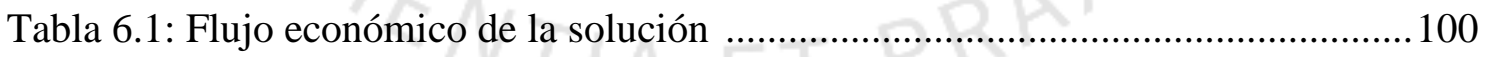

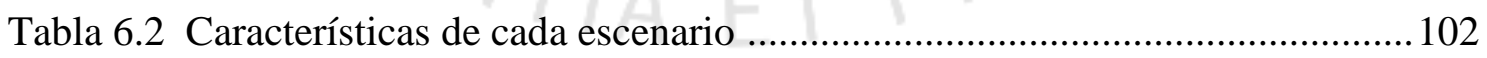

Tabla 6.3: Flujo económico del escenario optimista de la solución ............................ 103

Tabla 6.4: Flujo económico del escenario pesimista de la solución .............................. 103

Tabla 6.5: Resultados ponderados de escenarios que afectarían la solución ............... 104

Tabla 6.6: Análisis ambiental de la solución propuesta .............................................. 105 


\section{ÍNDICE DE FIGURAS}

Figura 1.1: Evolutivo del volumen de ventas en soles por tipo de producto de ALIEX .7

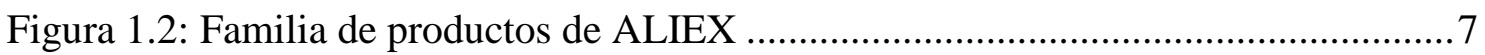

Figura 1.3: Productos de consumo masivo - ALIEX ........................ 8

Figura 1.4: Productos de consumo semi industrial - ALIEX ........................................ 8

Figura 1.5: Productos de consumo industrial - ALIEX …............................................

Figura 1.6: Descripción de productos básico, real y aumentado - ALIEX ..................... 10

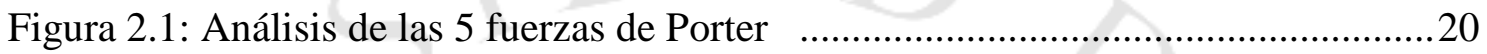

Figura 2.2: Matriz producto - tamaño empresa .........................................................2 22

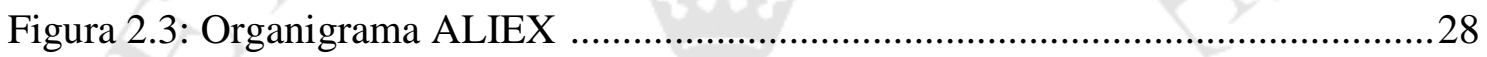

Figura 2.4: Macro proceso de ALIEX...................................29

Figura 2.5: Causas de devoluciones de productos por mes de ALIEX .........................37

Figura 2.6: Desempeño de los procesos de ALIEX ................................................. 42

Figura 3.1: Diagrama de Operaciones del Proceso - Producción de mayonesa en sachets

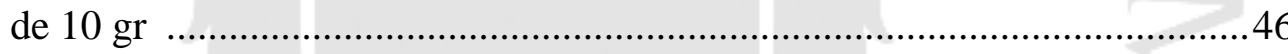

Figura 3.2: Diagrama de balance de materia - Producción de mayonesa en sachets de 10 gr )

Figura 3.3: Evolutivo del indicador de utilización de licuadora en \% (HNP/HBP).....48

Figura 3.4: Desviación estándar de la utilización de la licuadora .49

Figura 3.5: Evolutivo del indicador Productividad Mano de Obra $(\mathrm{Kg} / \mathrm{HH})-$

Licuado.

Figura 3.6: Evolutivo de cumplimiento Productividad Mano de Obra (\%) vs.

Productividad mano de obra estándar - Licuado

Figura 3.7: Desviación estándar Productividad Mano de Obra (Kg/HH) - Licuado .....51

Figura 3.8: Evolutivo del indicador utilización en porcentaje - Envasado ......................52

Figura 3.9: Desviación estándar de la utilización de la envasadora de 10 gr

Figura 3.10: Evolutivo del indicador productividad de mano de obra (Cajas/HH) -

Envasado

Figura 3.11: Evolutivo de cumplimiento del indicador productividad de mano de obra (PMO) vs. Productividad de mano de obra estándar en porcentaje - 
Figura 3.12: Desviación estándar productividad mano de obra - Envasado .55

Figura 3.13: Diagrama de Causa - Efecto: KPI Eficiencia (utilización de la envasadora automática Fustec y Productividad Mano de Obra del envasado de Mayonesa 10gr) .56

Figura 3.14: Diagrama de Causa - Efecto: KPI Eficiencia de Línea (utilización de la licuadora y Productividad Mano de Obra del licuado de Mayonesa 10gr)57

Figura 4.1: Diagrama de Pareto - Causas de problemas en el proceso de producción ..63

Figura 5.1: Metodología PMBOK (Project Management Body of Knowledge) para implementar un MRP I (Planeamiento de requerimiento de materiales) ...73

Figura 5.2: Flujo de Inputs y Outputs de un MRP I (Planeamiento de requerimiento de materiales)

Figura 5.3: Diagrama de Flujo para la implementación de un MRP I (Planeamiento de requerimiento de materiales) - Contratación del analista PCP.

Figura 5.4: Esquema software de ALIEX actual.

Figura 5.5: Diagrama de Flujo para la implementación de un software MRP I

(Planeamiento de requerimiento de materiales). .84

Figura 5.6: Esquema software propuesto .86

Figura 5.7: Outputs del módulo PCP (Planeamiento y control de la producción) de Capataz Flex

Figura 5.8: Flujo para la implementación del programa de mantenimiento preventivo. 90

Figura 5.9: Diagrama de flujo del bloque A .92

Figura 5.10: Diagrama de flujo del bloque B .94

Figura 5.11: Evolutivo del indicador de utilización de licuadora en porcentaje (HNP/NBP) - Escenario actual

Figura 5.12: Pronóstico del indicador utilización de licuadora en porcentaje (HNP/NBP) - Escenario meta ............................................................................. 96

Figura 6.1: Evolutivo ventas en soles 2015 - Cajas de 252 sachets de 10 gr...... 101 


\section{ÍNDICE DE ANEXOS}

Anexo 1: Formato de encuesta virtual para la definición de las estrategias genéricas de ALIEX

Anexo 2: Puntuación obtenida en la encuesta sobre ventajas competitivas .................114 Anexo 3: Plan de trabajo de mantenimiento preventivo para la licuadora de mayonesa

Anexo 4: Plan de trabajo de mantenimiento preventivo para la envasadora sacheteadora 


\section{RESÚMEN EJECUTIVO}

El objetivo general de la presente mejora aplicada busca incrementar la eficiencia del proceso productivo de mayonesa envasada y para ello cuenta con 6 capítulos los cuales se describirán a continuación.

ALIEX es una empresa familiar que inició operaciones en los años 80 en una pequeña casa en San Borja y actualmente cuenta con una planta en el distrito de Lurín. Los tipos de productos que ofrece son principalmente salsas de mesa y pulpas de fruta. Mercados mayoristas, minoristas, distribuidores, autoservicios, bodegas son los mercados a los que se dirige. La principal estrategia genérica de ALIEX es liderazgo en costos. Asimismo, mediante justificaciones técnicas, sociales y económicas se determinó que es factible cumplir el objetivo general planteado de la investigación.

Después de realizar un análisis interno y externo de ALIEX se determinó que el proceso con mayores oportunidades de mejora es producción. Se eligió mejorar la línea de producción de mayonesa pues es la salsa de mesa que genera más ingresos en soles a la empresa.

Luego de analizar los indicadores de desempeño del proceso de mayonesa se identificó que las principales causas que limitaban obtener el resultado deseado en ellos eran el no tener un planeamiento y control de la producción adecuado, no contar con un programa de mantenimiento preventivo para las máquinas y la inexistencia de una envasadora automática solo para el envasado de mayonesa. Es por ello que se propuso implementar un módulo MRP I (Material Requirement Planning) para lograr una adecuada planificación de materiales e insumos e implementar un programa de mantenimiento preventivo para evitar paradas prolongadas en las máquinas.

Finalmente se determinó que el proyecto es viable pues se logrará obtener los resultados deseados en los indicadores de desempeño del proceso de producción y se obtendrá un VAN S/. 17,247 de y una TIR de $31 \%$. 


\section{EXECUTIVE SUMMARY}

The general objective of this research is to increase the efficiency of the mayonnaise production process. In the next lines below, it is described how the objective is achieved.

ALIEX is a family business that started operations in the 80 's in a small house in San Borja and now the factory is located the district of Lurín. The main products ALIEX offers are sauces for food and fruit pulps. Traditional markets, retailers, distributors, small markets are the markets to which the business is focused on. ALIEX's main generic strategy is cost leadership. Also, due to technical, social and economic explanations, it was concluded that it is possible to achieve the research general objective.

Having made an internal and external analysis of ALIEX, it was identified that the process with more opportunities for improvement is production. It was chosen to improve the production process of mayonnaise because it gives more income (in soles) to the company than the other sauces.

Having analyzed the KPIs performance of the mayonnaise process, it was identified that the main causes which limited achieve the desired result were not having a correct production planning and control, not having a preventive maintenance program of the machines and the absence of an automatic packaging machine only for package mayonnaise. Thas is the reason why it was proposed to get a Material Requirement Planning (MRP) module to have a correct material planning and to implement a preventive maintenance program to avoid prolonged machine stops.

Finally, it was concluded that the project will get the desired results in production KPIs and refering to economic results the research will obtain a VAN of S /. 17,247 and a TIR of $31 \%$. 


\section{CAPÍTULO I: CONSIDERACIONES GENERALES DE LA INVESTIGACIÓN}

\subsection{Antecedentes de la empresa}

\subsubsection{Breve descripción de la empresa y reseña histórica}

ALIEX es una empresa de capitales peruanos que se dedica a la producción y comercialización de salsas de mesa y pulpas de fruta. En este sentido articula todas las etapas de la cadena de valor, desde el cultivo, cosecha hasta el procesamiento, envasado y comercialización de sus productos bajo exigentes normas de calidad.

ALIEX ha diversificado sus operaciones en tres tipos de productos que son; de consumo industrial, consumo semi-industrial y consumo masivo. Cada uno se está comercializando de forma incremental en su respectivo canal.

Dentro de consumo industrial existen productos como pulpas de frutas destinadas a empresas industriales como son Gloria, Laive, AJE, Sodexo, Delosi, etc. Estas importantes empresas los usan como materia prima para la preparación de yogures y refrescos que distribuyen a nivel nacional.

Dentro de consumo Semi-industrial se encuentra productos desarrollados para la industria gastronómica nacional como salsas de mesa: mayonesa, kétchup, mostaza, ajíes, entre otros. Pensando en la economía de estos negocios ALIEX proporciona formatos voluminosos que permitan ahorrar costos en envases. Estos productos se comercializan en el canal tradicional (mayoristas) y distribuidores especializados.

Dentro de consumo masivo se encuentran también salsas de mesa pero en formatos más pequeños, desarrollados para el consumo de todo tipo de personas, tanto jóvenes como adultos. En este mercado se incluyen sabores más innovadores y exclusivos debido a los distintos gustos del consumidor final usando envases seleccionados de la mejor calidad. Estos productos se comercializan en las mejores cadenas de autoservicios como Plaza Vea, Tottus y Makro. 


\section{$\underline{\text { Reseña Histórica }}$}

En los años 80 el Ingeniero Luis Cacho, joven profesor de la Universidad Agraria producía con sus alumnos una mermelada tan rica que su esposa Esperanza Meza encontró en este potaje una oportunidad. Por eso, con apenas un perol de bronce y una cocina de Kerosene, la pareja empezó a producir en casa 50 Kilos de mermelada al día, la cual se vendía en su totalidad en las bodegas de San Borja. Muy pronto entraron a colaborar en la cocina los hermanos menores de Esperanza (Alberto y Javier Meza), que en poco tiempo se convirtieron en socios mayoritarios. Se trataba de una sociedad formada voluntariamente, e informal en la toma de decisiones con una laxa estructura jerárquica. Se podría decir que cada uno de los socios asumía simultáneamente los roles de propietarios, directivos y operario cuando era necesario.

En lo referente al control de la empresa no hubo problemas. Los dueños estuvieron al tanto de todo lo que sucedía, ejerciendo control de todas las actividades que creían convenientes. No fueron necesarios sistemas de información sofisticados ya que toda la información se encontraba dentro de la cabeza de los fundadores y en documentos muy simples como agendas personales. A continuación se da una breve referencia del perfil de los socios fundadores:

Socio 1: Luis Cacho Rojas. Ingeniero de Industrias Alimentarias de la Universidad Nacional Agraria, con maestría en tecnología de alimentos den Bélgica. Se desempeñó como catedrático en su misma universidad y tenía un perfil científico y conservador. Ocupaba el cargo de Gerente de Producción.

Socio 2: Alberto Meza Cacho: Ingeniero Industrial de la Universidad de Lima. Trabajó desde egresado en la empresa familiar. Tenía un perfil de temperamento equilibrado y carácter muy carismático. Ocupaba el cargo de Gerente Administrativo.

Socio 3: Javier Meza Cacho, Ingeniero de Industrias Alimentarias de la Universidad Nacional Agraria. Desde egresado trabajó gestionando las actividades comerciales de la empresa familiar. Tiene un perfil comercial, extrovertido e intuitivo. Ocupaba el cargo de Gerente Comercial.

Posteriormente llego la época de la inflación y era difícil conseguir fresas para la mermelada, por lo que los socios decidieron producir kétchup ya que tenían un amigo 
que les regalaba tomates que sobraban de su chacra. Entonces Javier Meza, quien desde muchacho demostró su gusto por las ventas, empezó a ofrecer este producto en baldes de 5 Kilos a restaurantes de Miraflores y San Isidro, pero pronto se dio cuenta de que la verdadera oportunidad de crecer estaba en los mercados mayoristas. "Si en locales como el Mediterráneo Chicken se vendían 20 baldes de kétchup, cada quincena en Caquetá y la Parada se vendían 600 baldes" afirma Javier Meza. Este producto se revendía en pollerías de los conos de lima.

Había llegado el momento de crecer como industria. Así en 1990 los socios compraron un terreno en Canto Grande para elaborar Kétchup, retomar la producción de mermelada de fresa y empezar a elaborar mostaza y mayonesa con su marca Paraíso Tropical, la cual posteriormente se cambió por Walibi. Pero como en esa época los socios todavía no tenían el capital necesario para importar máquinas industriales, entonces decidieron fabricar su propio molino coloidal y varias licuadoras que replicaron de otras fábricas, ya que Luis era ingeniero y la creatividad le sobraba. De esa manera, pudieron colocar sus productos en provincias. En el 2002 los socios compraron un terreno en Lurín a donde se mudó toda la planta ya que Canto Grande les había quedado chico. Ya en Lurín, se empezó a desarrollar nuevas versiones de kétchup, mostaza y mayonesa, además de pulpas de fruta, las cuales se empezaron a vender a clientes corporativos como Gloria, Laive, Sodexo etc.

Lamentablemente, en Diciembre del 2007, un accidente de tránsito acabó con la vida de Luis y Alberto, es entonces cuando Javier se hizo cargo de la empresa y se propuso nuevos retos. Posteriormente en el año 2013 Gilmer Cacho, hijo de Luis, después de haber terminado su MBA, asumió la gerencia general donde se encuentra desempeñándose actualmente.

\subsubsection{Descripción de los productos o servicios ofrecidos}

En la tabla 1.1 se detalla la familia de salsas de mesa y concentrados de fruta natural que ALIEX produce y comercializa. Asimismo, se muestra en la figura 1.1 el volumen de ventas en soles que tiene cada tipo producto, donde se observa que el producto con mayor participación es la mayonesa. Cabe resaltar que el $62 \%$ de la venta total de ALIEX en el año 2015 fue por ventas de salsas de mesa (mostaza, mayonesa y kétchup). 
Tabla 1.1

Listado de productos de ALIEX

\begin{tabular}{|c|c|c|c|c|}
\hline Tipo de salsa & Envase & $\begin{array}{l}N^{\circ} \text { unidades } \\
\text { por envase }\end{array}$ & Unidad & $\begin{array}{l}\text { Peso por } \\
\text { unidad }\end{array}$ \\
\hline \multirow{6}{*}{ Ketchup } & & & Balde & $20 \mathrm{~kg}$ \\
\hline & & & Balde & $10 \mathrm{~kg}$ \\
\hline & Pack & 4 & Balde & $4 \mathrm{~kg}$ \\
\hline & Caja & 250 & Sachet & $10 \mathrm{gr}$ \\
\hline & Caja & 6 & Bolsa Doy Pack & $1 \mathrm{~kg}$ \\
\hline & Caja & 12 & Bolsa Doy Pack & $200 \mathrm{gr}$ \\
\hline \multirow{7}{*}{ 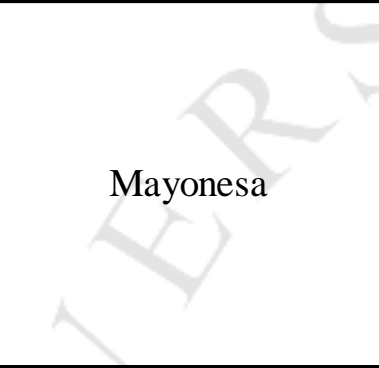 } & + & & Balde & $20 \mathrm{~kg}$ \\
\hline & & & Balde & $10 \mathrm{~kg}$ \\
\hline & Pack & 4 & Balde & $4 \mathrm{~kg}$ \\
\hline & Caja & 250 & Sachet & $10 \mathrm{gr}$ \\
\hline & Caja & 1000 & Sachet & $5 \mathrm{gr}$ \\
\hline & Caja & 12 & Bolsa Doy Pack & $200 \mathrm{gr}$ \\
\hline & Caja & 14 & Bolsa Doy Pack & $1 \mathrm{~kg}$ \\
\hline \multirow[t]{5}{*}{ 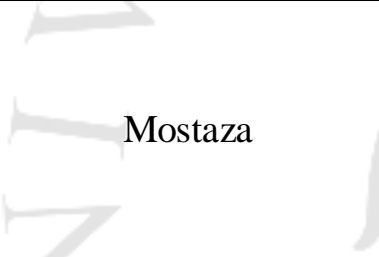 } & & & Balde & $10 \mathrm{~kg}$ \\
\hline & Pack & 4 & Balde & $4 \mathrm{~kg}$ \\
\hline & Caja & 250 & Sachet & $10 \mathrm{gr}$ \\
\hline & Caja & 14 & Bolsa Doy Pack & $1 \mathrm{~kg}$ \\
\hline & Caja & 12 & Bolsa Doy Pack & $200 \mathrm{gr}$ \\
\hline Mermelada & & & Balde & $20 \mathrm{~kg}$ \\
\hline Concentrado chicha & Caja & 14 & Bolsa & $1 \mathrm{~kg}$ \\
\hline \multirow{2}{*}{$\begin{array}{c}\text { Concentrados de pulpas } \\
\text { de fruta }\end{array}$} & Caja & 14 & Bolsa & $1 \mathrm{~kg}$ \\
\hline & Caja & 1 & Bolsa & $20 \mathrm{~kg}$ \\
\hline \multirow{2}{*}{ Pasta de tomate } & Pack & 4 & Balde & $4 \mathrm{~kg}$ \\
\hline & Caja & 12 & Bolsa Doy Pack & 200 gr \\
\hline \multirow{2}{*}{$\begin{array}{c}\text { Aji criollo/ Aceitunesa / } \\
\text { Mayoqueso }\end{array}$} & Caja & 12 & Bolsa Doy Pack & $200 \mathrm{gr}$ \\
\hline & Caja & 250 & Sachet & $10 \mathrm{gr}$ \\
\hline \multirow{2}{*}{ Vinagretas } & Caja & 12 & Bolsa Doy Pack & $200 \mathrm{gr}$ \\
\hline & Caja & 6 & Bolsa Doy Pack & $1 \mathrm{~kg}$ \\
\hline
\end{tabular}

Fuente: ALIEX, (2016) 
Figura 1.1

Evolutivo del volumen de ventas en soles por tipo de producto de ALIEX

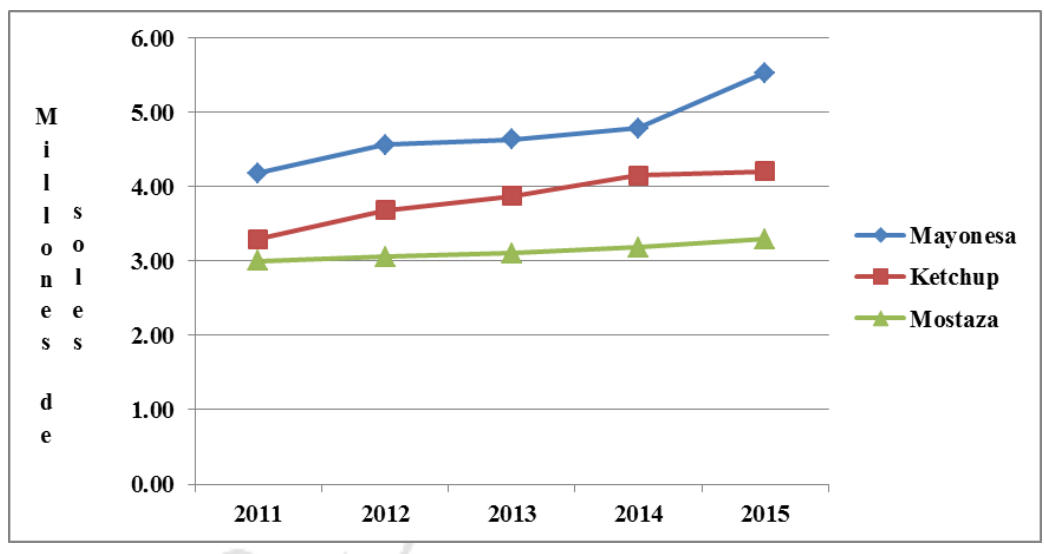

Fuente: ALIEX, (2016)

En la figura 1.2 se puede visualizar los distintos formatos de cada tipo de producto, los cuales se fabrican para comercializarlos en distintos tipos de mercados (tradicionales, modernos) dirigidos a distintos tipos de clientes finales. ALIEX ha dividido los productos en 3 tipos de negocio de acuerdo al tipo de mercado: consumo masivo, consumo semi industrial y consumo industrial.

Figura 1.2

Familia de productos de ALIEX

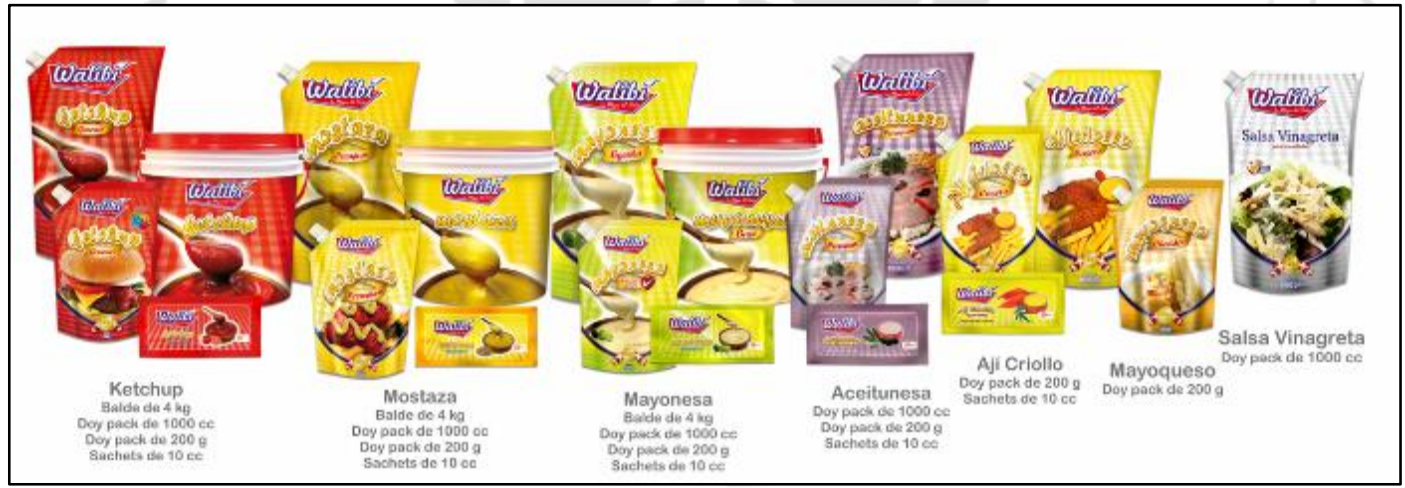

Fuente: ALIEX, (2016)

Dentro del consumo masivo se encuentran productos desarrollados para el consumo de todos los segmentos poblacionales los cuales se muestran en la figura 1.3. La idea es complementar las comidas con los sabores más innovadores, usando insumos y envases en formatos pequeños y exclusivos. Dentro de ellos se puede encontrar mayonesa, kétchup, mostaza, aceitunesa, ají, y mayoqueso. Dichos formatos se 
comercializan en el canal moderno, principalmente en supermercados, mercados periféricos y bodegas.

Figura 1.3

Productos de consumo masivo - ALIEX

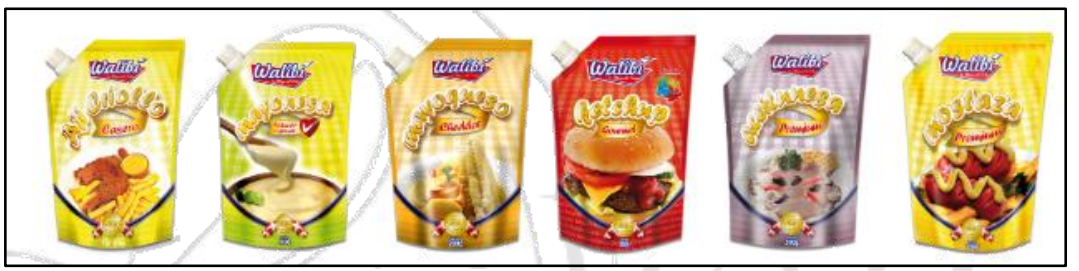

Fuente: ALIEX, (2016)

Dentro del consumo semi industrial se encuentran productos en formatos voluminosos (figura 1.4) que permiten ahorrar en envases. Dichos productos son desarrollados para la industria gastronómica nacional. Asimismo, se comercializan en el canal tradicional (mercados mayoristas y minoristas) y distribuidores especializados. Dentro de ellos se encuentra mostaza, kétchup y mayonesa. En esta categoría se incluyen también los formatos sachets pues se busca colocarlos en restaurantes.

\section{Figura 1.4}

Productos de consumo semi industrial - ALIEX
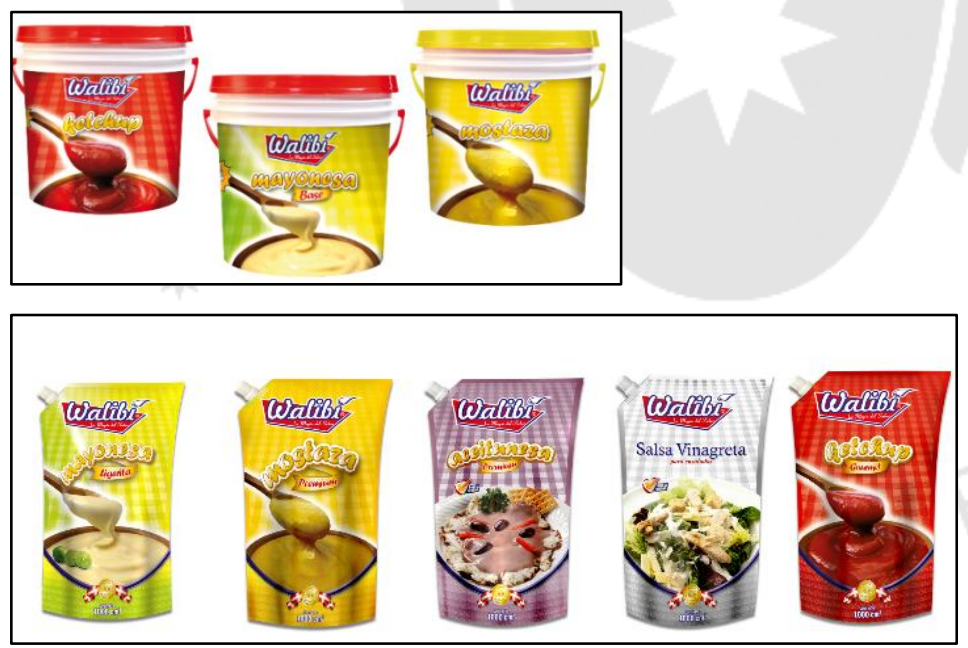

Fuente: ALIEX, (2016)

Dentro del consumo industrial se encuentra productos que están destinados a empresas industriales como son Gloria, Laive, AJE, Sodexo, Delosi, etc. Se puede encontrar concentrado de chicha morada, pulpas de fruta naturales y pasta de tomate como se muestra en la figura 1.5 . 
Figura 1.5

Productos de consumo industrial - ALIEX

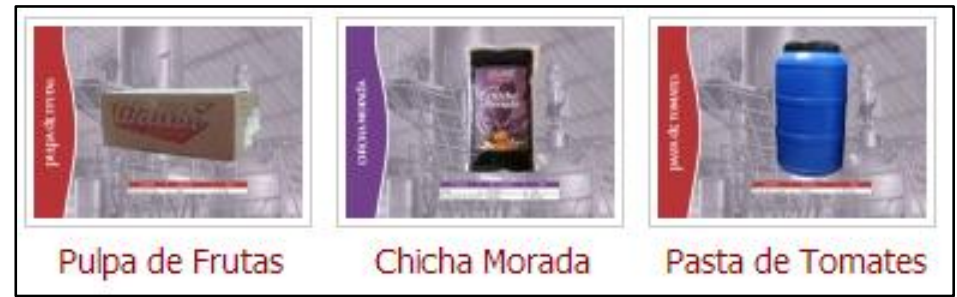

Fuente: ALIEX, (2016)

Niveles de producto

Como se ha visto, principalmente ALIEX produce y comercializa salsas de mesa. Como se observa en la figura 1.6, el producto básico son distintas salsas de mesa que buscan otorgarle un mejor sabor a las comidas peruanas

El producto real está compuesto de un alto nivel de calidad, durabilidad y confiabilidad de las salsas. Asimismo, están acompañadas de empaques de calidad que facilitan el consumo de cada mercado objetivo, así por ejemplo para el consumo semi industrial se les ofrece formatos voluminosos mientras que para el consumo masivo se ofrecen empaques más pequeños y sofisticados. Adicionalmente, los empaques llevan la marca, logo, imagen de los productos, ingredientes e información nutricional. Por otro lado, actualmente las estrategias desarrolladas por ALIEX, están enfocadas en darle mayor valor a la marca WALIBI.

$\mathrm{Al}$ analizar el producto aumentado, en los últimos años se ha trabajado en la facilidad de entrega del producto al consumidor final, es por eso que ALIEX penetró sus productos al canal moderno, específicamente a los autoservicios más reconocidos. Asimismo la fuerza de venta de ALIEX hace la entrega de los productos en el puesto de venta del cliente gracias a la flota de camiones con los que cuenta ALIEX. Por otro lado, ALIEX brinda financiación de pago de 45 días a sus clientes (de consumo semi industrial) 
Figura 1.6

Descripción de producto básico, real y aumentado - ALIEX

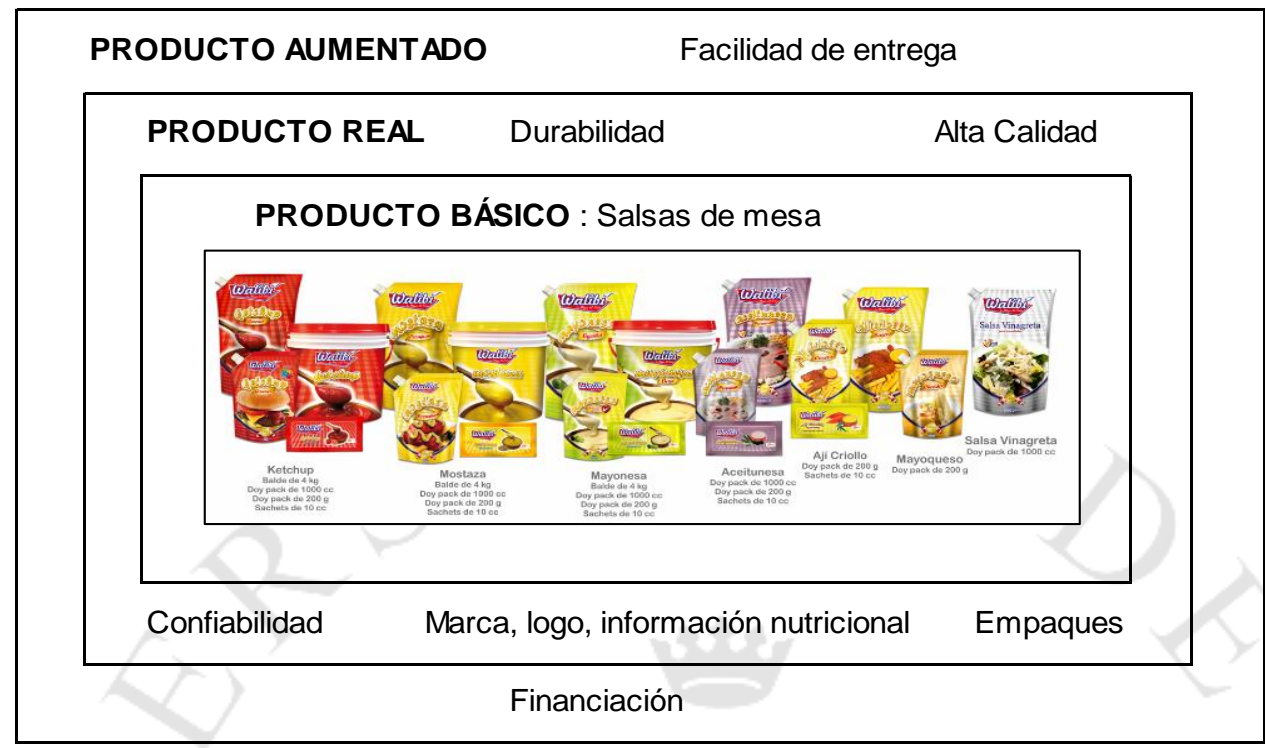

Elaboración propia

Con la finalidad de identificar qué aspecto de los niveles del producto es más valorado por los clientes, de los 240 clientes directos que maneja ALIEX, se realizaron 60 encuestas a los principales clientes, lo que significa el $25 \%$ del universo. Al analizar la tabla 1.2 se concluyó que el producto básico es lo más valorado, lo que incluye sabor, olor y textura.

Tabla 1.2

Valoración de aspectos de niveles de productos de ALIEX

\begin{tabular}{|c|l|c|c|}
\hline \multirow{2}{*}{ Nivel de producto } & \multicolumn{1}{|c|}{ Factores } & Frecuencia & Peso \\
\hline \multirow{3}{*}{ Básico } & El producto en si: sabor, textura, olor & 16 & $27 \%$ \\
\hline \multirow{3}{*}{ Real } & Calidad & 9 & $15 \%$ \\
\cline { 2 - 4 } & Durabilidad & 6 & $10 \%$ \\
\cline { 2 - 4 } & Confiabilidad & 5 & $8 \%$ \\
\cline { 2 - 4 } & Marca, logo & 4 & $7 \%$ \\
\cline { 2 - 4 } & Empaques & 2 & $7 \%$ \\
\cline { 2 - 4 } & Información nutricional & 8 & $13 \%$ \\
\hline \multirow{2}{*}{ Aumentado } & Facilidad de entrega & 6 & $10 \%$ \\
\cline { 2 - 4 } & Financiación & $\mathbf{6 0}$ & $\mathbf{1 0 0 \%}$ \\
\hline
\end{tabular}

Elaboración propia 


\subsubsection{Descripción del mercado objetivo de la empresa}

Actualmente, ALIEX cuenta con tres unidades de negocio estratégicas bien definidas y clasificadas según el modelo de negocio, canales de comercialización y segmentación socioeconómica y geográfica de los consumidores finales. Como se muestra en la tabla 1.3, la unidad B2B va principalmente dirigida a los mercados mayoristas y minoristas periféricos (con una fuerza de ventas propia de ALIEX) orientados a un segmento socioeconómico C y D. También se trabaja con distribuidores externos orientados a un segmento socioeconómico A y B. En esta unidad de negocio se ofrecen productos de consumo semi industrial e industrial (venta directa).

Por su parte la unidad de negocio B2C va principalmente a los canales modernos (autoservicios) y mercados periféricos también orientados a un segmento socioeconómico A, B y C donde se ofrecen productos de consumo masivo. Cabe recalcar que ALIEX inició su comercialización en mercados mayoristas ofreciendo productos de consumo semi industrial, posteriormente se buscó llegar al consumidor final mediante canales modernos y mercados minoristas. Asimismo, actualmente ALIEX se encuentra trabajando en incrementar la penetración en los autoservicios con el objetivo de darle valor a la marca.

Por último se encuentra la unidad exportación, el cual mediante un bróker se busca llegar a clientes de segmento A del extranjero. Dicha unidad aún tiene bastante por desarrollarse.

Tabla 1.3

Mercado Objetivo de ALIEX

\begin{tabular}{|c|c|c|c|c|c|}
\hline $\begin{array}{l}\text { Unidad de } \\
\text { negocio }\end{array}$ & Canales de comercialización & Tipo de Productos & Consumidor final & \begin{tabular}{|c|} 
Segmentación \\
N.S.E
\end{tabular} & $\begin{array}{c}\text { Segmentación } \\
\text { Geográfica }\end{array}$ \\
\hline \multirow{3}{*}{$\mathrm{B} 2 \mathrm{~B}$} & $\begin{array}{l}\text { Mercado Mayorista/ Mercados } \\
\text { minoristas }\end{array}$ & $\begin{array}{l}\text { Consumos semi } \\
\text { industrial }\end{array}$ & Horecas & $\mathrm{C}-\mathrm{D}$ & \begin{tabular}{|c|} 
Conos y \\
Provincia \\
\end{tabular} \\
\hline & Distribuidores insitucionales & $\begin{array}{l}\text { Consumos semi } \\
\text { industrial }\end{array}$ & Horecas & A & $\begin{array}{c}\text { Lima } \\
\text { metropolitana }\end{array}$ \\
\hline & Venta Directa & Consumo industrial & $\begin{array}{c}\text { Empresas } \\
\text { industriales }\end{array}$ & $\mathrm{A}-\mathrm{B}$ & $\begin{array}{c}\text { Lima } \\
\text { metropolitana }\end{array}$ \\
\hline \multirow{2}{*}{$\mathrm{B} 2 \mathrm{C}$} & Autoservicios & Consumo masivo & \multirow{2}{*}{ Amas de casa } & \multirow{2}{*}{$A-B-C$} & \multirow{2}{*}{$\begin{array}{c}\text { Lima } \\
\text { metropolitana }\end{array}$} \\
\hline & Mercados periféricos, bodegas & Consumo masivo & & & \\
\hline Exportación & Broker & $\begin{array}{l}\text { Consumo masivo - } \\
\text { Consumo semi } \\
\text { industrial }\end{array}$ & Amas de casa & A & Otros Países \\
\hline
\end{tabular}

Elaboración Propia 


\subsubsection{Estrategia general de la empresa}

La empresa ALIEX maneja 3 ventajas competitivas, que aplica en cada una de las tres unidades de negocio o nichos de mercado en los que participa. Sin embargo se ha medido la intensidad de cada una de las ventajas mediante el análisis de ciertos factores de la industria alimentaria relacionados con cada tipo de ventaja competitiva.

Mediante unas encuestas virtuales (vista en el Anexo 01), los colaboradores de ALIEX asignaron un puntaje (del 1 al 10) a cada uno de estos factores para obtener la intensidad de cada ventaja competitiva de la empresa, las puntuaciones dadas por los colaboradores se encuentra detallado en el Anexo 02. Cabe resaltar que la empresa participa en diferentes segmentos de mercado usando diferentes modelos de negocio, con la intención de diversificar riesgos y apostar por varias posibilidades de crecimiento. En la Tabla 1.4 se muestra el promedio simple de cada característica evaluada en la encuesta sobre el potencial y capacidad de la empresa para la aplicación de cada estrategia. Asimismo muestra el puntaje promedio por cada estrategia.

Los resultados indicaron que ALIEX tiene como principal estrategia competitiva el liderazgo de costos (con 6.5). Si se habla de logística de entrada cabe resaltar su alianza estratégica con proveedores de tomate, almacenes propios en terrenos de bajo costo. Hablando del tema operativo, resalta la experiencia y know how para la producción masiva de sus productos tradicionales y el ahorro en empaques simples. En el área de ventas y marketing la empresa maneja canales de comercialización en donde sus clientes priorizan el precio como principal variable de compra. En el último eslabón de la cadena de valor, que es la logística de salida, ALIEX dispone de bajos costes de almacenamiento ya que cuenta con almacenes propios de bajo costo. Cabe mencionar que ALIEX aprovecha la ventaja competitiva de bajos costos mediante un modelo de negocio B2B y una segmentación socioeconómica en niveles C y D usando los canales de distribución tradicionales (mercados mayoristas).

ALIEX tiene como segunda ventaja competitiva el Enfoque o segmentación (5.6) ya que fabrica productos específicos para clientes específicos en elevados volúmenes reduciendo así los costos, además manteniendo relaciones cercanas con los clientes para conocer sus especificaciones técnicas y aplicarlas mediante mucho trabajo en desarrollo e investigación. A través de las funciones de logística de salida, la empresa tiene capacidad de almacenamiento para los productos de los clientes industriales más 
importantes. ALIEX aplica esta ventaja competitiva igualmente mediante un modelo de negocios B2B con clientes industriales como Gloria, Laive, Aje, Tasa. Delosi.

Según el análisis la empresa ALIEX sólo tiene un 3.9 (de promedio simple en las características que lo componen) de aplicación en Diferenciación de Producto, ya que la empresa ha empezado a lanzar recién hace algunos años salsas de mesa con formatos más sofisticados y de mayor calidad en canales modernos (autoservicios) donde los clientes puedan pagar precios más elevados y prioricen la calidad e imagen

Tabla $1 . \dot{4}$

Tipo de Estrategias generales de ALIEX

\begin{tabular}{|c|c|c|c|}
\hline $\begin{array}{c}\text { Tipo de } \\
\text { estrategia }\end{array}$ & Características & $\begin{array}{c}\text { Puntaje } \\
\text { Promedio }\end{array}$ & $\begin{array}{c}\text { Puntaje } \\
\text { promedio }\end{array}$ \\
\hline \multirow[t]{8}{*}{$\begin{array}{l}\text { Diferenciación de } \\
\text { producto }\end{array}$} & $\begin{array}{l}\text { Especialización en producir productos de alto valor } \\
\text { agregado }\end{array}$ & 3.6 & \multirow{8}{*}{3.9} \\
\hline & Posicionamiento por calidad de productos & 5.8 & \\
\hline & Empaques y envases sofisticados. & 3.5 & \\
\hline & Inversión en publicidad masiva & 2.3 & \\
\hline & Fuerza de ventas en autoservicios y bodegas & 2.5 & \\
\hline & Poder de negociación con autoservicios y bodegas & 3.5 & \\
\hline & Certificaciones de calidad & 5.9 & \\
\hline & $\begin{array}{l}\text { Alta capacidad de producción de productos } \\
\text { sofisticados }\end{array}$ & 4 & \\
\hline \multirow{8}{*}{$\begin{array}{l}\text { Liderazgo en } \\
\text { costos }\end{array}$} & Bajos costos de producción & 4.9 & \multirow{8}{*}{6.5} \\
\hline & Posicionamiento por bajo precio de productos & 6.6 & \\
\hline & $\begin{array}{l}\text { Fuerza de ventas en mercados tradicionales } \\
\text { (mayoristas) }\end{array}$ & 8.3 & \\
\hline & Fuerza de ventas en negocios de comida & 4.3 & \\
\hline & Empaques y envases simples & 6.4 & \\
\hline & Certificaciones de calidad & 5.9 & \\
\hline & $\begin{array}{l}\text { Alta capacidad de producción de productos } \\
\text { tradicionales }\end{array}$ & 7.8 & \\
\hline & $\begin{array}{l}\text { Poder de negociación en mercados tradicionales } \\
\text { (mayoristas) }\end{array}$ & 7.5 & \\
\hline \multirow[t]{5}{*}{$\begin{array}{l}\text { Enfoque } \quad y \\
\text { segmentación }\end{array}$} & $\begin{array}{l}\text { Cultivo de relaciones personales con los clientes } \\
\text { finales }\end{array}$ & 5.2 & \multirow{5}{*}{5.6} \\
\hline & Poder de negociación con clientes industriales & 6.1 & \\
\hline & $\begin{array}{l}\text { Capacidad para desarrollar productos } \\
\text { personalizados }\end{array}$ & 5.8 & \\
\hline & Certificaciones de calidad & 5.9 & \\
\hline & Bajos costos de producción & 4.9 & \\
\hline
\end{tabular}

Elaboración Propia

\subsection{Objetivos de la investigación (general y específicos)}

- Objetivo general

$\checkmark$ Incrementar la eficiencia del proceso de producción de mayonesa envasada de la empresa ALIEX SAC maximizando el uso de recursos disponibles y la producción obtenida. 
- Objetivos específicos

$\checkmark$ Identificar las posibles causas que originan desviaciones en los indicadores de desempeño de proceso productivo analizando y evaluando los procesos claves.

$\checkmark$ Analizar indicadores de producción y gestión.

$\checkmark$ Proponer soluciones que incrementen la eficiencia.

\subsection{Alcance y limitaciones de la investigación}

El estudio abarca aspectos de gestión interna a fin de generar una propuesta que se enfoque en mejorar los procesos de la empresa familiar ALIEX cuya sede está en Lima. La información ha estado completamente disponible por parte de la empresa.

Las limitaciones se centran en la dificultad del acceso a la información de la competencia, especialmente en lo referente al aspecto financiero y de gestión de desempeño de sus procesos.

\subsection{Justificación de la investigación}

\section{- Técnica}

Es técnicamente factible realizar el estudio de mejora ya que se utilizaran diversas herramientas de ingeniería industrial las cuales facilitarán el diagnóstico y análisis de los procesos de producción de ALIEX. Dichas herramientas contribuirán al planteamiento y elección de soluciones que permitan eliminar los problemas existentes en la actualidad.

\section{- Económica}

Es económicamente viable ya que al mejorar el proceso de producción optimizando los tiempos de espera, gestionando un mejor planeamiento y control de la producción se reducirán costos, lo cual se verá reflejado en una mayor productividad. Dicha situación conllevara a tener una mayor rentabilidad.

\section{- Social}

Aplicando la mejora los principales beneficiados serán los colaboradores y la empresa misma. Los ingresos de ambas partes se verán incrementados gracias al aumento de la eficiencia de los diversos procesos, lo que incrementará las 
utilidades a fin de año. Asimismo, el clima laboral de la empresa también será mejor porque los procesos serán mucho más ordenados, se llevará un control lo cual facilita la gestión, originando buenas relaciones interpersonales.

\subsection{Hipótesis de la investigación}

La eficiencia del proceso de producción de mayonesa envasada de la empresa ALIEX SAC se incrementará al optimizar el proceso maximizando la producción y el uso de los recursos disponibles.

\subsection{Marco referencial de la investigación}

Como marco referencial se tomarán en cuenta los siguientes estudios de mejora realizados para el curso de seminario de investigación II y las siguientes tesis:

- Estudio para la mejora de la productividad de una Planta de concentrado de cobre en la empresa Enproyec. Pallete Herrera, Agustín Manuel. Lima, 2009. (06875- SEM)

- Mejora aplicada en el área de producción de una empresa panificadora. Carmelo Oria, Jose Junor. Wai Lee Wong, Danny Chun. Lima, 2012. (07359- SEM)

- Mejora de la productividad en el sistema de producción en una empresa vinícola. Pietrapiana Chiappe, Fabio Fernando. Lima 2007.

El primer estudio de mejora citado se refiere realizar la mejora de una planta de concentrado de cobre para incrementar la productividad. La similitud que se puede identificar en el presente estudio de mejora, es que ambas investigaciones tienen planteado el mismo objetivo; incrementar la eficiencia de los procesos. Por otro lado, existe una gran diferencia; el producto. En dicha investigación el producto es concentrado de cobre mientras que en el presente producto se trata de mayonesa envasada. Por su parte el tercer estudio también busca incrementar la eficiencia en los procesos sin embargo se trata de bebidas alcohólicas. 
El segundo estudio de mejora habla sobre una mejora en el área de producción de una empresa panificadora. Dentro de las similitudes esta que también se desea mejorar el área de producción como en el presente trabajo de investigación. Sin embargo en el producto a obtener es panetón mientras que el proceso de producción el cual se enfoca la presente mejora es mayonesa envasada en sachets de $10 \mathrm{gr}$.

\subsection{Marco conceptual}

A continuación se definirán algunos conceptos básicos que se deben tener en cuenta al leer el presente trabajo de investigación

- Eficiencia de línea: Indica las horas netas producidas versus las horas brutas programadas, es decir qué tanto se ha aprovechado la maquinaria respecto a las horas programadas. El cálculo se realiza en base a la cantidad de horas producidas reales versus las horas producidas programadas y la velocidad estándar establecida por la planta.

- Productividad mano de obra: Indica el nivel de eficiencia de la producción. Se define como la relación entre lo que se produce y los recursos requeridos para obtener dicha producción. Para el presente trabajo se analizó la productividad de mano de obra calculando la cantidad de $\mathrm{kg}$ producidos de mayonesa entre las horas hombres utilizadas. Se espera que se utilice la mínima cantidad de recursos para producir lo deseado.

- Unidad de negocio B2B (“Business to Business"): modelo de negocio cuyo mercado objetivo se centra en otras empresas. Por ejemplo, ALIEX ofrece productos con formatos voluminosos los cuales son utilizados como insumos para otros negocios como por ejemplo restaurantes para el caso de salsas de mesa o como empresas como GLORIA, LAIVE, AJEPER para el caso de pulpas de fruta, chicha.

- Unidad de negocio B2C (“Business to Customer"): modelo de negocio Negocio cuyo mercado objetivo se centra en el consumidor final. Para este caso los productos de consumo masivo (formatos más pequeños) se comercializan en autoservicios, mercados mayoristas, minoristas etc. 
- MRP I (Material Requierement Planning): Es un sistema de planificación de los requerimientos de materiales y productos que tiene como objetivo asegurar la disponibilidad (en cantidad y momento preciso) de materias primas, insumos y productos finales para cumplir con los planes de programación del área productiva y con la demanda del producto.

- Modelo PMI (Project management institute): es una organización internacional que se dedica al estudio y promoción de la Dirección de Proyectos. La asociación describe los fundamentos de la Dirección de Proyectos a través del Project Management Book Of Knowledge (PMBOK), una guía donde se establecen los estándares que orientan la gestión de proyectos, y que configura lo que se considera como el método PMI. 


\section{CAPÍTULO II. ANÁLISIS SITUACIONAL DE LA EMPRESA Y SELECCIÓN DEL SISTEMA O PROCESO A SER MEJORADO}

\subsection{Análisis Externo de la Empresa}

\subsubsection{Análisis del entorno global}

En la tabla 2.1 se observa la matriz PEST, la cual fue utilizada para analizar el entorno global. En el aspecto económico, la economía peruana comenzó el año 2016 con un crecimiento del $3.41 \%$ en Enero (El Comercio, Marzo 2016). Dicho crecimiento fue debido a un mayor consumo en los hogares de las familias peruanas y los sectores primarios (INEI, Marzo 2016). Al enfocarse un poco más en el sector en el que se desarrolla ALIEX, el sector alimentario, se observa una iniciativa del gobierno a través del Ministerio de Producción y otras asociaciones públicas y privadas (ADEX, Promperú, Sociedad IN, CCL, entre otros) en la organización de eventos y ferias especializadas para integrar a las empresas alimentarias con los canales de distribución internacional y local.

Por otro lado, existe una concentración del consumo en Lima que representa el $70 \%$ de las ventas. Según la publicación de El Comercio (Noviembre 2015), se ha identificado que el canal tradicional (mayoristas, mercados, bodegas) mueve el $70 \%$ de las ventas, mientras que el $30 \%$ se desarrolla en el canal de autoservicios (cadenas de supermercados: CENCOSUD, Supermercados Peruanos, Grupo Falabella), cabe mencionar que este último canal se encuentra en crecimiento pues cada año se abren mayor cantidad de tiendas retail. Por otra parte, existen canales de comercialización enfocados a negocios de comida como lo son Mayorsa y Makro, este último ya cuenta con experiencia en otros países latinoamericanos. En la actualidad se están desarrollando nuevos canales de comercialización y distribución para los productos alimenticios, el canal tradicional se está manteniendo, pero los autoservicios están en penetración pues el Perú es un mercado interesante para las cadenas latinoamericanas. 
Por otro lado existe un auge del sector de gastronomía peruana (Gastón Acurio, Diciembre 2015), que se hace atractiva para inversionistas de diversos tipos y de muchos países del mundo, quienes están viniendo cada vez más al país para evaluar diversos tipos de inversiones en el rubro.

Según ALICORP, en la actualidad se observa un traslado de los consumidores frecuentes hacia las salsas envasadas. Ello se debe a los beneficios que aportan los formatos pequeños como facilidad de uso, calidad y sabor.

En el aspecto tecnológico se observa una mayor penetración de tecnologías importadas tanto en sistemas de información como en maquinaria.

Tabla 2.1

\begin{tabular}{|c|c|}
\hline Factores & Descripción \\
\hline Político - Legal & $\begin{array}{l}\text { Iniciativas del Gobierno y del Ministerio de Producción y otras } \\
\text { asociaciones públicas y privadas (ADEX, Promperú, Sociedad } \\
\text { IN, CCL, entre otros) de organiación de eventos y ferias } \\
\text { especializadas para integrar a las empresas alimentarias con los } \\
\text { canales de distribución internacionales y locales. }\end{array}$ \\
\hline \multirow{5}{*}{ Económico } & Crecimiento de la economía peruana en $3.41 \%$ en Enero 2016 \\
\hline & $\begin{array}{l}\text { Canal tradicional (mayoristas, mercados, bodegas) mueve el } \\
70 \% \text { de las ventas }\end{array}$ \\
\hline & $\begin{array}{l}\text { Canal de autoservicios (cadenas de supermercados: } \\
\text { CENCOSUD, Supermercados Peruanos, Grupo Falabella) } \\
\text { mueve el } 30 \% \text { de las ventas. Es un canal en crecimiento y } \\
\text { desarrollo pues cada año se abren mayor cantidad de tiendas } \\
\text { retail }\end{array}$ \\
\hline & $\begin{array}{l}\text { Existencia de autoservicios mayoristas con bastante expertis en } \\
\text { el mercado }\end{array}$ \\
\hline & Auge gastronomía peruana \\
\hline Social & $\begin{array}{l}\text { Los consumidores frecuentes se han trasladado al consumo de } \\
\text { salsas de mesa ya envasadas }\end{array}$ \\
\hline Tecnológico & $\begin{array}{l}\text { Mayor penetración de tecnologías importadas al Perú } \\
\text { (maquinaria,sistemas de información) }\end{array}$ \\
\hline
\end{tabular}

Elaboración propia

\subsubsection{Análisis del entorno competitivo y del mercado}

En la figura 2.1 se muestran las 5 fuerzas competitivas de Porter, lo cual ayudará a identificar qué tan competitivo es ALIEX en el mercado nacional. 
Figura 2.1

Análisis de las 5 fuerzas de Porter

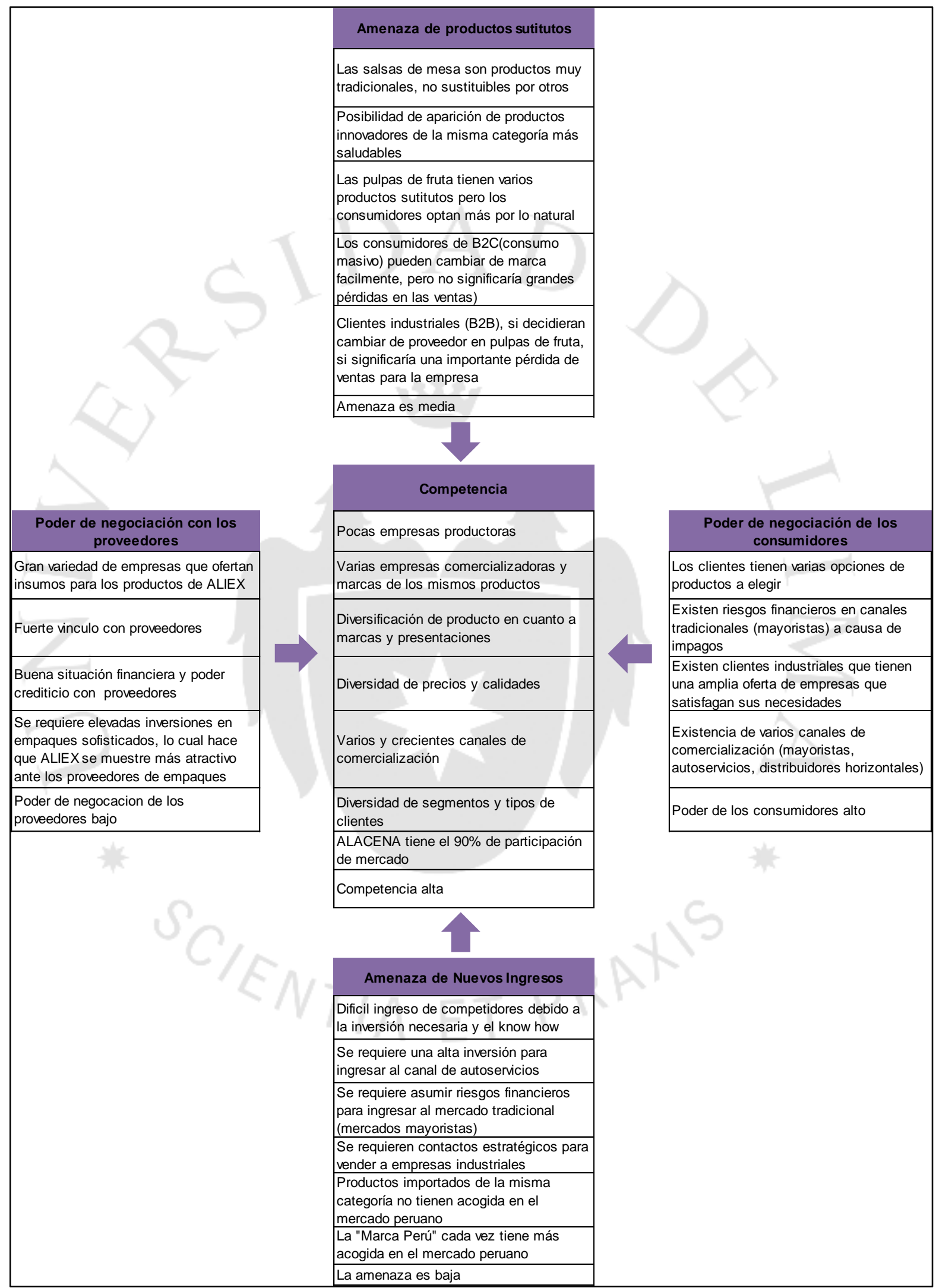

Elaboración propia 
- Rivalidad entre los competidores

Lo destacable es que se tiene un mercado oligopólico, pues pocas empresas manejan este mercado. Sin embargo en este oligopolio hay una diversificación de producto en cuanto a marcas y presentaciones dirigido a mercados específicos variando en precio y calidad. Estas pocas empresas tienen sus propios y variados canales de comercialización, su principal trabajo en este sector es desarrollo de estos canales. Si bien el poder de la competencia es alto, se denota un aspecto positivo la posibilidad de desarrollar canales de comercialización por parte de ALIEX. Por otro lado hay diversos tipos de consumidores en diversos tipos de segmentos quienes buscan adquirir el producto que se adecúe mejor a sus necesidades. Ante ello, se concluye que existe una gran rivalidad entre los competidores.

Cabe mencionar que los subsectores de alimentos donde ALIEX forma parte, existe un mercado oligopólico, donde el mayor protagonista es ALICORP, el cual se caracteriza por ser una empresa con una complejidad organizacional así como presentar un amplio portafolio de productos que se extienden a varias categorías de alimentos. Otros competidores que se destacan son Nestlé Perú y Unilever, que a pesar de su amplia cartera de productos y complejidad organizacional, tienen poca participación en el mercado de salsas de mesa con sus marcas Maggi y Libby’s para Nestlé así como Hellman's para Unilever.

Para el caso específico del mercado de la mayonesa en el Perú, éste se encontraba tradicionalmente dominado por las marcas extranjeras Hellmann`s y Maggi. Sin embargo la mayonesa Alacena de la empresa Alicorp, ingresó al mercado en el 2000, obteniendo el $90 \%$ del mercado peruano. Su estrategia se enfocó en identificar el sabor de la mayonesa que más gusta a los peruanos y entre sus ingredientes incluye el limón. La marca Alacena supo obtener partido de los aspectos culturales, como el orgullo por lo peruano y la comida peruana.

La figura 2.2 presenta una matriz producto - tamaño empresa, en la que se grafica la situación de los protagonistas del mercado de salsas de mesa en donde ALIEX interviene, aquí se observa una relación entre la complejidad de una organización respecto a la oferta de productos de las empresas. En este sentido se observa que el principal competidor de ALIEX (ALICORP) y las demás empresas, no solo son corporaciones que venden salsas de mesa, sino que 
ofrecen varios productos de diversas categorías. Como consecuencia ALIEX tiene una competencia fuerte.

Figura 2.2

Matriz producto - Tamaño empresa

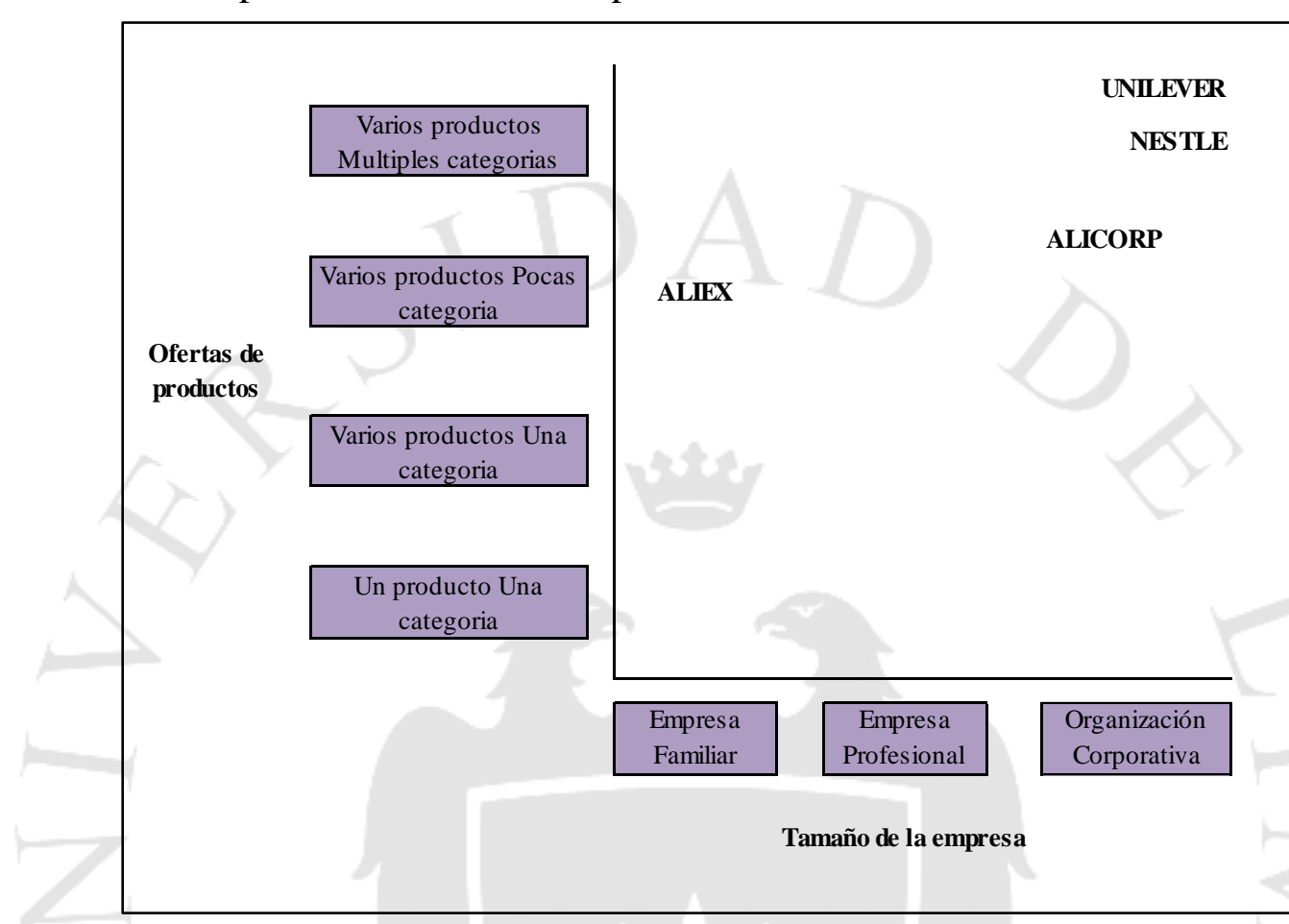

Fuente: ALIEX, (2016)

- Amenaza de nuevas empresas en el sector

Durante los últimos años la gastronomía peruana ha venido creciendo constantemente. Lo que conlleva a pensar que día a día se establecen nuevos negocios o pequeñas empresas que hacen más grande el sector alimentario. Sin embargo es difícil que sean competencia para la empresa debido a la inversión requerida en infraestructura y por el know how requerido. Adicionalmente existen altos costos de entrada para comercializar los productos en autoservicios y se requiere asumir riesgos financieros si es que se desea ingresar al mercado tradicional, es decir al mercado mayorista. En cuanto a los productos importados de la misma categoría, no necesariamente tendrían la acogida deseada en el mercado nacional debido a su sabor. Asimismo, la "Marca Perú" cada día toma más importancia entre los consumidores. 
Se prevé que se mantendrá un mercado con pocos protagonistas, por lo menos en los productos que tiene ALIEX, esto resulta poco atractivo para un nuevo competidor puesto que el mercado ya está prácticamente dividido entre ellos; además el contactarse con los clientes industriales implica una red de contactos de los gerentes comerciales.

En conclusión podemos afirmar que la amenaza de nuevos ingresos para el mercado de salsas de mesa es baja.

- Poder de negociación de los clientes

Dentro del mercado de salsas de mesa existe una gran oferta de productos, presentaciones y marcas, lo cual ocasiona que el mercado de salsas sea un mercado altamente competitivo, asi como la existencia de varios canales de comercialización (mayoristas, autoservicios, distribuidores horizontales etc). En consecuencia, la comercialización de dichos productos encuentra dificultades que superar pues los consumidores tienen una variedad de productos a elegir, ello puede justificar la poca lealtad a la marca. Adicionalmente, en el canal tradicional existen riesgos financieros al existir una amenaza de impagos por parte de los clientes. Por otra parte, ALIEX también produce y comercializa pulpas de fruta para el canal industrial a empresas líderes en el mercado vendiéndole concentrados de fruta a empresas industriales como Gloria, Laive, Ajeper, Sodexo, entre otras.

En conclusión se puede decir que el poder de negociación de los consumidores es alto porque tienen una gran variedad de productos a elegir y porque las empresas grandes citadas anteriormente al ser sumamente reconocidas en el país tienen una variedad de proveedores a elegir para adquirir sus pulpas de fruta, pudiendo decidir dejar de comprarle a ALIEX si es que lo desea.

- Poder de negociación de los proveedores

Se puede afirmar que el poder de negociación de los proveedores es bajo debido a que existen diversas empresas que ofertan al mercado insumos alimenticios para diversos productos y ALIEX puede elegir la que mejor se adapte a sus requerimientos ya sea precio, calidad, cantidad etc. Asimismo, ALIEX tiene 
poder crediticio con sus proveedores de materia prima y mantiene un fuerte vínculo con ellos, lo cual le otorga poder de negociación. Por otro lado, en los últimos años la empresa ha decidido invertir en empaques sofisticados para sus salsas con la finalidad de diferenciarse en el mercado, por lo que la empresa se hace más interesante a la vista de los proveedores de empaques.

- Amenaza de productos sustitutos

En este caso, las salsas de mesa son productos muy tradicionales lo cual los convierte en productos no sustituibles por otros. Sin embargo, pueden aparecer productos innovadores de la misma categoría como nuevas salsas de mesa con la tendencia de productos más naturales y sobretodo saludables (caso del aceite de sacha ichi) pero esto tomaría bastante tiempo para que se convierta en hábitos de los consumidores, quienes están acostumbrados a las tradicionales sabores de las salsas de mesa como mayonesa, kétchup y mostaza. En el caso de pulpas de frutas, existen muchos productos sustitutos, pero los consumidores optan mucho más por productos naturales. Un factor que jugaría en contra es la baja lealtad de los consumidores en la marca lo cual implica que el cliente opte por los sustitutos en el negocio B2C (productos de consumo masivo), pero estas variaciones no significan perdidas de venta significativas. Por su parte los clientes industriales (B2B), si decidieran cambiar de proveedor en pulpas de fruta, si significaría una importante pérdida de ventas para la empresa. En conclusión la amenaza de productos sustitutos es media.

\subsubsection{Identificación y evaluación de las oportunidades y amenazas del entorno}

Luego de haber hecho una revisión de la empresa y la calificación y validación respectiva por parte de la gerencia de la empresa, se determinaron las principales oportunidades y amenazas de ALIEX, las cuales se muestran en la Matriz de evaluación factores externos (EFE) en la Tabla 2.2. De la tabla se concluye que el total ponderado está por encima del promedio (2.5), lo que significa que las estrategias de ALIEX están aprovechando adecuadamente las oportunidades del mercado y minimizando las amenazas. 
Tabla 2.2

Matriz Evaluación factores externos (EFE)

\begin{tabular}{|c|c|c|c|}
\hline Factores externos claves & Valor & Calificación & $\begin{array}{l}\text { Valor } \\
\text { Ponderado }\end{array}$ \\
\hline \multicolumn{4}{|l|}{ Oportunidades } \\
\hline $\begin{array}{l}\text { Buena situación económica del país que permite asumir más } \\
\text { riesgos }\end{array}$ & 0.12 & 4 & 0.480 \\
\hline $\begin{array}{l}\text { Posibilidad del ingreso en autoservicios para posicionar la marca } \\
\text { Walibí }\end{array}$ & 0.06 & 4 & 0.240 \\
\hline $\begin{array}{l}\text { Existen otros mercados de restaurantes A y B donde no hay } \\
\text { participación aún. }\end{array}$ & 0.09 & 3 & 0.270 \\
\hline $\begin{array}{l}\text { Posible asociación con compañías y gremios para realizar } \\
\text { diferentes proyectos }\end{array}$ & 0.03 & 1 & 0.030 \\
\hline Contactos con personas dedicadas a la exportación & 0.06 & 2 & 0.120 \\
\hline $\begin{array}{l}\text { Se puede establecer mayores relaciones y fidelización de clientes } \\
\text { institucionales }\end{array}$ & 0.09 & 3 & 0.270 \\
\hline $\begin{array}{l}\text { Contar con un equipo de fuerza de ventas que puede dedicar más } \\
\text { horas hombre a la promoción de la marca. }\end{array}$ & 0.06 & 4 & 0.240 \\
\hline Amenazas & & & \\
\hline $\begin{array}{l}\text { Proveedores incumplidos o informales que pueden parar la } \\
\text { producción y venta }\end{array}$ & 0.09 & 4 & 0.360 \\
\hline $\begin{array}{l}\text { Clientes informales importantes con riesgo de incumplimiento de } \\
\text { pagos }\end{array}$ & 0.09 & 3 & 0.270 \\
\hline Buenas oportunidades laborales que ocasionarían fuga de talentos. & 0.09 & 3 & 0.270 \\
\hline La competencia está entrando cada vez más a provincias & 0.06 & 2 & 0.120 \\
\hline $\begin{array}{l}\text { Muchos competidores desarrollan mejores presentaciones de sus } \\
\text { productos }\end{array}$ & 0.06 & 4 & 0.240 \\
\hline Existencia de marcas consolidadas & 0.06 & 2 & 0.120 \\
\hline Subida de precios de materia prima. & 0.03 & 3 & 0.090 \\
\hline & 1 & & 3.120 \\
\hline
\end{tabular}

Elaboración propia

\subsection{Análisis Interno de la Empresa}

\subsubsection{Análisis del direccionamiento estratégico: visión, misión y objetivos organizacionales}

A continuación se detallará y se analizará la visión, misión y objetivos de ALIEX.

- Visión

"Queremos lograr la mejor calidad en nuestros productos y mayor éxito en los canales donde competimos, para beneficio de nuestros clientes y consumidores, de nuestros trabajadores y sus familias." 
La visión de ALIEX está incompleta pues si bien es cierto, transmite el objetivo fundamental, no detalla el negocio ni lugar donde ALIEX compite (marco competitivo), ni las habilidades que debe desarrollar para lograr el éxito (ventajas competitivas). En la tabla 2.3, se detalla la información faltante en la visión de ALIEX según lo elementos que debe tener una visión.

Tabla 2.3

Elementos de la visión de ALIEX

\begin{tabular}{|l|l|l|}
\hline \multicolumn{1}{|c|}{ Obje tivo Fundamental } & Ventajas compe titivas & \multicolumn{1}{|c|}{ Marco competitivo } \\
\hline $\begin{array}{l}\text { "Queremos lograr la mejor } \\
\text { calidad en nuestros } \\
\text { productos y mayor éxito en } \\
\text { los canales donde } \\
\text { competimos" }\end{array}$ & $\begin{array}{l}\text { Debería mencionar sus } \\
\text { estrategias genéricas ya } \\
\text { sea liderazgo en costo, } \\
\text { diferenciación o enfoque }\end{array}$ & $\begin{array}{l}\text { Debería mencionar que el } \\
\text { negocio es salsas de mesa } \\
\text { para distintos tipos de } \\
\text { consumos (masivo, } \\
\text { industrial, semi industrial) }\end{array}$ \\
\hline
\end{tabular}

Fuente: ALIEX, (2016)

- Misión

"Somos una empresa agro industrial que suministra alimentos (Salsas de mesa, pulpas de frutas, pastas) de alta calidad, para satisfacer las necesidades del mercado; lo logramos aprovechando y procesando en forma responsable y eficiente".

La misión de ALIEX se encuentra bien redactada, pues contiene todos los elementos que una misión debe tener. A continuación mostramos sus elementos en la tabla 2.4

\section{Tabla 2.4}

Elementos de la misión de ALIEX

\begin{tabular}{|c|c|c|c|}
\hline ¿Quienes somos? & $\begin{array}{c}\text { ¿Cuál es nuestro } \\
\text { producto? }\end{array}$ & $\begin{array}{c}\text { ¿Cuál es nuestro } \\
\text { propósito? }\end{array}$ & $\begin{array}{c}\text { ¿Cuál es nuestra } \\
\text { ventaja competitiva? }\end{array}$ \\
\hline $\begin{array}{c}\text { Somos una empresa } \\
\text { agroindustrial }\end{array}$ & $\begin{array}{c}\text { que suministra alimentos } \\
\text { (Salsas de mesa, pulpas } \\
\text { de frutas, pastas) de alta } \\
\text { calidad }\end{array}$ & $\begin{array}{c}\text { para satisfacer las } \\
\text { necesidades del mercado }\end{array}$ & $\begin{array}{c}\text { aprovechando y } \\
\text { procesando en forma } \\
\text { responsable y eficiente }\end{array}$ \\
\hline
\end{tabular}

Fuente: ALIEX, (2016)

- Objetivos organizacionales 
$\checkmark$ Automatización y simplificación de los procesos productivos.

$\checkmark$ Incrementar la eficiencia de los procesos de salsas de mesa

$\checkmark$ Mejorar el clima laboral mediante la realización de actividades de integración.

$\checkmark$ Adquirir sistemas de información más complejos que permitan llevar una mejor gestión de la información

$\checkmark$ Incrementar el valor de la marca de los productos WALIBI

ALIEX tiene bien definido qué es y qué quiere llegar a ser. Para ello busca cumplir objetivos organizacionales propuestos, los cuales evidencian acciones claras. Cabe recalcar que ALIEX debe contar con indicadores que permitan medir si los objetivos se están cumpliendo o no.

\subsubsection{Análisis de la organización y estructura organizacional}

$\mathrm{Al}$ analizar la estructura organizacional de ALIEX, se identifica que no está detallada el área de sistemas, lo que va en contra de uno de los objetivos organizacionales de la empresa de adquirir sistemas de información más complejos que permitan gestionar mejor la información. En consecuencia, se debe comenzar a dar más importancia a dicha área incluyéndola en el organigrama. Asimismo, se identificó que no existe un área de planeamiento y control de producción, situación que también va en contra uno de los objetivos de la empresa: "incrementar la eficiencia en los procesos de salsas de mesa", pues un departamento de planeamiento y control de producción jugará un rol importante en la disminución de costos, y por ende el incremento de la eficiencia.

Se identificó otro inconveniente en la estructura organizacional, el Gerente General también es accionista de la empresa, por ende pertenece a la junta de propietarios. Dicha situación es fuera de lo común debido a que normalmente en la Junta de propietarios se revisa la gestión del Gerente general, sin embargo en este caso, el Gerente general es juez y parte. Esto se debe principalmente a que es una empresa familiar y debe seguir desarrollándose organizacionalmente conforme pasen los años. En la figura 2.3 se muestra el organigrama de ALIEX. 
Figura 2.3

Organigrama ALIEX

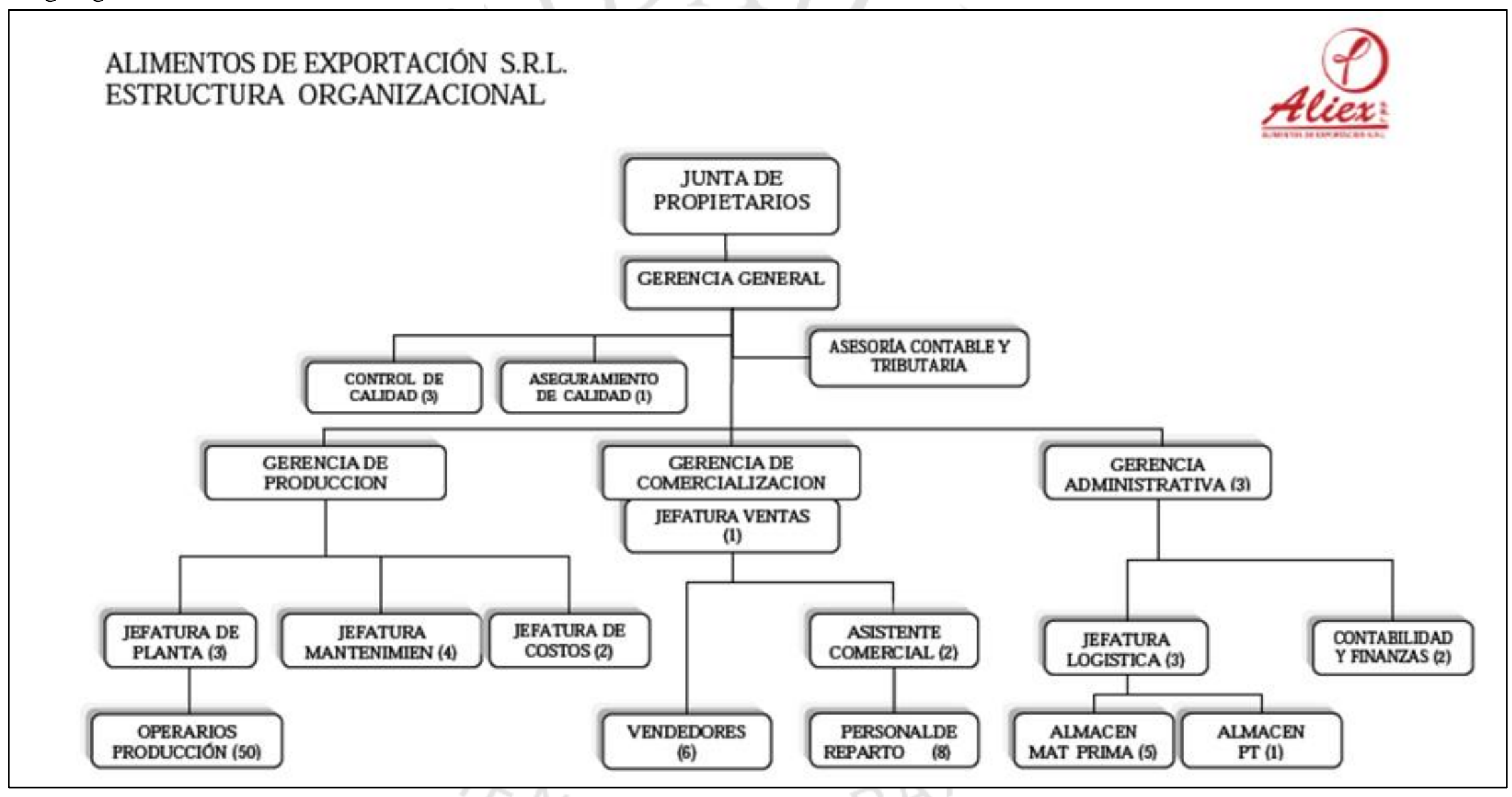

Fuente: ALIEX, (2016) 


\subsubsection{Identificación y descripción general de los procesos claves}

A continuación, en la figura 2.4 se muestra el macro proceso de ALIEX donde se muestran los procesos claves.

Figura 2.4

\section{Macroproceso de ALIEX}

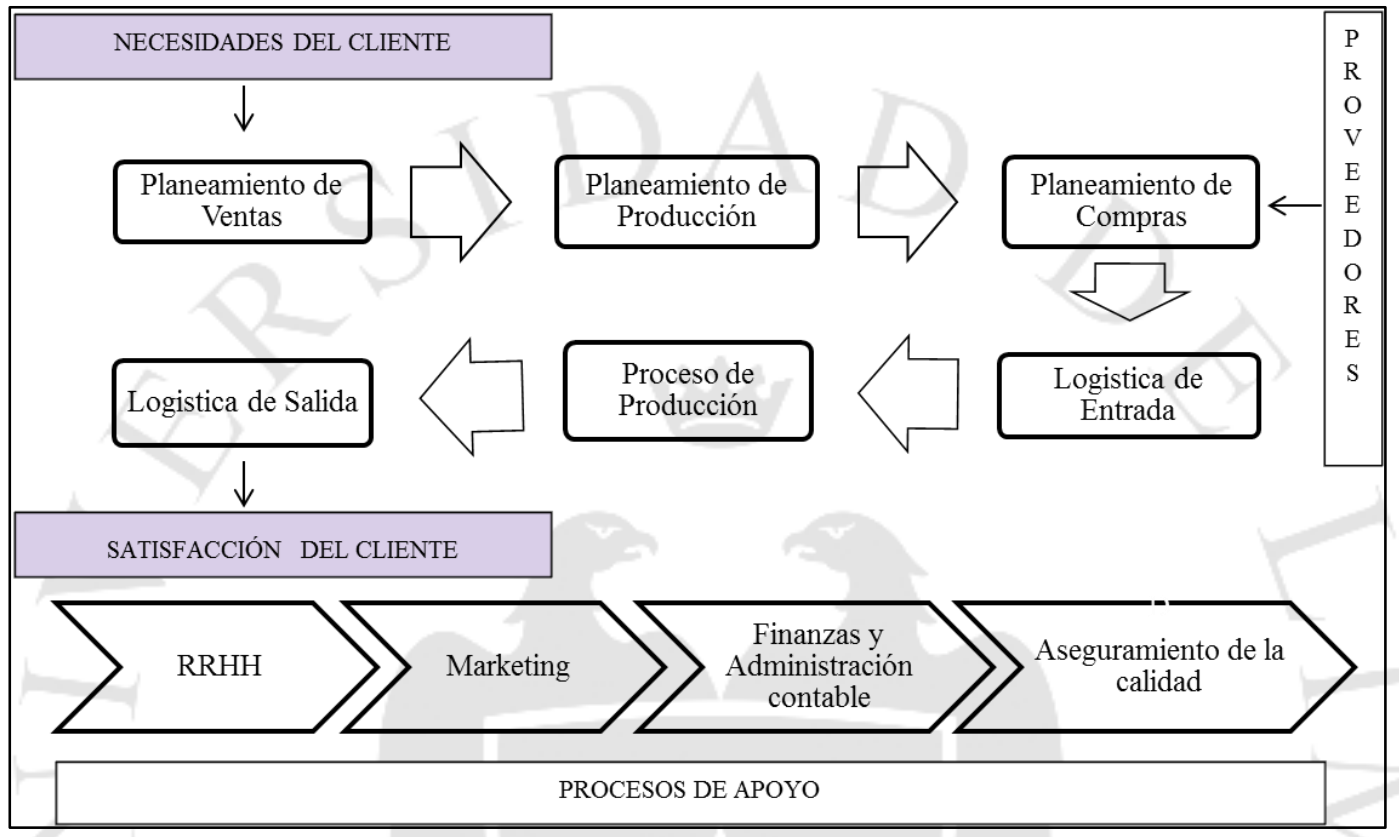

Elaboración propia

- Proceso de logística de entrada y salida

La logística de entrada se encarga de gestionar la compra de insumos y suministros diversos que son necesarios para la elaboración del producto, además de monitorear los stocks en almacén de materia prima. Esta gestión tiene como finalidad la búsqueda constante de mejores precios para la compra de insumos, optimizando el uso de recursos de la empresa, maximizando los rendimientos y minimizando costos. Asimismo, la logística de salida se encarga de monitorear los stocks en almacén de producto terminado y de asegurar que la distribución de los productos se realice de una manera eficiente, reduciendo costos y garantizando que el producto llegue al cliente en el momento deseado con la calidad deseada. Tal proceso tiene mucho por desarrollar ya que no se cuenta con indicadores establecidos que ayuden a tener una mejor gestión. Actualmente se cuenta con una ingeniera industrial y un practicante quienes se encargan de evaluar a los proveedores y realizar el proceso de compra así como 
el seguimiento del mismo, en el almacén de insumos se cuenta con un jefe y supervisor quienes son los responsables de gestionar el mismo, todo ello dentro de lo que es la logística de entrada. Igualmente para la logística de salida se cuenta con un jefe y supervisor del almacén de producto terminado.

- Proceso de gestión de la calidad

Este proceso se divide en dos, aseguramiento de calidad y gestión de calidad. Aseguramiento de calidad se encarga de garantizar que el producto otorgado al cliente cumpla con todos los parámetros técnicos y llegue al cliente en buen estado. En este proceso se encuentra el control de calidad, el cual abarca el control físico químico, microbiológico y organoléptico de los productos; control de insumos, materia prima y empaques. Asimismo, se encarga de detallar las especificaciones técnicas de los productos y verifica que los procedimientos de planta se cumplan bajo los estándares definidos.

Por otro lado, gestión de calidad se encarga de la elaboración, revisión y documentación del sistema de calidad. Actualmente no se cuenta con la ISO 9000, pero se cuentan con la certificación HACCP y se está implementando la certificación de seguridad y salud ocupacional. Actualmente se cuenta con una jefatura del área, quien es una ingeniera de industrias alimentarias y tiene a su cargo a 3 ingenieras de alimentos también. Una de las ingenieras es responsable de todo el control de calidad, la otra ve temas de aseguramiento de calidad y la tercera trabaja en gestión de calidad.

- Proceso Financiero y Administración contable

Procesos que involucran al sistema de Tesorería y la gestión financiera operativa de caja-bancos, asignación de recursos para el pago de impuestos y proveedores. Además es responsable de la recepción del dinero físico y monitoreo de depósitos bancarios de los clientes. Esta gestión tiene como finalidad asegurar la liquidez de la empresa mediante la minimización de riesgos de no pago o retraso de cobranza. Para dicha gestión se cuenta con una administradora de empresas junto con su asistente.

Por otro lado se tiene el proceso de administración contable, donde se lleva el registro y control de todas las operaciones comerciales de la empresa, se realiza el registro y custodia de los comprobantes de pago, es responsable del 
ordenamiento de cuentas, pago de impuestos y presentación de estados financieros reales y legales. La finalidad de la gestión es alinear los procedimientos de la empresa con los estándares gubernamentales y proporcionar la información contable financiera lo más rápida y exacta posible. Se cuenta con dos contadores quienes se encargan de las labores diarias y adicionalmente se cuenta el outsourcing contable constante de la empresa Rivas y Asociados, quienes asesoran a la empresa en temas contables, tributarios y laborales.

- Proceso de recursos humanos

Proceso donde se lleva la administración del personal de la empresa aplicando el Reglamento Interno de Trabajo, control de asistencia, control y registro de horas extras, programación del pago de haberes y beneficios sociales, reclutamiento de personal, evaluación del personal y generación de valor en el factor humano de la empresa. Actualmente la empresa ALIEX cuenta una administradora y asistente, quienes se encargan del reclutamiento del personal y la evaluación constante de los mismos principalmente.

- Proceso de mantenimiento

No es un proceso tan desarrollado por ALIEX. Mantenimiento brinda el soporte necesario en caso una máquina de la planta falle. Dentro se tiene a un jefe de mantenimiento, junto a 4 operarios u asistentes, adicionalmente se cuenta con un operario de mantenimiento quien es el responsable del almacén de mantenimiento.

- Proceso de producción

Se encarga de reafirmar el core bussines de la empresa, mediante la ejecución de las labores de producción de la totalidad de productos comercializados por la empresa. Tiene como principal objetivo incrementar al máximo la productividad, dominando cada proceso de producción de todos los productos elaborados por la empresa, satisfaciendo las expectativas del mercado y potenciales clientes en cuanto a la variedad y calidad de los productos. La planta está conformada por 80 operarios de jornada completa y 5 jefes de producción por cada línea productiva. 
- Proceso de Ventas y Marketing

Es uno de los procesos claves de ALIEX, junto con producción. Se encarga principalmente de comercializar los productos en diversos canales de distribución (autoservicios, mercados tradicionales mayoristas y minoristas etc). Se toma en cuenta las características y necesidades de clientes con la finalidad de dirigir correctamente los productos a los mercados objetivos. Adicionalmente, se llevan las acciones de supervisión antes, durante y después del proceso de ventas. Por su parte, marketing tiene como objetivo principal, darle mayor valor a la marca de los productos de ALIEX, realizando promociones y publicidad que fomenten el consumo de los productos. Actualmente el gerente general lleva la labor de gerente comercial, se cuenta con un jefe de ventas, y una fuerza de ventas de 10 personas.

\subsubsection{Análisis de los indicadores generales de desempeño de los procesos claves} (metas, resultados actuales, tendencias, brechas, comparativos)

A continuación se presentarán los principales indicadores para el negocio.

\section{- Indicadores del proceso de producción}

En esta sección solo mencionaremos los indicadores productivos, puesto que más adelante, en el capítulo III se detallarán sus resultados de forma evolutiva con su respectivo análisis.

\section{$\checkmark$ Eficiencia de línea (\% Utilización maquinaria)}

Es un índice de desempeño del proceso. Indica las horas netas de producción entre las horas brutas empleadas mensuales y explica el nivel uso de la capacidad productiva de los equipos de fabricación y envasado de la planta. El objetivo de estos análisis es controlar y mejorar las eficiencias de los principales procesos productivos de la empresa.

Eficiencia de línea $\%=$ Horas netas producidas

Horas totales empleadas

Productividad de mano de obra

Índice que indica la cantidad de $\mathrm{Kg}$. producidos por hora hombre empleada.

$$
\text { Productividad Mano de Obra }=\frac{\mathrm{Kg} \text { producidos }}{\text { Horas hombre empleadas }}
$$




\section{- Indicadores del proceso de ventas}

$\checkmark$ Crecimiento anual de las ventas

Indica el \% de crecimiento de las ventas respecto al año anterior.

$$
\% \text { Crecimiento }=\frac{\text { Total S/. Último año }- \text { Total S/. Año anterior }}{\text { Total S/. Año anterior }}
$$

Tabla 2.5

Historial crecimiento ventas totales de ALIEX

\begin{tabular}{|c|c|c|c|c|}
\cline { 3 - 5 } \multicolumn{1}{c|}{} & \multirow{2}{*}{ Total S/. } & \multirow{2}{*}{ \% Crecimiento } & \multicolumn{2}{c|}{ \% Crecimiento } \\
\cline { 3 - 5 } \multicolumn{1}{c|}{} & & & CI & CSI + CM \\
\hline 2010 & S/. 10,850,169 & $18 \%$ & $15 \%$ & $18 \%$ \\
\hline 2011 & S/. 14,051,568 & $30 \%$ & $71 \%$ & $21 \%$ \\
\hline 2012 & S/. 16,863,435 & $20 \%$ & $51 \%$ & $13 \%$ \\
\hline 2013 & S/. 17,270,328 & $2 \%$ & $-4 \%$ & $5 \%$ \\
\hline 2014 & S/. 17,610,409 & $2 \%$ & $-6 \%$ & $4 \%$ \\
\hline 2015 & S/. 20,908,384 & $19 \%$ & $56 \%$ & $5 \%$ \\
\hline
\end{tabular}

Fuente: ALIEX, (2016)

En la tabla 2.5, se observa que las ventas crecieron significativamente en el último año, cifra que incluye promociones y descuentos. El crecimiento ha sido impulsado por productos de consumo industrial (CI), principalmente por la confitura de fresa vendida a Gloria.

\section{- Indicadores del proceso financiero}

$\checkmark$ Indicadores de liquidez

Evalúa la capacidad de la empresa para atender sus obligaciones a corto plazo:

Liquidez Corriente: Compara el Activo corriente con el Pasivo corriente y se obtiene mediante la fórmula:

$$
\text { Liquidez corriente }=\frac{\text { Activo Corriente }}{\text { Pasivo Corriente }}
$$

En la tabla 2.6 se visualiza que el valor del ratio aumentó del 2011 al 2013 de S/. 1.33 a S/. 1.54 y disminuyó para el ejercicio del 2013 al 2015 de S/. 1.54 
a S/. 1.72 y S/. 1.5. Esta pequeña disminución no afecta la capacidad de pago que tiene ALIEX para hacer frente a sus obligaciones de corto plazo.

Prueba Ácida: Este indicador proporciona como medida más exigente de la capacidad de pago de la empresa en el corto plazo, se excluye las existencias del análisis porque son los activos menos líquidos y los más sujetos a pérdidas en caso de quiebra y/o siniestro

\section{Prueba Ácida $=\frac{\text { Activo Corriente }- \text { Inventarios }}{\text { Pasivo Corriente }}$}

De la Tabla 2.6, el indicador se encuentra en S/. 0.73 en el 2011, aumentando a S/. 0.92 para el 2014 y disminuyendo a S/. 0.84 para el 2015; esto se debe por la disminución del monto en la cuenta Caja y Bancos.

Indicadores de endeudamiento

Muestran la cantidad de recursos que son obtenidos de terceros para el negocio. Expresan el respaldo que tiene la empresa frente a sus deudas totales.

Estructura del capital: Muestra el grado de endeudamiento con relación al patrimonio, es decir el respaldo que tienen las empresas frente a sus deudas totales.

$$
\text { Estructura de Capital }=\frac{\text { Total Pasivo }}{\text { Total Patrimonio }}
$$

Este ratio evalúa el impacto del pasivo total con relación al patrimonio. Como se ve en la Tabla 2.6, por cada S/. 1 aportado por los dueños existe S/. 1.09 que es vía deuda contraída con terceros (esto para el año 2015). ALIEX cuenta con un respaldo de $92 \%$ de su patrimonio para cubrir el total de sus deudas, esto es posible debido a la capitalización efectuada por los socios los años anteriores y utilidades retenidas que mantiene dentro de su patrimonio.

Endeudamiento: Representa el porcentaje de fondos de participación de los acreedores, ya sea en el corto o largo plazo, en los activos de la empresa

$$
\text { Endeudamiento }=\frac{\text { Total Pasivo }}{\text { Total Activo }}
$$


Se observa de la Tabla 2.6, que la dependencia de la deuda contraída que mantiene la empresa con terceros es de un $60 \%$ en el 2011 y $52 \%$ para el año 2015 a pesar de haberse endeudado con la financiación de bancos y terceros por la adquisición de medios de transporte y máquinas para la planta. Es adecuado endeudarse cuando se trate de adquirir activos fijos, porque esto permitirá tener efectivo para poder afrontar otras situaciones más de corto plazo.

\section{$\checkmark$ Indicadores de Rentabilidad}

$>$ ROE (Rendimiento sobre Recursos Propios): Este Ratio mide el porcentaje de utilidad o pérdida obtenida por cada nuevo sol que los socios han invertido en la empresa, es decir refleja la capacidad de la empresa para generar utilidad.

$$
\mathrm{ROE}=\frac{\text { Utilidad neta }}{\text { Patrimonio }}
$$

En la tabla 2.6, se observa una disminución considerable de $19 \%$ en el 2011 a 9\% en el 2012. Para los siguientes años la rentabilidad se recuperó a 29\% para el año 2013, 24\% para el 2014 y 22\% para el 2015, lo cual significa que por cada S/. 100 invertido en el capital de ALIEX, ha ganado una utilidad bruta de S/.22.0.

ROI (Rendimiento del Capital Invertido): Este Ratio mide el beneficio que se obtiene por cada unidad monetaria invertida en el negocio durante un periodo.

$$
\mathrm{ROE}=\frac{\text { Utilidad neta }}{\text { Activo Total }}
$$

Observando la Tabla 2.6, el rendimiento sobre los activos ha disminuido para el año 2015 de $15 \%$ a 11\%. Sin embargo dichas cifras muestran una mejora respecto a los años 2011 y 2012. 
Dupont: Relaciona los índices de gestión y los márgenes de Utilidad. Este índice muestra una rentabilidad más limpia pues no considera depreciaciones, ni amortizaciones ni intereses.

$$
\text { Dupont } \frac{\text { Utilidad neta }}{\text { Total Activo }}
$$

De igual manera el índice Dupont ha venido mejorando desde el el 2011 cuyo rendimiento fue de $12 \%$ al 2015 cuyo rendimiento es de $18 \%$.

Tabla 2.6

Historial de indicadores financieros ALIEX

\begin{tabular}{|l|c|c|c|c|c|}
\cline { 2 - 6 } \multicolumn{1}{c|}{} & $\mathbf{2 0 1 1}$ & $\mathbf{2 0 1 2}$ & $\mathbf{2 0 1 3}$ & $\mathbf{2 0 1 4}$ & $\mathbf{2 0 1 5}$ \\
\hline Liquidez Corriente & 1.33 & 1.17 & 1.54 & 1.72 & 1.50 \\
\hline Prueba Ácida & 0.73 & 0.48 & 0.86 & 0.92 & 0.84 \\
\hline Estructura del Capital & 1.47 & 1.38 & 0.98 & 0.83 & 1.09 \\
\hline Endeudamiento & 0.60 & 0.58 & 0.49 & 0.45 & 0.52 \\
\hline ROE & $19 \%$ & $9 \%$ & $29 \%$ & $24 \%$ & $22 \%$ \\
\hline ROI & $8 \%$ & $4 \%$ & $15 \%$ & $13 \%$ & $11 \%$ \\
\hline Dupont & $12 \%$ & $6 \%$ & $25 \%$ & $21 \%$ & $18 \%$ \\
\hline
\end{tabular}

Fuente: ALIEX, (2016)

\section{- Indicadores del proceso de gestión de calidad}

Costos por devoluciones de productos

Indica el costo incurrido por productos que han sido devueltos por haber presentado algún defecto. En la tabla 2.7 se muestra el evolutivo en soles del primer semestre del año 2016.

\section{Tabla 2.7}

Costo (S/.) incurridos por productos devueltos

\begin{tabular}{|c|c|c|c|c|c|c|c|c|}
\cline { 2 - 8 } \multicolumn{1}{c|}{} & ene-16 & feb-16 & mar-16 & abr-16 & may-16 & jun-16 & jul-16 & ago-16 \\
\hline $\begin{array}{c}\text { Costos por } \\
\text { devoluciones (S/.) }\end{array}$ & $\mathrm{S} / .772$ & $\mathrm{~S} / .1,710$ & $\mathrm{~S} / .199$ & $\mathrm{~S} / .10,075$ & $\mathrm{~S} / .410$ & $\mathrm{~S} / .427$ & $\mathrm{~S} / .542$ & $\mathrm{~S} / .422$ \\
\hline
\end{tabular}

Fuente: ALIEX, (2016)

Asimismo en la figura 2.5 se muestran las principales causas que ocasionaron tales costos por devoluciones. El mayor porcentaje de los costos en 
todos los meses ha sido por el motivo "calidad del envase - proveedor" excepto los meses de Abril y Junio donde el motivo principal fue "Problema comercial" (devolución por fecha de vencimiento). De esta manera, en el acumulado del primer semestre del año, se observa que las principales causas por devolución son "Problema comercial" (57\%) y "Calidad del envase - proveedor" (26\%).

Figura 2.5

Causas de devoluciones de productos por mes de ALIEX

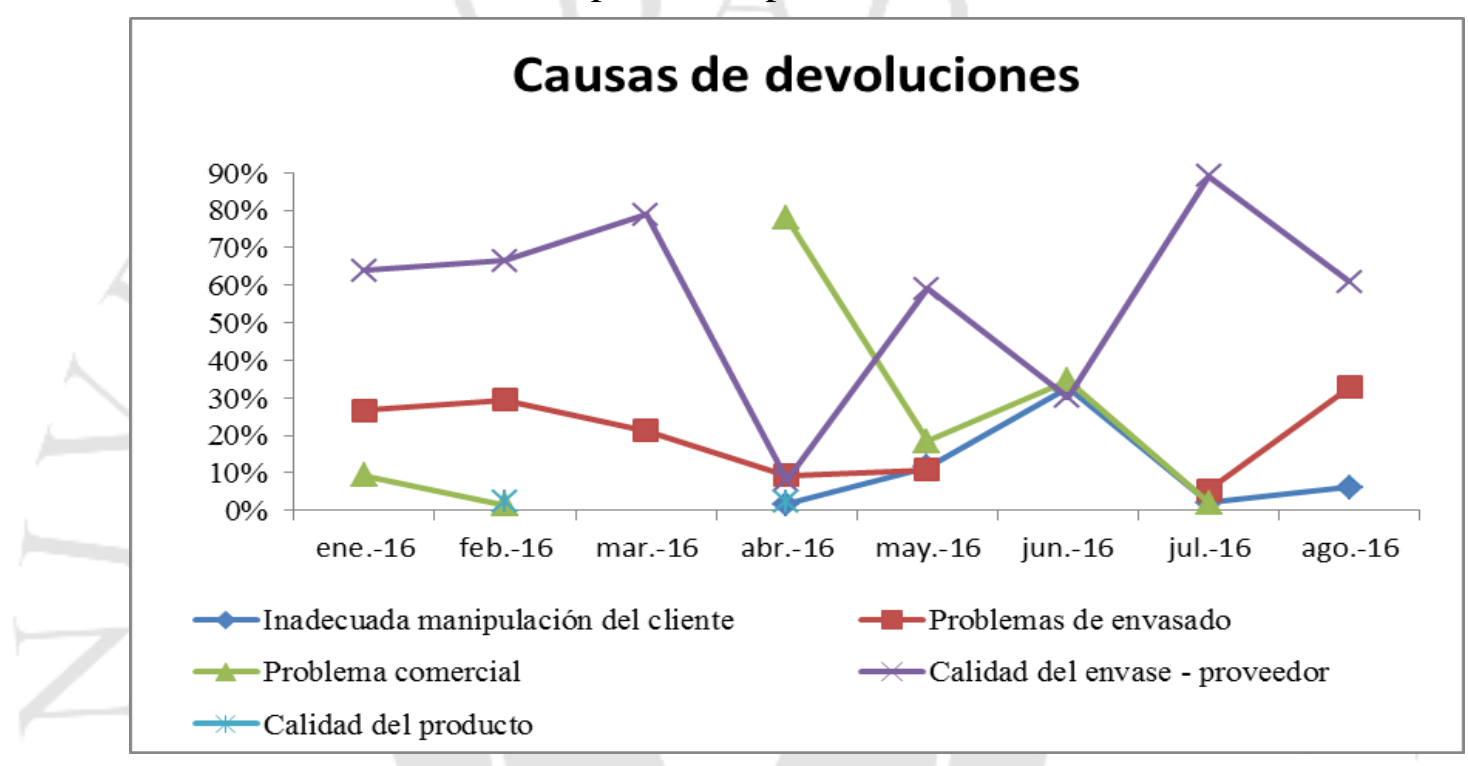

Fuente: ALIEX, (2016)

ALIEX no cuenta con indicadores de gestión del proceso logístico,

recursos humanos ni mantenimiento.

\subsubsection{Determinación de posibles oportunidades de mejora}

Después de haber realizado un análisis interno y externo de ALIEX se plantean las siguientes oportunidades de mejora:

- Actualizar el organigrama pues, no se ha incluido el área de sistemas, proceso clave para el cumplimiento de uno de los objetivos organizacionales de adquirir sistemas de información más completos para una mejor gestión de la información. Asimismo se debe incorporar un proceso de planeamiento y control de la producción dentro del proceso productivo, pues es clave para lograr la eficiencia. 
- Se deberá realizar una revisión de las funciones del gerente general, para evaluar la posibilidad de contratar a una persona que lleve la gerencia el área comercial.

- Se deberá realizar una revisión en los indicadores comerciales, pues las ventas mostraron un crecimiento muy positivo para el 2015, y se deben enfocar los esfuerzos para que esto continúe así los próximos años.

- Los indicadores productivos no son estándares ni estables. Se debe buscar la manera de que el porcentaje de utilización de la maquinaria sea la deseada por la planta, lo que conlleva a identificar tiempos muertos para eliminarlos.

- La rentabilidad de ALIEX ha venido incrementando desde el 2012, año en que la empresa mostró resultados deficientes. Es por ello que ALIEX debe seguir enfocando sus esfuerzos incrementando las ventas y optimizar al máximo sus recursos.

- Una de las causas principales de devoluciones es la "calidad del envase proveedor", por ello se deberá realizar un mejor control de calidad de los envases recibidos, o de lo contrario evaluar otros proveedores. Asimismo, debe haber una mejor gestión en el almacén de producto terminado, pues otra de las causas principales es devolución de producto por "problema comercial", es decir por producto con fecha de vencimiento cercana.

- ALIEX debe implementar indicadores de gestión para los procesos de mantenimiento, recursos humanos y logísticos

\subsubsection{Selección del sistema o proceso a mejorar}

Para determinar los procesos con mayor oportunidades de mejora, se utilizó la metodología de Análisis Factorial de Alfred W. Klein, mediante la cual se le dio un valor a cada proceso de la organización, según la ponderación de la Tabla de Klein de la tabla 2.8 
Tabla 2.8

Ponderación Tabla de Klein

\begin{tabular}{|c|c|c|}
\cline { 2 - 3 } \multicolumn{1}{c|}{} & Variables & Puntaje \\
\hline A & Muy Adecuado & 4 \\
\hline B & Adecuado & 2 \\
\hline C & Poco adecuado & 1 \\
\hline
\end{tabular}

Fuente: Kleeberg H, (2013)

Tabla 2.9

Factor Klein - Ventas y Marketing

\begin{tabular}{|l|l|c|c|c|}
\hline \multicolumn{2}{|c|}{ Análisis de Klein } & \multicolumn{3}{c|}{ Ponderación } \\
\hline \multicolumn{2}{|c|}{ Ventas y Marketing } & A & B & C \\
\hline $\mathbf{1}$ & Gestión de mercado orientado a los clientes & & $\mathrm{X}$ & \\
\hline $\mathbf{2}$ & Obtención de información sobre la competencia & & $\mathrm{X}$ & \\
\hline $\mathbf{3}$ & Obtención de información sobreclientes potenciales & & $\mathrm{X}$ & \\
\hline $\mathbf{4}$ & Fuerza de Ventas & & & $\mathrm{X}$ \\
\hline $\mathbf{5}$ & Publicidad & & & $\mathrm{X}$ \\
\hline
\end{tabular}

Tabla 2.10

Factor Klein - Logística

\begin{tabular}{|c|c|c|c|c|}
\hline \multirow{2}{*}{\multicolumn{2}{|c|}{$\begin{array}{c}\text { Análisis de Klein } \\
\text { Logistica }\end{array}$}} & \multicolumn{3}{|c|}{ Ponderación } \\
\hline & & \multirow{2}{*}{$\frac{\mathrm{A}}{\mathrm{X}}$} & \multirow[t]{2}{*}{ B } & \multirow{2}{*}{ C } \\
\hline 1 & Búsqueda de mejores precios de proveedores & & & \\
\hline 2 & Cantidad de insumos adecuados en el momento requerido & & e & $\mathrm{x}$ \\
\hline 3 & Distribución oportuna de los productos & & $\mathrm{X}$ & \\
\hline \multirow[t]{2}{*}{4} & Monitoreo constante de stock en almacenes & & $\mathrm{X}$ & \\
\hline & & 1 & 2 & 1 \\
\hline \multicolumn{2}{|c|}{ Elaboración propia } & \multicolumn{3}{|c|}{$56 \%$} \\
\hline
\end{tabular}


Tabla 2.11

Factor Klein - Aseguramiento de la calidad

\begin{tabular}{|c|l|c|c|c|}
\hline \multicolumn{2}{|c|}{ Análisis de Klein } & \multicolumn{3}{c|}{ Ponderación } \\
\hline \multicolumn{2}{|c|}{ Aseguramiento de la Calidad } & A & B & C \\
\hline $\mathbf{1}$ & Control fis icoquímico, microbiológico y organoléptico & $\mathrm{X}$ & & \\
\hline $\mathbf{2}$ & Control de insumos, materia prima y materiales de empaque & $\mathrm{X}$ & & \\
\hline $\mathbf{3}$ & Elaboración de especificaciones de productos & $\mathrm{X}$ & & \\
\hline $\mathbf{4}$ & Verificación de procedimientos de limpieza de planta & & $\mathrm{X}$ & \\
\hline $\mathbf{5}$ & Auditorías externas & $\mathrm{X}$ & & \\
\hline $\mathbf{6}$ & Investigación y desarrollo de producto & & $\mathrm{X}$ & \\
\hline $\mathbf{7}$ & Seguridad y Salud Ocupacional & $\mathrm{X}$ & & \\
\hline
\end{tabular}

Tabla 2.12

Factor Klein - Recursos Humanos

\begin{tabular}{|l|l|c|c|c|}
\hline \multicolumn{2}{|c|}{ Análisis de Klein } & \multicolumn{3}{c|}{ Ponderación } \\
\hline \multicolumn{2}{|c|}{ Recursos Humanos } & A & B & C \\
\hline $\mathbf{1}$ & Calificación de los colaboradores & & $\mathrm{X}$ & \\
\hline $\mathbf{2}$ & Motivación de los colaboradores & & $\mathrm{X}$ & \\
\hline $\mathbf{3}$ & Capacitaciones al personal & & $\mathrm{X}$ & \\
\hline $\mathbf{4}$ & Nivel de puntualidad & $\mathrm{X}$ & & \\
\hline $\mathbf{5}$ & Nivel de ausentismo & & $\mathrm{X}$ & \\
\hline $\mathbf{6}$ & Ambiente de la empresa & $\mathrm{X}$ & & \\
\hline
\end{tabular}

Tabla 2.13

Factor Klein - Finanzas y Contabilidad

\begin{tabular}{|l|l|c|c|c|}
\hline \multicolumn{2}{|c|}{ Análisis de Klein } & \multicolumn{3}{c|}{ Ponderación } \\
\hline \multicolumn{2}{|c|}{ Finanzas y Contabilidad } & A & B & C \\
\hline $\mathbf{1}$ & Sistema de contabilidad financiera & $\mathrm{X}$ & & \\
\hline $\mathbf{2}$ & Sistema de contabilidad de costos & & $\mathrm{X}$ & \\
\hline $\mathbf{3}$ & Cumplimiento de presupuesto vs. Real & $\mathrm{X}$ & & \\
\hline $\mathbf{4}$ & Rentabilidad & & $\mathrm{X}$ & \\
\hline \multicolumn{2}{|c|}{} & $\mathbf{2}$ & $\mathbf{2}$ & $\mathbf{0}$ \\
\cline { 2 - 5 } & & \multicolumn{3}{|c|}{$\mathbf{7 5 \%}$} \\
\hline
\end{tabular}


Tabla 2.14

Factor Klein - Producción

\begin{tabular}{|c|l|c|c|c|}
\hline \multicolumn{2}{|c|}{ Análisis de Klein } & \multicolumn{3}{c|}{ Ponderación } \\
\hline \multicolumn{2}{|c|}{ Producción } & A & B & C \\
\hline $\mathbf{1}$ & Llegada a tiempo de la materia prima & & & X \\
\hline $\mathbf{2}$ & Trabajo con capacidad instalada & & & $X$ \\
\hline $\mathbf{3}$ & Manejo de Almacenes & & $\mathrm{X}$ & \\
\hline $\mathbf{4}$ & Maquinaria adecuada en producción & & & $\mathrm{X}$ \\
\hline $\mathbf{5}$ & Procesos descritos & & & $\mathrm{X}$ \\
\hline $\mathbf{6}$ & Utilización de materia prima e insumos & & $\mathrm{X}$ & \\
\hline $\mathbf{7}$ & Eficiencia en la producción. & & $\mathrm{X}$ & \\
\hline
\end{tabular}

Tabla 2.15

Factor Klein - Mantenimiento

\begin{tabular}{|c|l|c|c|c|}
\hline \multicolumn{2}{|c|}{ Análisis de Klein } & \multicolumn{3}{c|}{ Ponderación } \\
\hline \multicolumn{2}{|c|}{ Mantenimiento } & A & B & C \\
\hline $\mathbf{1}$ & Sistema de mantenimiento reactivo & X & & \\
\hline $\mathbf{2}$ & Sistema de mantenimiento preventivo & & & X \\
\hline $\mathbf{3}$ & Calidad y Cantidad de herramientas & $\mathrm{X}$ & & \\
\hline $\mathbf{4}$ & Calificación del personal & & $\mathrm{X}$ & \\
\hline \multirow{2}{*}{ Elaboración propia } & $\mathbf{2}$ & $\mathbf{1}$ & $\mathbf{1}$ \\
\cline { 2 - 5 } & & \multicolumn{3}{|c|}{$\mathbf{3 9}$} \\
\hline
\end{tabular}

En la tabla 2.16, se presenta un resumen con los respectivos procesos y su desempeño actual expresado en porcentaje.

Tabla 2.16

Ponderación desempeño de procesos

\begin{tabular}{|l|c|}
\hline \multicolumn{1}{|c|}{ Proceso evaluado } & Desempeño (\%) \\
\hline Producción & $36 \%$ \\
\hline Ventas y Marketing & $40 \%$ \\
\hline Logistica & $56 \%$ \\
\hline Recursos humanos & $67 \%$ \\
\hline Mantenimiento & $69 \%$ \\
\hline Finanzas y contabilidad & $75 \%$ \\
\hline Aseguramiento de la calidad & $86 \%$ \\
\hline
\end{tabular}

Elaboración propia 
Gracias al análisis de Klein realizado se puede concluir que los procesos con más problemas críticos y con mayores oportunidades de mejora son producción con un menor puntaje, así como ventas y marketing, como se observa en la figura 2.6.

Figura 2.6

Desempeño de los procesos de ALIEX

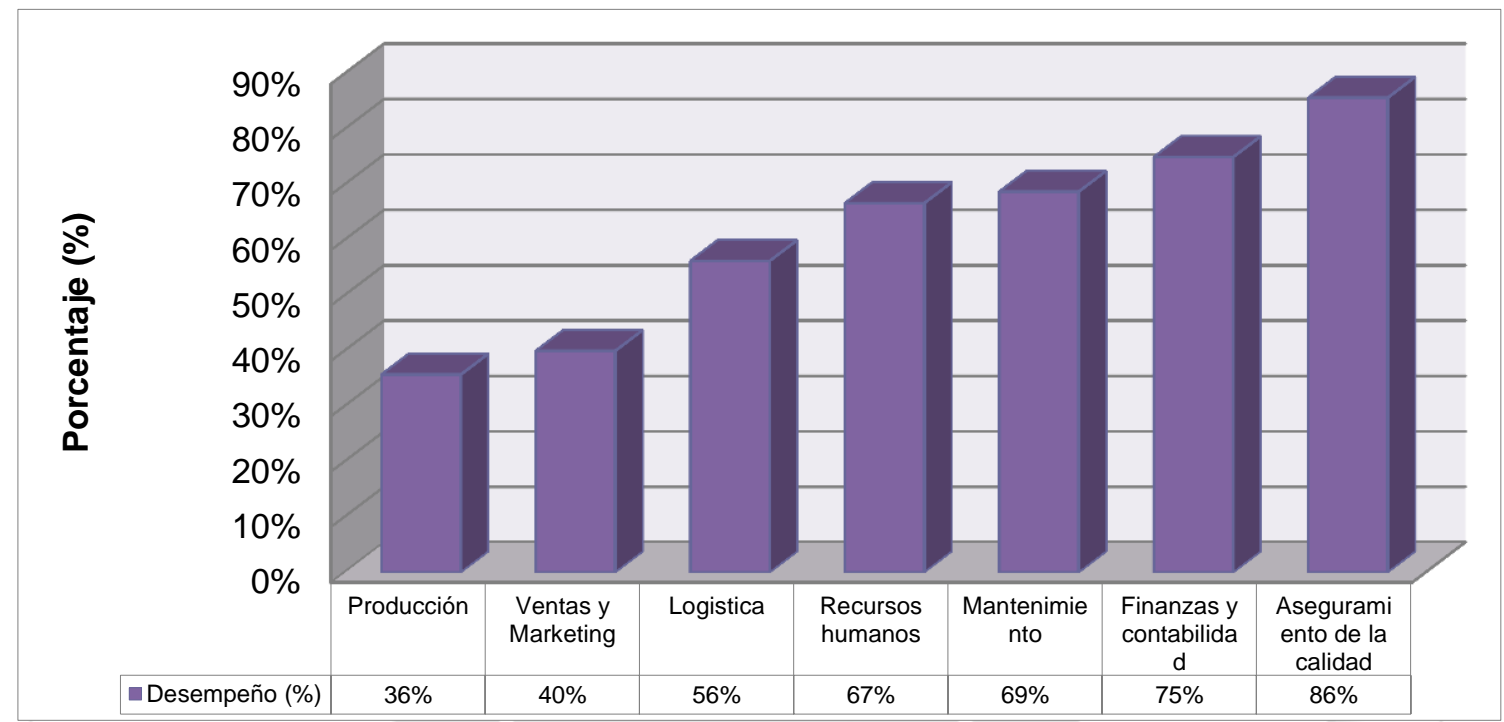

Elaboración propia

Después de haber determinado que el proceso con mayores oportunidades de mejora es el proceso de producción, se eligió mejorar la línea de producción de mayonesa porque es el producto que presenta el mayor porcentaje de la venta anual de salsas de mesa en la empresa ALIEX en los últimos años como se mostró en el capítulo I, en la figura 1.1.

Asimismo, se eligió enfocar el estudio en las presentaciones de mayonesa en sachets de 10 gr. a pesar que los formatos de $4 \mathrm{~kg}$ y $1 \mathrm{Kg}$. tienen una mayor participación en la venta de ALIEX como se observa en la tabla 2.17. Sin embargo, si se analiza con mayor detalle, en la tabla 2.18 se observa que el formato en sachets de 10 gr presentó un crecimiento de 57\% para el año 2015 lo que significa que tiene un potencial de venta debido principalmente al desarrollo de la gastronomía peruana y los esfuerzos de ALIEX para comercializar dicho producto. 
Tabla 2.17

Ventas Totales históricas de Mayonesa en soles por tipo de formato

\begin{tabular}{|l|c|c|c|c|c|c|c|c|c|c|}
\cline { 2 - 14 } \multicolumn{1}{c|}{} & \multicolumn{2}{c|}{2015} & \multicolumn{2}{c|}{2014} & \multicolumn{2}{c|}{2013} & \multicolumn{2}{c|}{2012} & \multicolumn{2}{c|}{2011} \\
\hline $\begin{array}{c}\text { Venta Mayonesa } \\
\text { (Millones de soles) }\end{array}$ & \multicolumn{2}{|c|}{5.53} & \multicolumn{2}{|c|}{4.79} & \multicolumn{2}{|c|}{4.64} & \multicolumn{2}{c|}{4.57} & \multicolumn{2}{c|}{4.18} \\
\hline 4KG(Millones de S/.) & 2.44 & $44 \%$ & 2.24 & $47 \%$ & 2.23 & $48 \%$ & 2.40 & $53 \%$ & 2.35 & $56 \%$ \\
\hline 1KG(Millones de S/.) & 1.73 & $31 \%$ & 1.57 & $33 \%$ & 1.42 & $31 \%$ & 1.35 & $30 \%$ & 1.28 & $31 \%$ \\
\hline 10GR (Miles de S/.) & 887 & $16 \%$ & 566 & $12 \%$ & 499 & $11 \%$ & 430 & $9 \%$ & 300 & $7 \%$ \\
\hline 10KG (Miles de S/.) & 64 & $1 \%$ & 138 & $3 \%$ & 264 & $6 \%$ & 152 & $3 \%$ & 70 & $2 \%$ \\
\hline 50GR (Miles de S/.) & 132 & $2 \%$ & 109 & $2 \%$ & 132 & $3 \%$ & 189 & $4 \%$ & 151 & $4 \%$ \\
\hline 200GR (Miles de S/.) & 136 & $2 \%$ & 100 & $2 \%$ & 90 & $2 \%$ & 46 & $1 \%$ & 28 & $1 \%$ \\
\hline 5GR (Miles de S/.) & 143 & $3 \%$ & 64 & $1 \%$ & 0 & $0 \%$ & 0 & $0 \%$ & 0 & $0 \%$ \\
\hline 20KG (Miles de S/.) & 0 & $0 \%$ & 0 & $0 \%$ & 0 & $0 \%$ & 0 & $0 \%$ & 2 & $0.06 \%$ \\
\hline
\end{tabular}

Fuente: ALIEX, (2016)

Tabla 2.18

Crecimiento de ventas mayonesa en sachets de 10 gr

\begin{tabular}{|c|c|c|}
\cline { 2 - 3 } \multicolumn{1}{c|}{} & $\begin{array}{c}\text { Venta Mayonesa } \\
\mathbf{1 0} \mathbf{~ g r}\end{array}$ & $\begin{array}{c}\% \\
\text { Crecimiento }\end{array}$ \\
\hline 2011 & S/. 299,874 & \\
\hline 2012 & S/. 429,978 & $43 \%$ \\
\hline 2013 & S/. 499,170 & $16 \%$ \\
\hline 2014 & S/. 565,856 & $13 \%$ \\
\hline 2015 & S/. 887,236 & $57 \%$ \\
\hline
\end{tabular}

Fuente: ALIEX, (2016) 


\section{CAPÍTULO III. DIAGNÓSTICO DEL PROCESO DE PRODUCCIÓN DE MAYONESA}

\subsection{Análisis del proceso de producción de mayonesa}

\subsubsection{Caracterización detallada del proceso de producción de mayonesa}

Existen distintas presentaciones y/o formatos para comercializa la mayonesa. Al haber elegido enfocar el presente estudio en mayonesa en sachets de 10 gr, se describirá dicho proceso de producción.

El proceso de elaboración de mayonesa tiene que producirse con el mayor cuidado, ya que es esencial preservar el buen estado de los ingredientes, que son fácilmente perecibles. Para ello, el ambiente debe encontrarse esterilizado y sellado, a una temperatura de $17^{\circ} \mathrm{C}$ y además ozonizada.

El proceso se inicia con el pesado de las yemas de huevo puras en el almacén de materias primas e insumos, cuya calidad ha sido analizada por un operario. Las yemas están localizadas específicamente en una cámara frigorífica a $3{ }^{\circ} \mathrm{C}$, en el mismo almacén. Luego de ser pesadas, las yemas son trasladadas al área de licuado y se colocan en la máquina licuadora. Junto con ellas se coloca saborizante de ajo, pimienta, mostaza base molida, goma Xantan (le da textura y brillo al producto), goma Guar (permite el espesor necesario de la mezcla), ácido cítrico, ácido láctico; ambos con el fin de controlar la acidez de la mezcla. Todos estos insumos son pesados previamente en el almacén. También se añade aceite esencial de limón, previamente diluido y pesado en la mesa de trabajo del área de licuado. El aceite esencial de limón se diluye con aceite natural para controlar la intensidad del sabor, y azúcar (previamente analizada en el laboratorio y pesada en el almacén). El último ingrediente antes de empezar la mezcla es el agua tratada, que se encuentra almacenada en tanques en la zona de tratado de agua. El agua se traslada a la máquina licuadora, donde se hace un primer licuado con los ingredientes previamente mencionados.

Luego, se licúa por segunda vez mientras un operario controla la uniformidad del producto al agregar almidón, previamente diluido con aceite vegetal en la mesa de trabajo del área de licuado. Una vez terminado el segundo licuado, el mismo operario 
hace una prueba de textura y sabor al producto en la misma área. Una vez terminado el segundo licuado, se procede al envasado de la misma.

Si se envasara en formatos de $10 \mathrm{gr}$, se traslada la mayonesa en recipientes de acero inoxidable hacia el área de envasado, donde la máquina envasadora Fustec ha codificado previamente los sachets traídos desde el almacén hacia la máquina. El contenido de los recipientes es introducido en la parte superior de la máquina mediante una bomba. Luego, se procede al envasado del producto. Una vez terminado el proceso, la máquina cuenta automáticamente 252 sachets y los separa. En el caso que la envasadora Fustec esté ocupada, el producto se vacia en tanques pulmón hasta que la llenadora esté lista para envasar.

El operario se encarga de trasladar los sachets de la faja transportadora a la mesa de trabajo del área de envasado, donde los coloca en bolsas, traídas desde el almacén. Una vez embolsados, se trasladan al área de embalaje, donde se colocan en cajas previamente armadas en la mesa de trabajo correspondiente.

Por último, las cajas son llevadas al almacén de productos terminados, donde se almacena la mayonesa para su posterior distribución. En la figura 3.1 se observa el diagrama de operaciones del proceso descrito. Asimismo en la figura 3.2 se muestra el diagrama del balance de materia del proceso descrito. 
Figura 3.1

Diagrama de Operaciones del Proceso - Producción de mayonesa en sachets de 10 gr

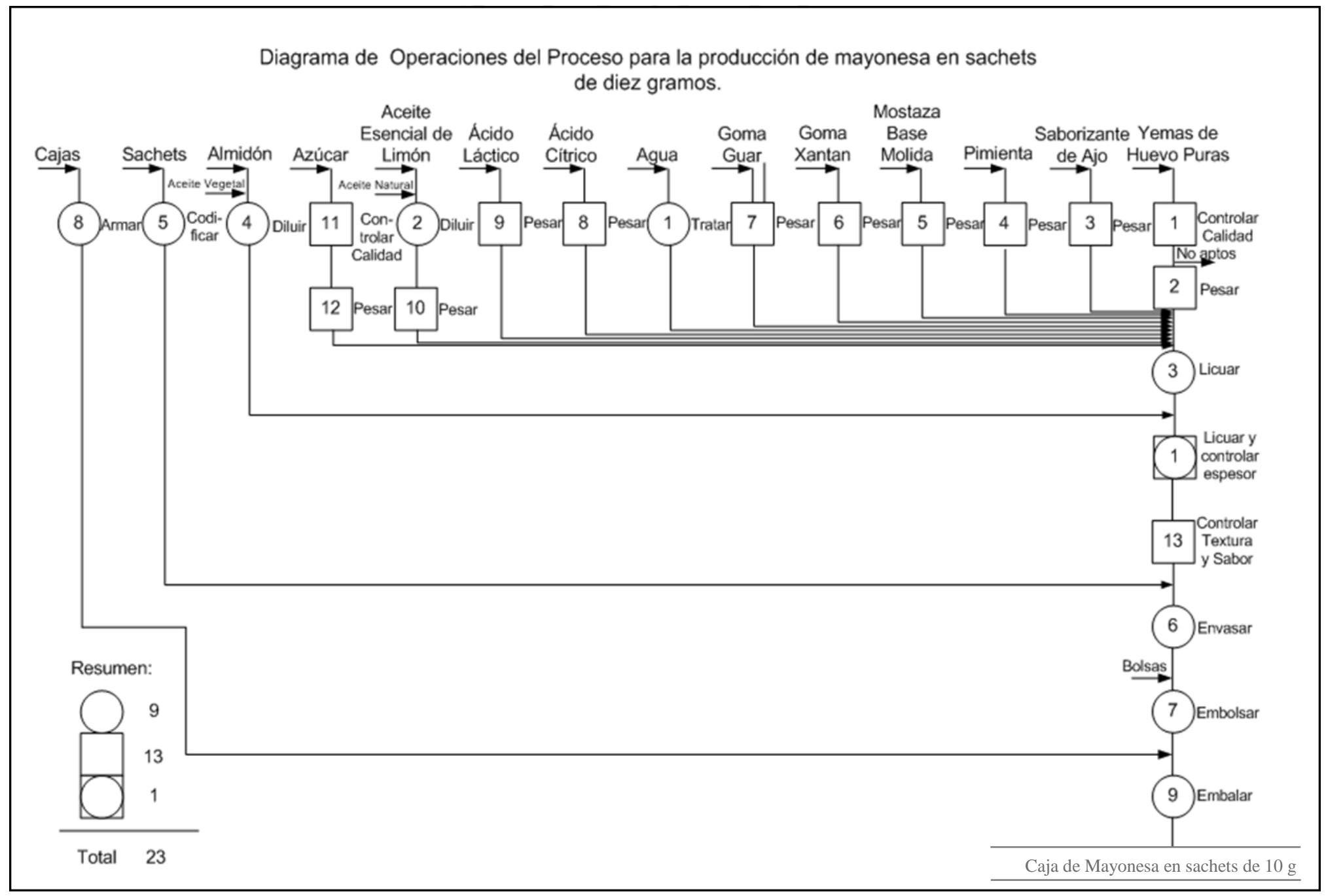

Elaboración propia 


\section{Figura 3.2}

Diagrama de balance de materia - Producción de mayonesa en sachets de 10 gr

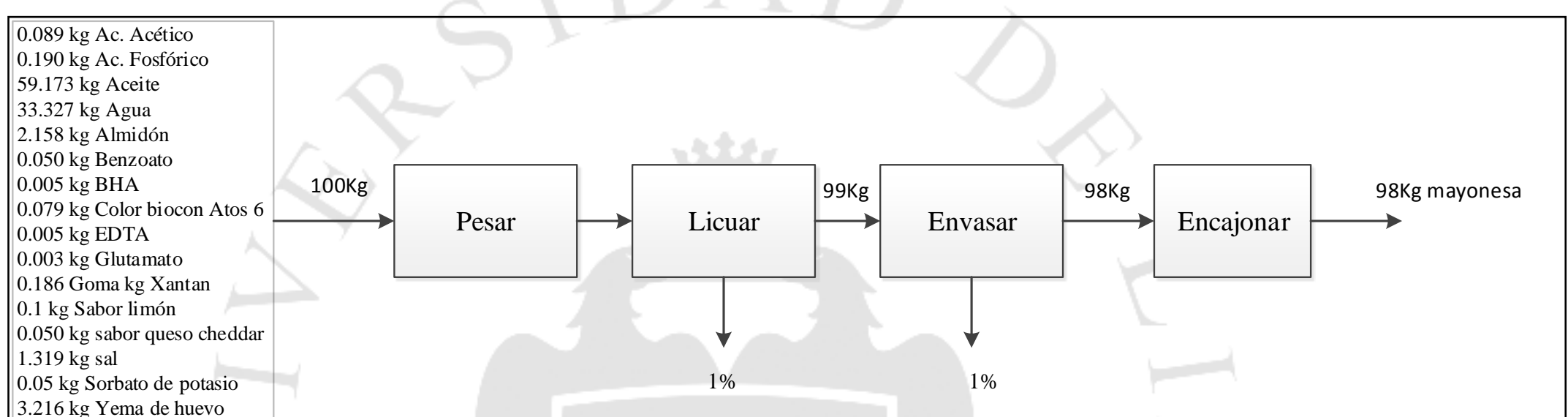

$3.216 \mathrm{~kg}$ Yema de huevo

Elaboración propia
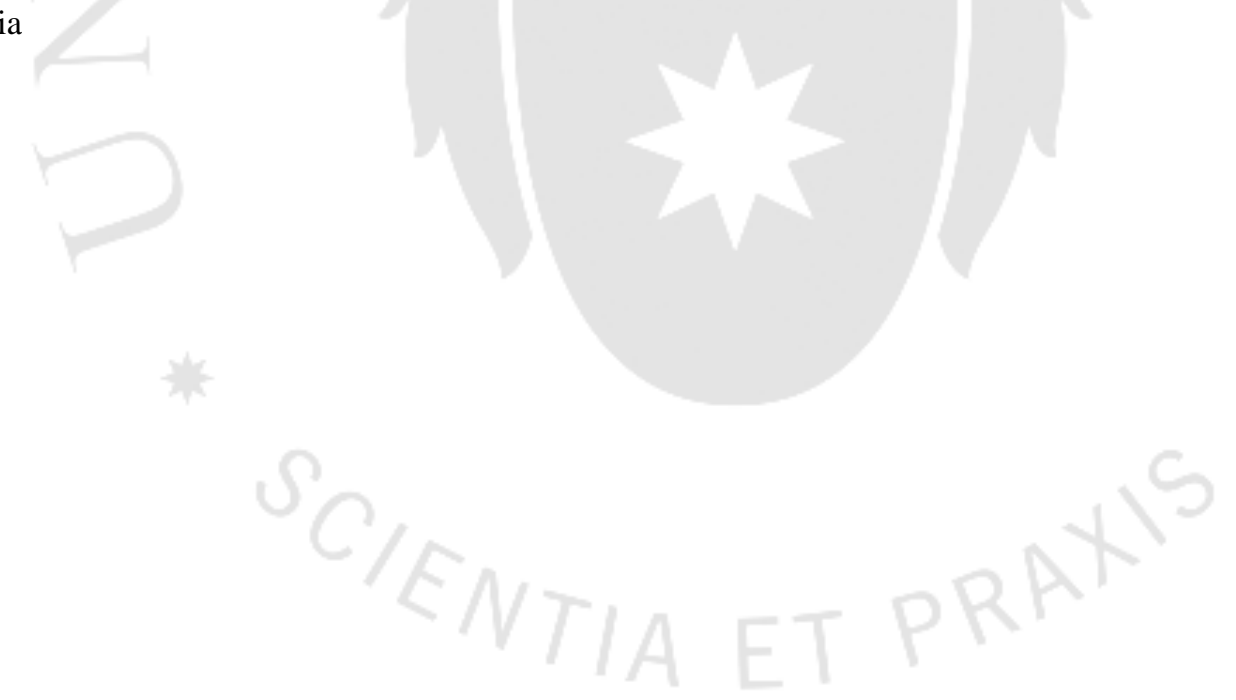


\subsubsection{Análisis de los indicadores específicos de desempeño del proceso de mayonesa (metas, resultados actuales, tendencias, brechas, comparativos)}

Como se mencionó, el proceso de mayonesa se divide en dos grandes procesos: licuado y envasado. El licuado se realiza en una licuadora industrial y se cuenta con una llenadora automática para el envasado en sachets de 10 gr. Se presentarán y analizarán los indicadores de desempeño de cada proceso.

\section{- Línea licuado/granel}

\section{$\checkmark$ Utilización de la licuadora}

Indica las horas netas producidas versus las horas brutas programadas, es decir qué tanto se ha aprovechado la licuadora respecto a las horas programadas mensuales. El cálculo se realiza en base a la cantidad de horas producidas reales versus las horas producidas programadas y la velocidad estándar establecida por la planta. Cabe recalcar que para dicho indicador se han descontado las horas de limpieza y almuerzo. A continuación presentamos un evolutivo del 2015 de los resultados del indicador en la tabla 3.1 y en a figura 3.3

\section{Tabla 3.1}

Evolutivo del indicador utilización de licuadora en porcentaje (HNP/HBP)

\begin{tabular}{|c|c|c|c|c|c|c|c|c|c|c|c|}
\hline Enero & Febrero & Marzo & Abril & Mayo & Junio & Julio & Agosto & Setiembre & Octubre & Noviembre & Diciembre \\
\hline $94 \%$ & $89 \%$ & $90 \%$ & $81 \%$ & $88 \%$ & $85 \%$ & $89 \%$ & $87 \%$ & $88 \%$ & $85 \%$ & $90 \%$ & $88 \%$ \\
\hline
\end{tabular}

Nota: (1) Velocidad estándar $425 \mathrm{Kg} / \mathrm{H}$ (2) Horas programadas por turno: $7.1 \mathrm{~h}, 1$ turno

Fuente: ALIEX, (2015)

Figura 3.3

Evolutivo del indicador utilización de licuadora en porcentaje (HNP/HBP)

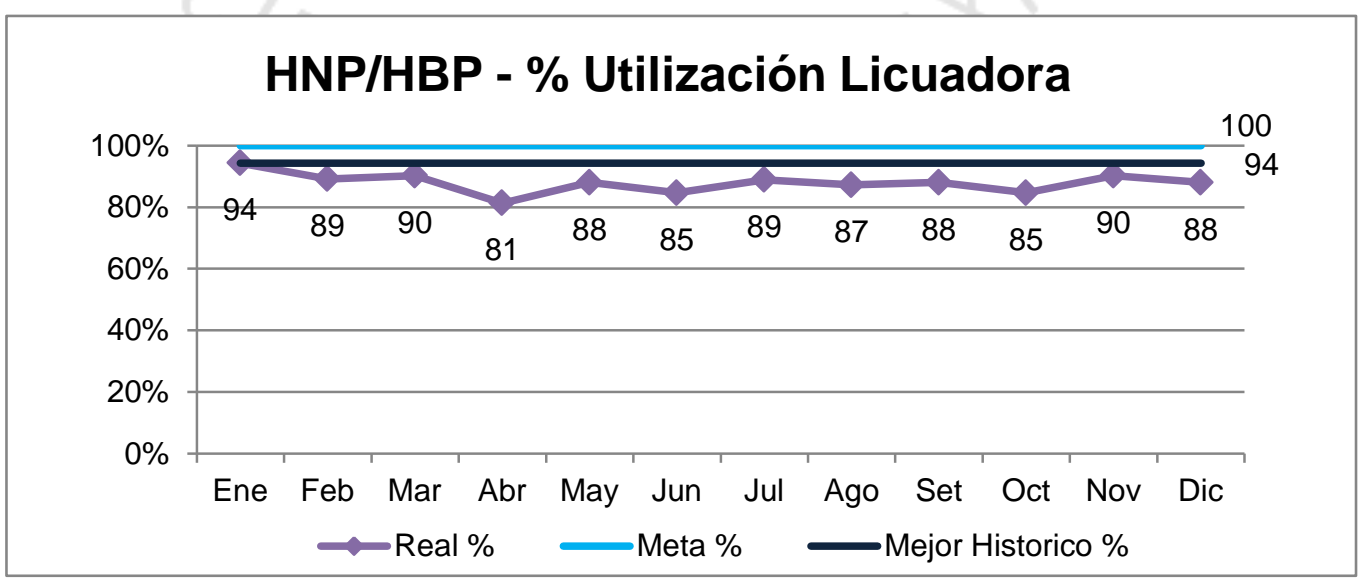

Elaboración propia 
El gráfico de la figura 3.3 evidencia que no existe estabilidad del indicador. El mejor histórico es 94\% en Enero 2015, sin embargo después de dicho periodo no se ha vuelto a obtener ese resultado. Por otro lado, desde Enero 2015 a Diciembre 2015 dicho indicador cayó y muestra una tendencia negativa. Cabe recalcar que lo ideal sería que se obtenga una utilización del 100\%, lo cual no ha sucedido en el último año.

A continuación se muestra un gráfico en la figura 3.4 donde se identifican los meses donde el indicador tuvo un comportamiento más atípico pues sobrepasó los límites máximos y mínimos de desviación estándar. La desviación estándar es de $3.30 \%$, y se observa que los meses de Enero y Abril se tuvo un comportamiento atípico. Sin embargo no es preocupante que el mes de Enero haya sobrepasado el límite máximo de desviación pues finalmente lo que se espera es que el indicador sea $100 \%$ todos los meses. Por su parte el valor de Abril si es extraño por lo que se tendrá que analizar las causas que originaron tal resultado.

Figura 3.4

Desviación estándar de la utilización de la licuadora

\section{Desviación estándar Utilización licuadora}

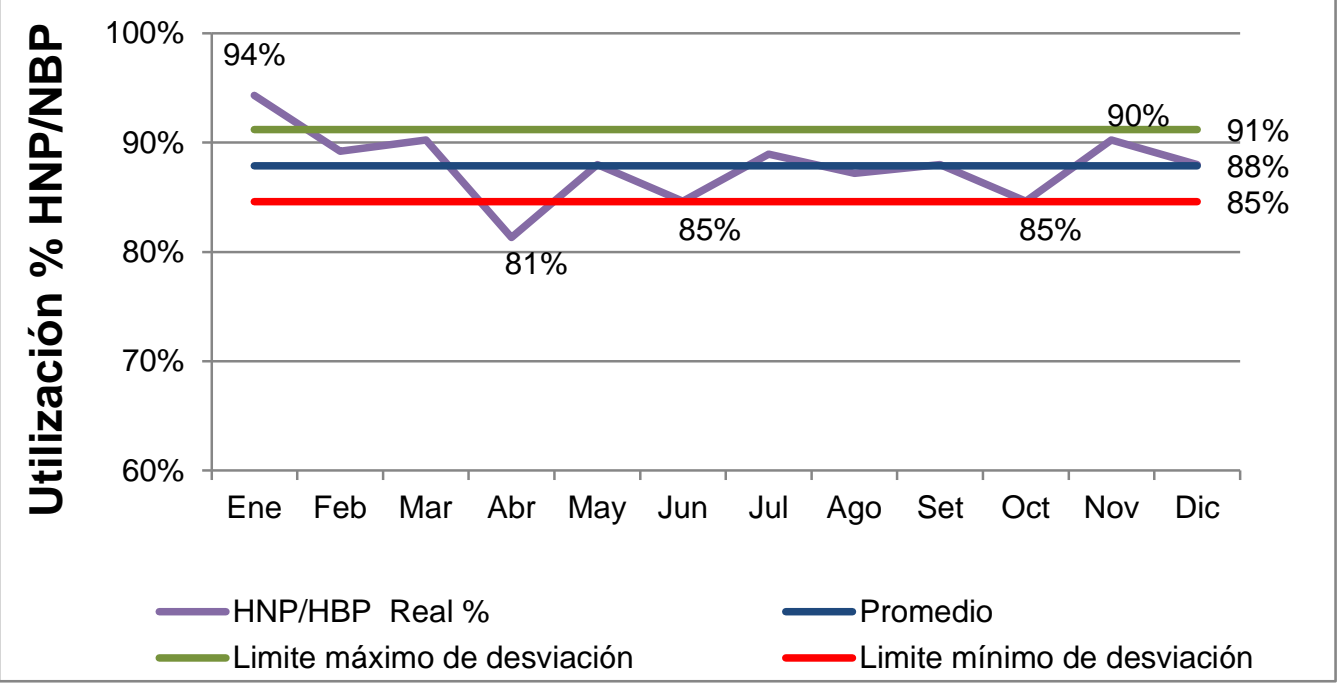

Elaboración propia 
Productividad Mano de obra (PMO)

Indica los $\mathrm{Kg}$ producidos por hora hombre. La planta ha establecido que la productividad de mano de obra óptima para el licuado es de $213 \mathrm{Kg} / \mathrm{HH}$. El cálculo se realiza en base a los kilos producidos mensuales versus el número de HH totales del mes. A continuación se presenta un evolutivo del resultado del indicador los últimos meses en la tabla 3.2 y figura 3.5.

Tabla 3.2

Evolutivo del indicador Productividad Mano de Obra (Kg/HH) - Licuado

\begin{tabular}{|c|c|c|c|c|c|c|c|c|c|c|c|}
\hline Enero & Febrero & Marzo & Abril & Mayo & Junio & Julio & Agosto & Setiembre & Octubre & Noviembre & Diciembre \\
\hline 208 & 192 & 204 & 182 & 196 & 192 & 202 & 194 & 196 & 192 & 204 & 196 \\
\hline
\end{tabular}

Nota: (1) PMO Estándar 213 Kg/HH (2) Horas programadas por dia: 7.1 h (3) Operarios:2

Fuente: ALIEX, (2015)

Figura 3.5

Evolutivo del indicador Productividad Mano de Obra $(\mathrm{Kg} / \mathrm{HH})$ - Licuado

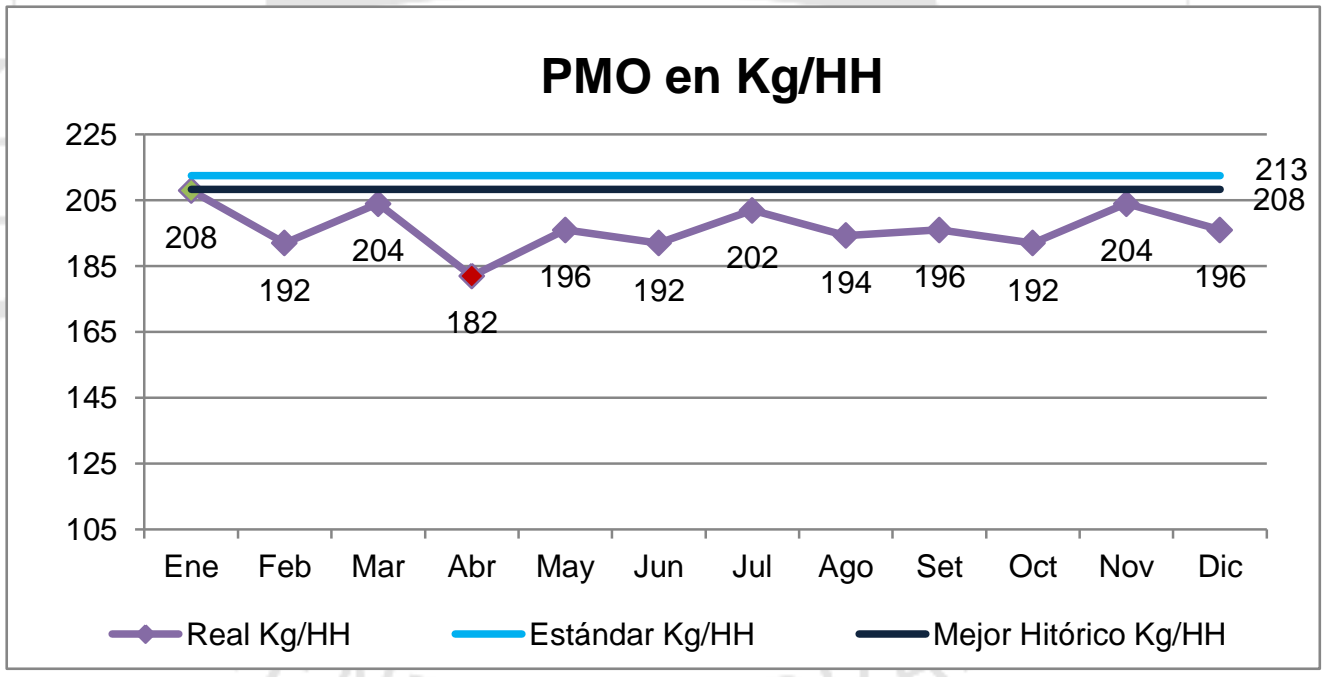

Elaboración propia

En la figura 3.5 se observa que nunca se ha logrado obtener la PMO estándar y, por su parte el mejor histórico ha sido $208 \mathrm{Kg} / \mathrm{HH}$.

En la figura 3.6 se presenta el cumplimiento en base a la productividad estándar establecida por la planta para entender mejor el comportamiento del indicador. 
Figura 3.6

Evolutivo de cumplimiento Productividad Mano de Obra (\%) vs. Productividad mano de obra estándar - Licuado

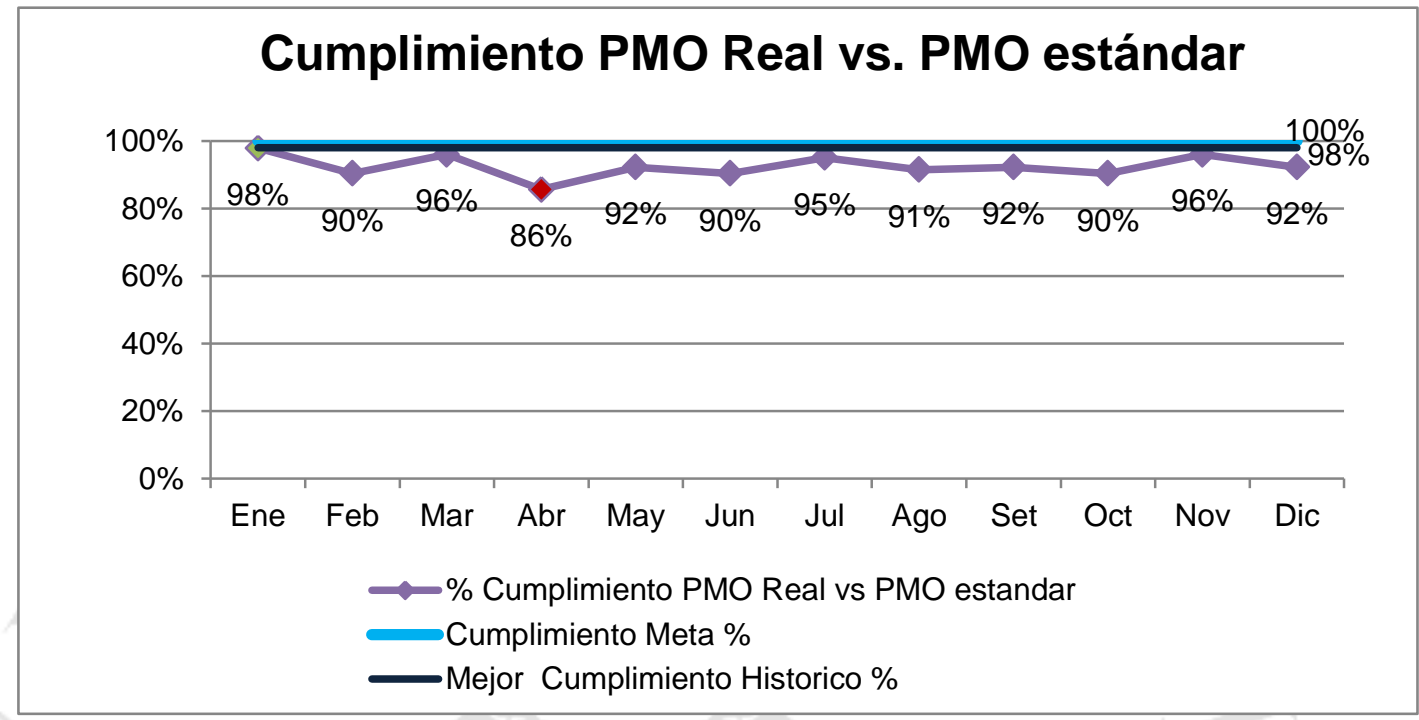

Elaboración propia

Figura 3.7

Desviación estándar Productividad Mano de Obra $(\mathrm{Kg} / \mathrm{HH})$ - Licuado

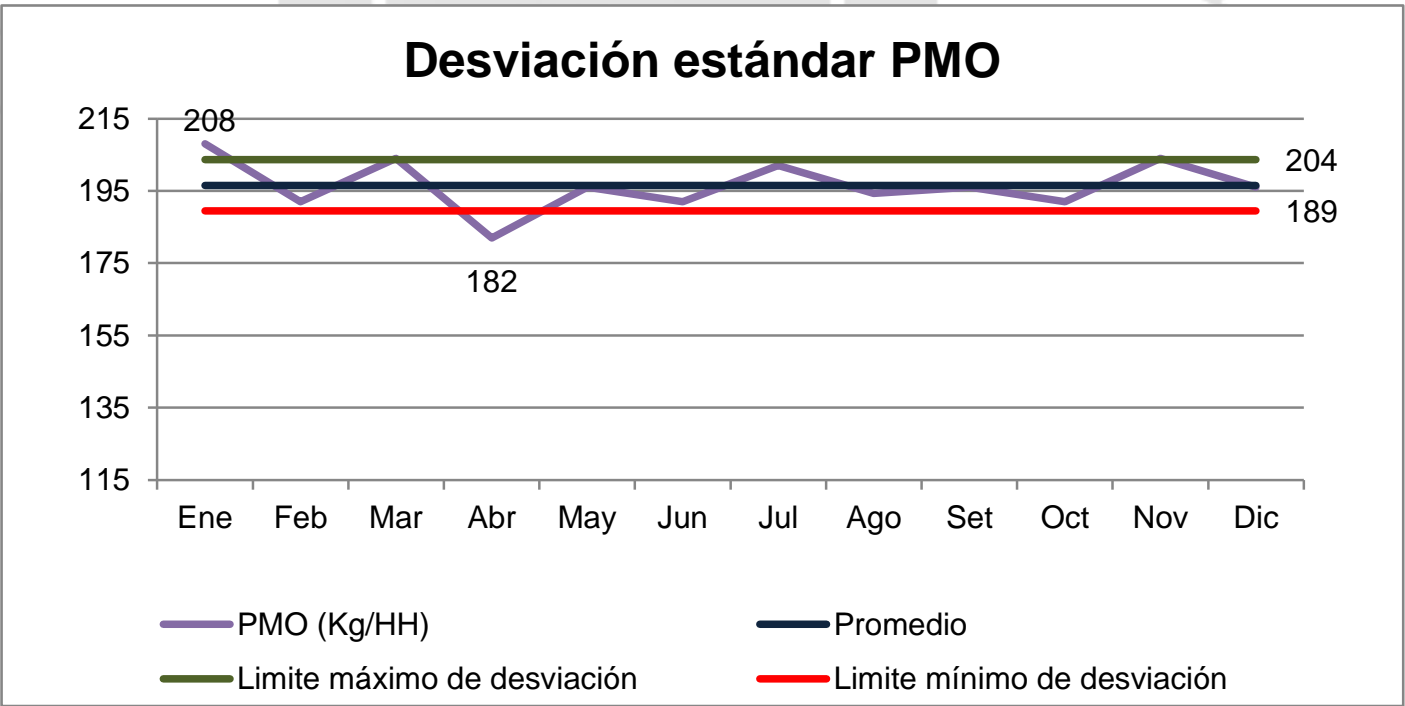

Elaboración propia

En la figura 3.7 se muestra la desviación estándar del indicador que es de 7.08. La mayor desviación es del mes de Enero (mes en que se tiene mejor cumplimiento como se ve en la figura 3.6), sin embargo no es preocupante pues conviene que el cumplimiento este lo más cerca del 100\%, sin embargo si lo es 
la del mes de Abril pues es el mes en que el cumplimiento se aleja más del 100\% y se deben identificar las causas que ocasionaron tal resultado.

\section{- Envasado 10 gr.}

$\checkmark$ Utilización de Fustec (eficiencia)

Indica las horas netas producidas versus las horas brutas programadas, es decir qué tanto hemos aprovechado la envasadora automática de $10 \mathrm{gr}$ respecto a las horas programadas mensuales. El cálculo se realiza en base a la cantidad de horas producidas reales versus las horas producidas programadas y la velocidad estándar establecida por la planta. A continuación presentamos un evolutivo de los resultados del indicador de los últimos meses en la tabla 3.3

Tabla 3.3

Evolutivo del indicador utilización de envasadora de 10 gr en porcentaje

\begin{tabular}{|c|c|c|c|c|c|c|c|c|c|c|c|}
\hline Enero & Febrero & Marzo & Abril & Mayo & Junio & Julio & Agosto & Setiembre & Octubre & Noviembre & Diciembre \\
\hline $78 \%$ & $79 \%$ & $76 \%$ & $73 \%$ & $73 \%$ & $74 \%$ & $79 \%$ & $80 \%$ & $77 \%$ & $79 \%$ & $79 \%$ & $80 \%$ \\
\hline
\end{tabular}

Nota: (1) Velocidad Estándar $1487.5 \mathrm{~kg} /$ turno (2) Horas programadas por turno: 8 h, 2.03 turnos

Fuente: ALIEX, (2015)

Figura 3.8

Evolutivo del indicador utilización en porcentaje - Envasado

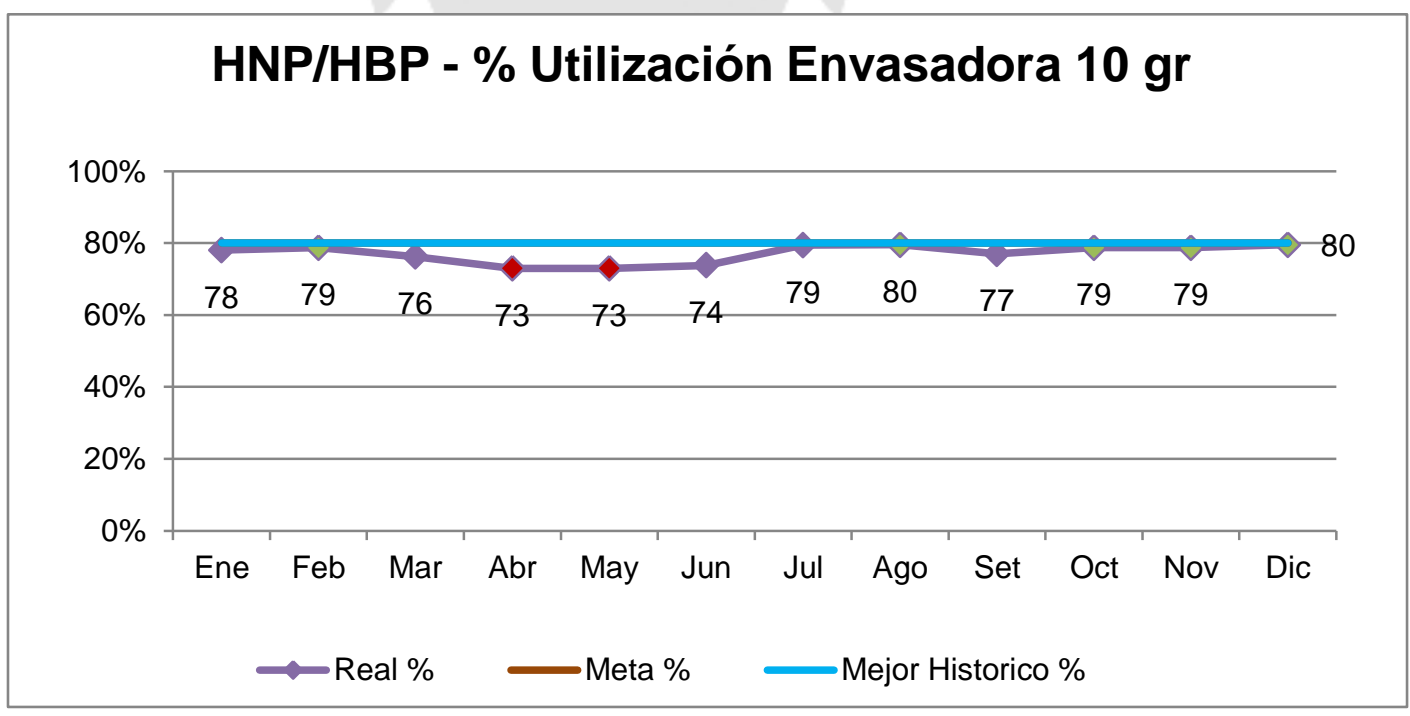

Elaboración propia

La empresa considera que una óptima utilización de la máquina automática es de $80 \%$, pues por su naturaleza siempre se tendrá que lidiar con 
factores ajenos como el armado y lavado de la misma diariamente. En la figura 3.8 se observa que solo se ha llegado 2 veces al \% de utilización meta. Por su parte se muestra una desviación estándar de $2.54 \%$ en la figura 3.9 , donde se debe tomar atención a los meses Abril y Mayo, donde el indicador excede los límites normales.

Figura 3.9

Desviación estándar de la utilización de la envasadora de 10 gr

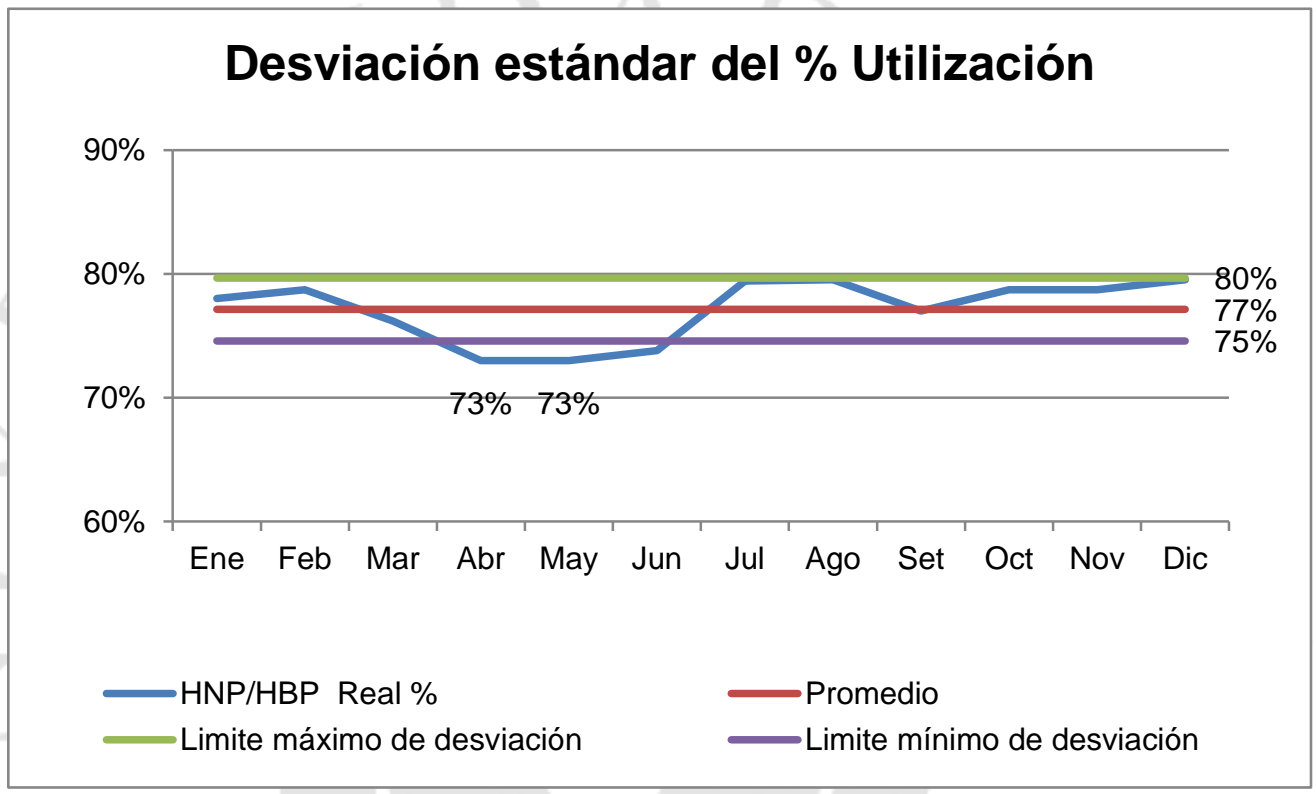

Elaboración propia

Productividad de mano de obra

Indica el número de cajas producidas por hora hombre. La planta ha establecido que la productividad de mano de obra óptima para el envasado es de 37 Cajas/HH. El cálculo se realiza en base a las cajas producidas mensuales versus el número de $\mathrm{HH}$ totales del mes. A continuación presentamos un evolutivo del resultado del indicador de los últimos meses en la tabla 3.4.

Tabla 3.4

Evolutivo del indicador productividad de mano de obra (Cajas/HH) - Envasado

\begin{tabular}{|c|c|c|c|c|c|c|c|c|c|c|c|}
\hline Enero & Febrero & Marzo & Abril & Mayo & Junio & Julio & Agosto & Setiembre & Octubre & Noviembre & Diciembre \\
\hline 31 & 33 & 30 & 32 & 34 & 33 & 32 & 33 & 34 & 35 & 33 & 34 \\
\hline
\end{tabular}

Nota: (1) PMO Estándar 37 Cajas/HH (2) Horas programadas por turno: 8 h, 2.03 turnos (3) 2 operarios Fuente: ALIEX, (2015) 
En la figura 3.10 se observa que nunca se ha logrado obtener el indicador de productividad de mano de obra (PMO) estándar y, por otro lado el mejor histórico ha sido 35 Cajas/HH en el mes de Octubre.

Figura 3.10

Evolutivo del indicador productividad de mano de obra (Cajas/HH) - Envasado

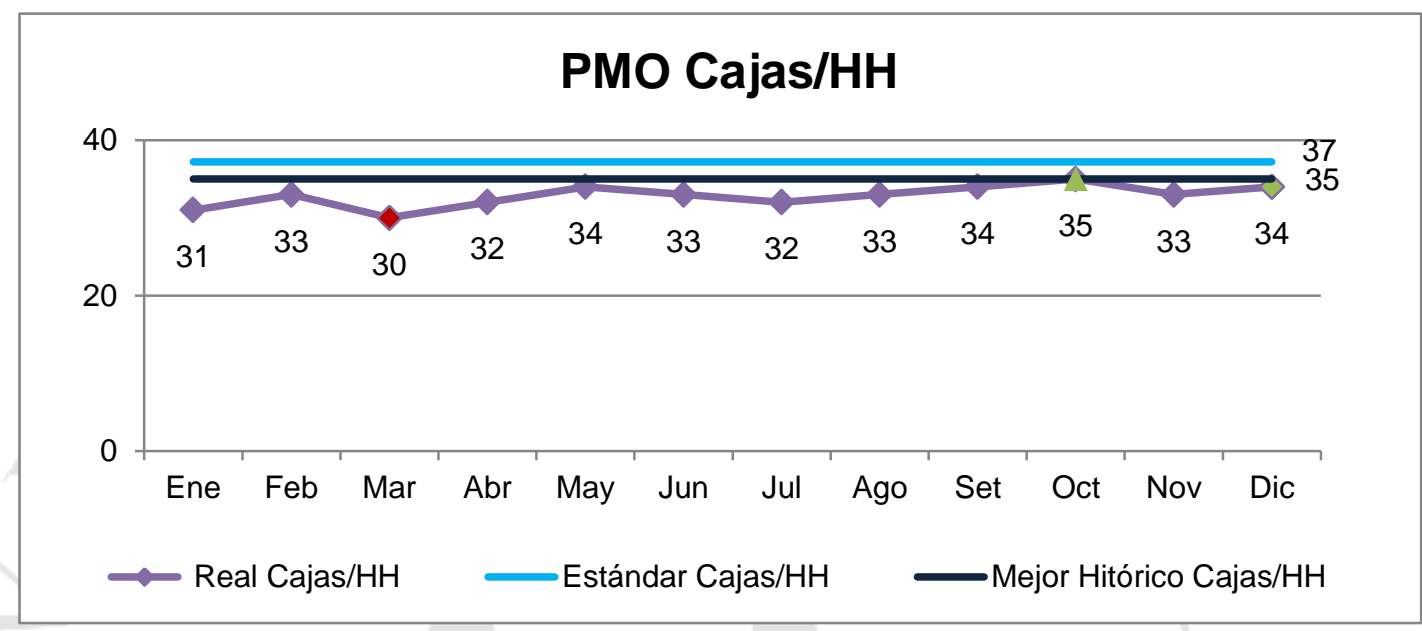

Elaboración propia

En la figura 3.11 se presenta el cumplimiento en base a la productividad estándar establecida por la planta.

Figura 3.11

Evolutivo de cumplimiento del indicador productividad de mano de obra (PMO) vs.

Productividad de mano de obra estándar en porcentaje - Envasado

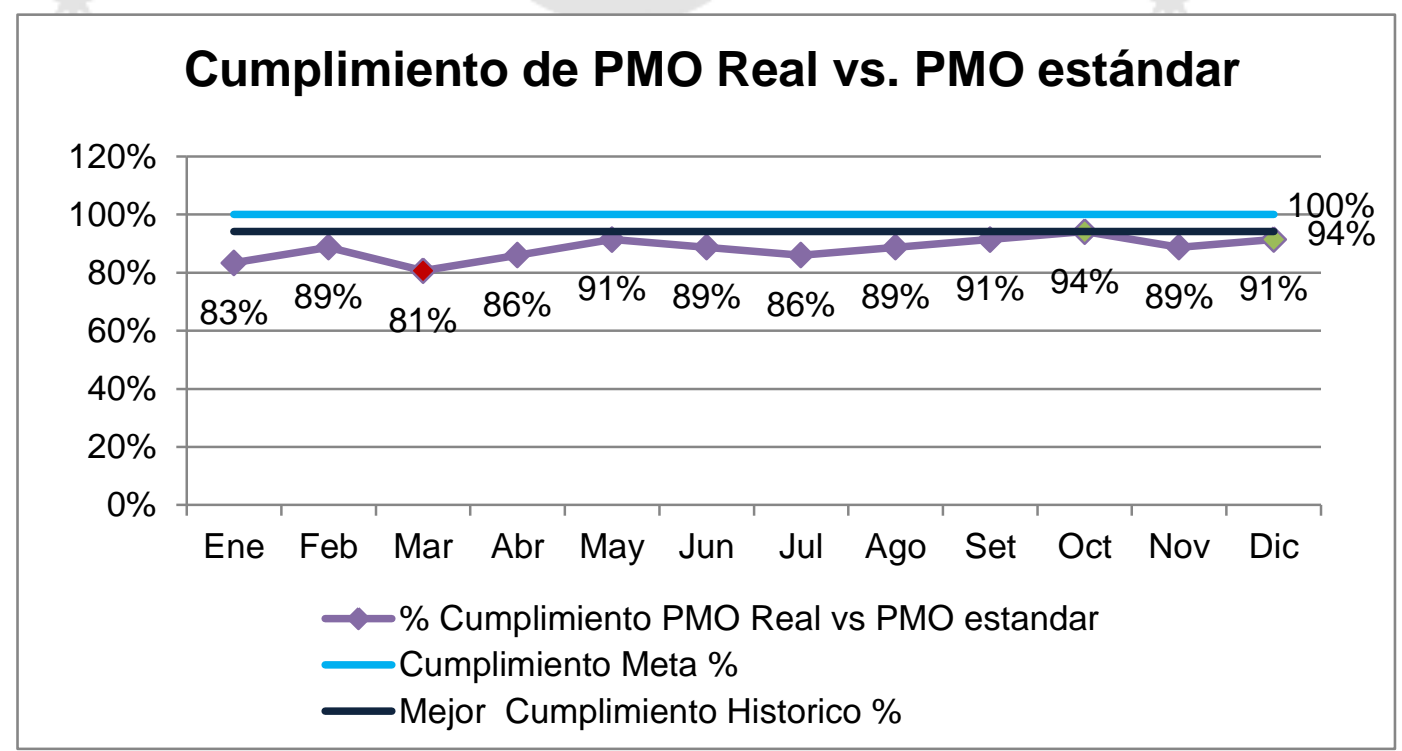

Elaboración propia 
Se observa que el cumplimiento no alcanza el $100 \%$ y tiene una alta variación (1.4 desviación estándar) a lo largo de los meses. Esto se debe básicamente a que solo se cuenta con 1 llenadora automática y si bien es cierto, en algunos meses la utilización de la envasadora es alta, no necesariamente se envasó mayonesa. De igual manera se debe prestar atención al valor de Marzo pues en la figura 3.12 se muestra el mes con mayor desviación estándar.

Figura 3.12

Desviación estándar productividad mano de obra - Envasado

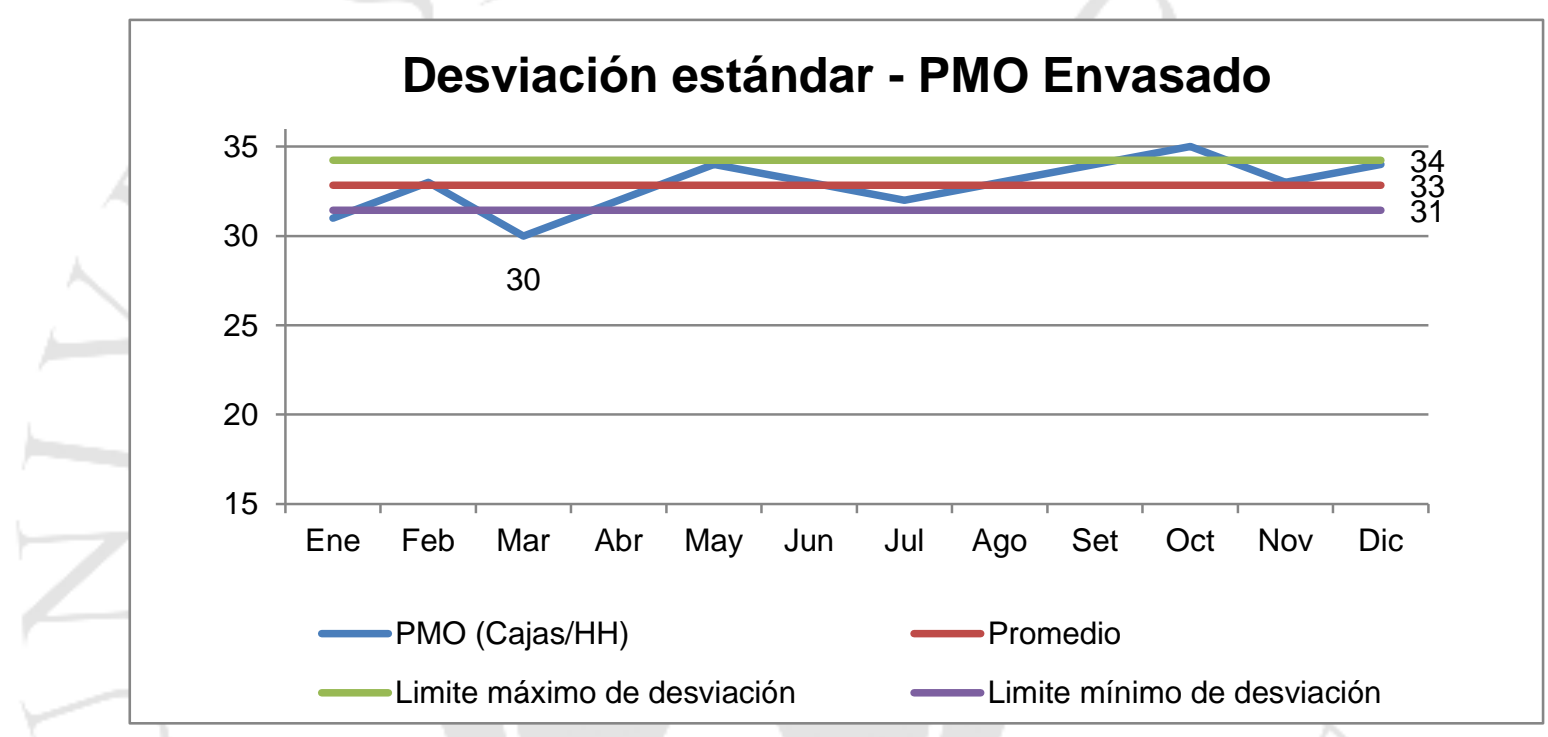

Elaboración propia

\subsection{Determinación de las causas raíz de los problemas hallados}

\subsubsection{Análisis de los factores que influyen favoreciendo o limitando los resultados actuales}

Después de haber analizado los principales indicadores del desempeño productivo, se concluye que no se logra obtener el resultado deseado por la empresa al no cumplir el objetivo y al presentar algunas desviaciones atípicas algunos meses del año en los indicadores. A continuación se identificarán las causas raíces que limitan lograr el resultado deseado. Para ello se utilizó el diagrama de Ishikawa de las figuras 3.13 y 3.14 . 
Figura 3.13

Diagrama de Causa - Efecto: KPI Eficiencia (utilización de la envasadora automática Fustec y Productividad Mano de Obra del envasado de Mayonesa 10 gr.)
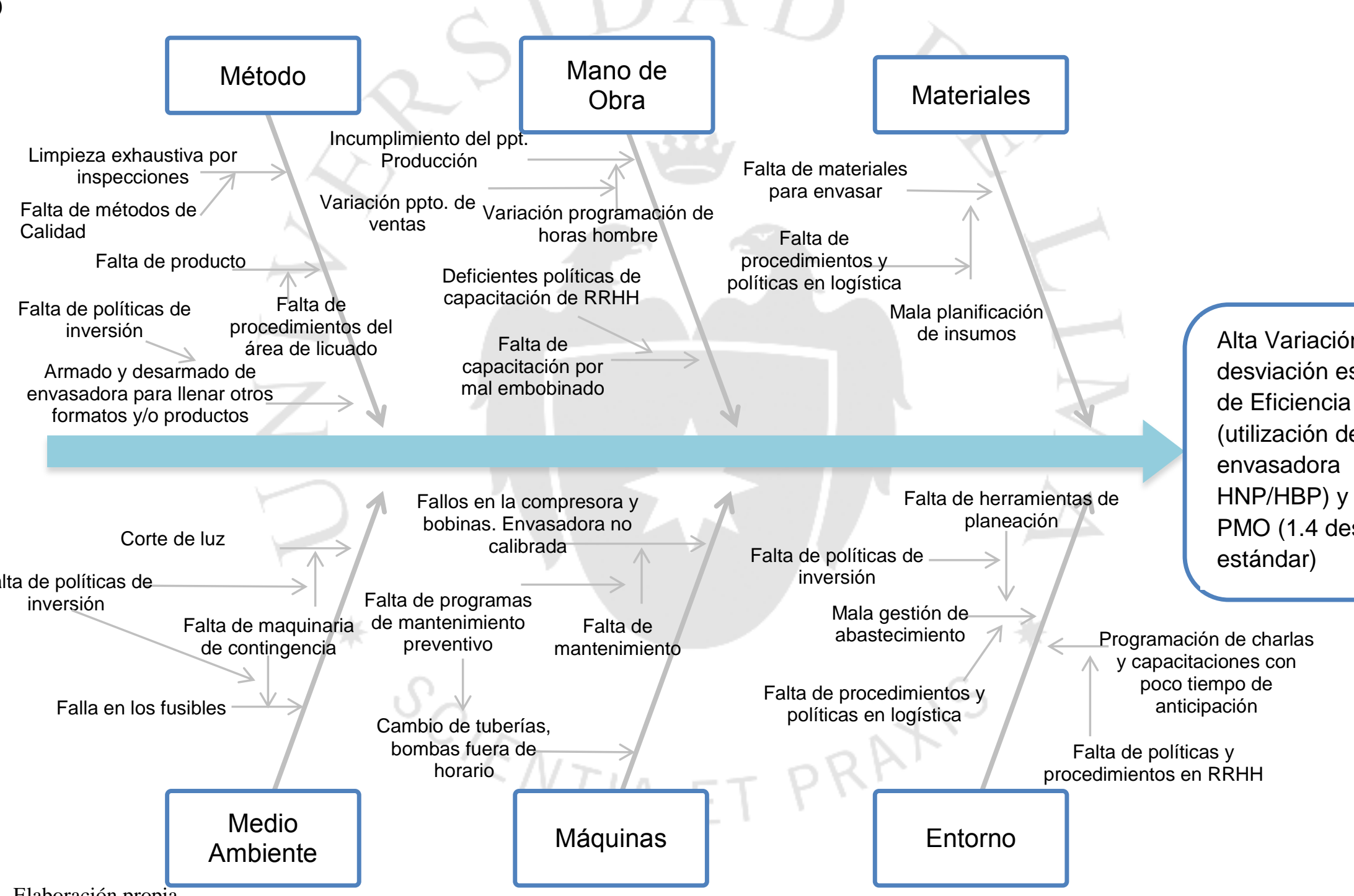

Alta Variación $(2.5 \%$ desviación estándar) de Eficiencia de línea (utilización de la envasadora HNP/HBP) y de PMO (1.4 desviación Falta de políticas de inversión

Corte de luz

Falla en los fusibles
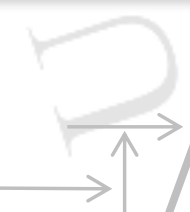

Falta de maquina de contingencia $s$

Medio

Ambiente

\section{Máquinas}

\section{Entorno}


Figura 3.14

Diagrama de Causa - Efecto: KPI Eficiencia de Línea (utilización de la licuadora y Productividad Mano de Obra de licuado de Mayonesa 10gr)

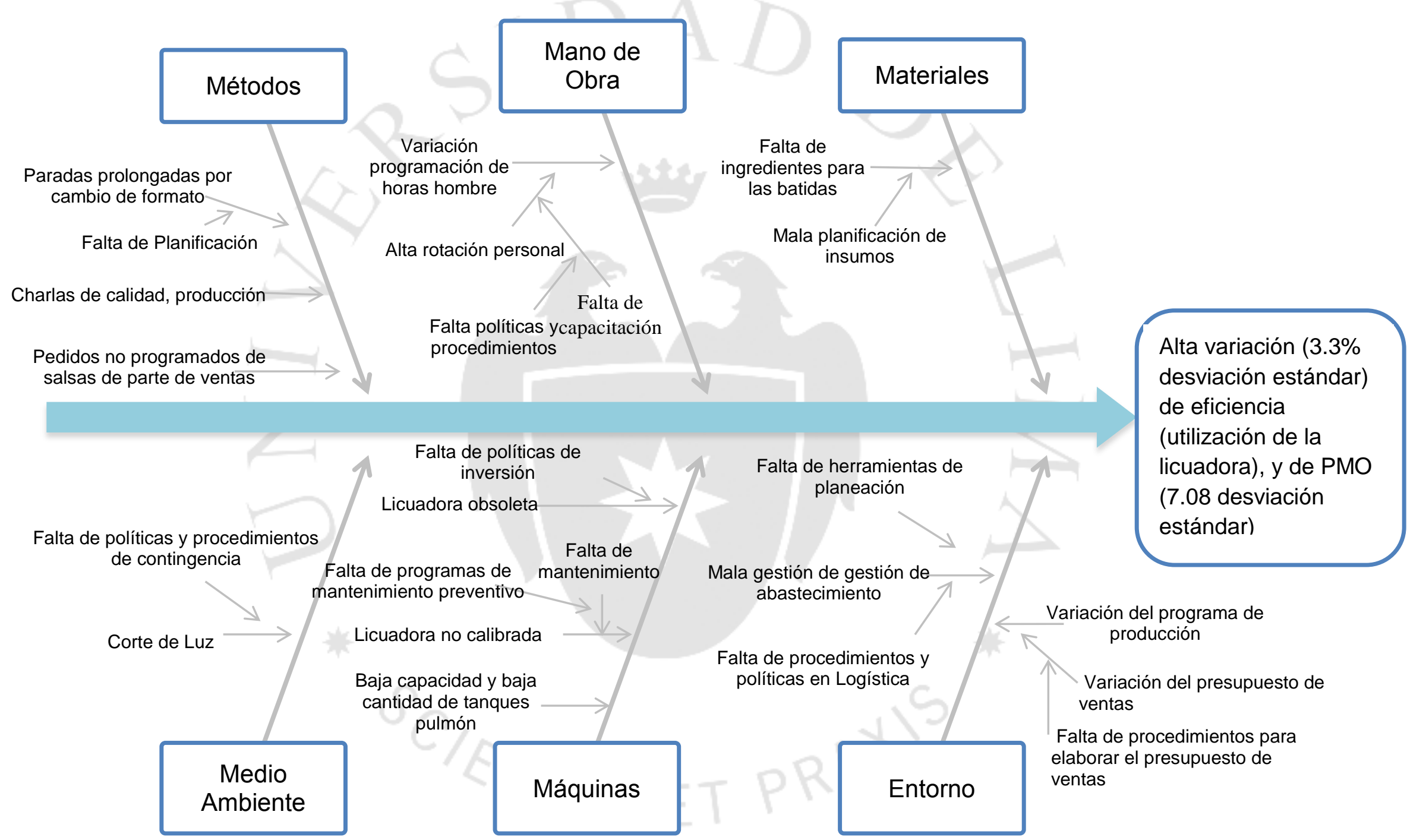

Elaboración propia 
Se realizó un focus group con el jefe de línea de mayonesa y los 4 operarios encargados de la estación de licuado y envasado, quienes colaboraron en identificar las causas raíces de cada problema encontrado en el diagrama Ishikawa. Una vez identificadas, se estableció el nivel de frecuencia de ocurrencia de cada una. Adicionalmente, mediante el método de Jean-Pierre Thibaut, método que brinda las herramientas para realizar el diagnóstico de una empresa, se categorizaron las causas raíz con el fin de identificar posibles soluciones para cada una de ellas. En la tabla 3.5 se observa lo descrito:

\section{Tabla 3.5}

Causas raíces de problemas identificados

\begin{tabular}{|c|c|c|c|}
\hline Causa & Frecuencia & Causa Raíz & Causa \\
\hline Baja capacidad de Tanques pulmón & Alta & $\begin{array}{l}\text { Falta de capacidad de tanques } \\
\text { pulmón }\end{array}$ & Recursos \\
\hline Licuadora obsoleta & Alta & & \\
\hline Paradas de máquina prolongadas & Alta & $\begin{array}{l}\text { Falta de politicas para } \\
\text { establecer un programa de }\end{array}$ & $\begin{array}{c}\text { Políticas y } \\
\text { procedimientos }\end{array}$ \\
\hline Falla en los fusibles/compresora y bobinas & Alta & & \\
\hline $\begin{array}{l}\text { Paradas por cambio de formato de envasadora } \\
\text { para envasar otros productos y formatos }\end{array}$ & Alta & $\begin{array}{l}\text { Inexistencia de una envasadora } \\
\text { automática para cada línea de } \\
\text { producción (Ketchup, mostaza, } \\
\text { mayonesa) }\end{array}$ & Recursos \\
\hline Falta de producto para envasar & Alta & \multirow{5}{*}{$\begin{array}{c}\text { No existe un programa de } \\
\text { planeamiento y control de la } \\
\text { producción adecuado }\end{array}$} & \multirow{5}{*}{$\begin{array}{c}\text { Políticas y } \\
\text { procedimientos }\end{array}$} \\
\hline Incumplimiento del presupuesto de producción & Alta & & \\
\hline Falta de insumos / materiales para producir & Alta & & \\
\hline Variación del programación de horas hombre & Alta & & \\
\hline Variación del programa de producción & Alta & & \\
\hline Falta de capacitación de embobinado & Baja & $\begin{array}{l}\text { Falta de politicas para } \\
\text { establecer un programa de } \\
\text { capacitación }\end{array}$ & $\begin{array}{c}\text { Políticas y } \\
\text { procedimientos }\end{array}$ \\
\hline Limpieza Exahusiva por inspecciones & Baja & \multirow{2}{*}{ Falta de políticas de calidad } & \multirow{2}{*}{$\begin{array}{c}\text { Políticas y } \\
\text { procedimientos }\end{array}$} \\
\hline Charlas de calidad no programadas & Baja & & \\
\hline
\end{tabular}

Elaboración propia

Se propondrán soluciones para aquellas causas raíz que muestran un nivel de frecuencia alta. A continuación se describen las causas raíz en base a la categorización realizada en la tabla 3.5 . 
- Políticas y Procedimientos

No existen procedimientos que determinen una correcta planificación de insumos ya que en varias ocasiones los insumos se han acabado, por ende, no se logra cumplir con la programación de producción del día y/o semana. En tal sentido, la materia prima a comprar debe ser producto de la planeación de la producción, la cual debe considerar tanto la demanda del producto, los niveles de inventario así como un stock de seguridad ante la posible aparición de pedidos no programados. Esto trae como consecuencia que no se tengan métodos que ayuden a gestionar una correcta planificación de insumos. Adicionalmente, el hecho de no contar con políticas de mantenimiento preventivo y solo reactivo, ocasiona largas paradas en el proceso de producción ya que las máquinas dejan de funcionar por un mal embobinado o un mal calibraje de la envasadora y/o licuadora

\section{- Recursos}

Por otro lado, el recurso maquinaria del envasado automático de 10 gr no tiene la suficiente capacidad para atender las 3 líneas productivas distintas (mayonesa, kétchup, mostaza). Se cuenta con una envasadora automática Fustec que atiende a los 3 procesos de envasado de $10 \mathrm{gr}$ mencionados anteriormente. Esto trae consigo un elevado número de paradas prolongadas (3 horas) por el cambio de formato del producto a envasar y la limpieza de la máquina.

Asimismo, existe una falta de capacidad de tanques pulmón para vaciar el producto luego del licuado. Actualmente, se utilizan tales tanques para que el producto espere y pueda pasar a llenarse en la envasadora automática Fustec una vez que se encuentre disponible. Sin embargo, se observa tiempo desperdiciado al no poder continuar con las batidas en la estación de licuado porque no se cuenta con la capacidad suficiente en los tanques para vaciar el producto. Este inconveniente ocasiona demoras en el proceso de licuado y además, al ser la mayonesa una salsa emulsionada fría con muchos ingredientes, queda expuesta a sufrir alteraciones químicas generándose mermas por detener el licuado de esa manera. 


\subsubsection{Identificación y evaluación de las fortalezas y debilidades de la Empresa.}

Luego de haber analizado las debilidades y fortalezas con el personal de ALIEX, se muestra la matriz de evaluación de factores internos (EFI) en la tabla 3.6, donde se visualiza que el total ponderado es mayor al promedio (2.5), lo que significa que ALIEX está aprovechando adecuadamente sus fortalezas para minimizar sus debilidades.

Tabla 3.6

Matriz de evaluación de factores internos (EFI)

\begin{tabular}{|l|c|c|c|}
\hline \multicolumn{1}{|c|}{ Factores externos claves } & Valor & Calificación & $\begin{array}{c}\text { Valor } \\
\text { Ponderado }\end{array}$ \\
\hline \multicolumn{1}{|c|}{ Fortalezas } & & & \\
\hline Marca posicionada y buen manejo del mercado tradicional & 0.10 & 4 & 0.4 \\
\hline Personal identificado y de confianza & 0.04 & 3 & 0.12 \\
\hline Presencia en mercado de provincias & 0.10 & 3 & 0.3 \\
\hline $\begin{array}{l}\text { Buena situación financiera y poder crediticio con } \\
\text { proveedores }\end{array}$ & 0.10 & 4 & 0.4 \\
\hline Fuerte vínculo con sus proveedores & 0.03 & 3 & 0.09 \\
\hline $\begin{array}{l}\text { Incremento de la participación en canal moderno de } \\
\text { consumo masivo. }\end{array}$ & 0.07 & 2 & 0.14 \\
\hline Buenas relaciones con los clientes de consumo industrial & 0.06 & 3 & 0.18 \\
\hline \multicolumn{1}{|c|}{ Debilidades } & & & 0 \\
\hline $\begin{array}{l}\text { Falta de tecnología para producir productos de mayor } \\
\text { valor agregado para otros mercados }\end{array}$ & 0.10 & 3 & 0.3 \\
\hline Deficiente mantenimiento preventivo de maquinaria & 0.04 & 2 & 0.08 \\
\hline Falta de posicionamiento de marca en mercados A y B & 0.10 & 4 & 0.4 \\
\hline Falta de planeamiento estratégico y presupuestario & 0.06 & 3 & 0.18 \\
\hline Falta de coordinación y comunicación entre áreas & 0.03 & 4 & 0.12 \\
\hline $\begin{array}{l}\text { No existen máquinas de envasado automáticas para cada } \\
\text { línea productiva, las máquinas se comparten para el } \\
\text { envasado de los 3 tipos de salsas. }\end{array}$ & 0.10 & 2 & 0.2 \\
\hline $\begin{array}{l}\text { Ausencia de un sistema informático sofisticado que pueda } \\
\text { gestionar la información de las distintas áreas. }\end{array}$ & 0.07 & 2 & 0.14 \\
\hline
\end{tabular}

Elaboración Propia 


\section{CAPÍTULO IV. DETERMINACIÓN DE LA PROPUESTA DE SOLUCIÓN}

\subsection{Planteamiento de alternativas de solución a la problemática encontrada.}

Como recomendación se propone a ALIEX realizar una revisión de su visión pues no queda claro cuáles son sus ventajas competitivas y cuál es su marco competitivo. Adicionalmente se debe agregar en el organigrama el área de sistemas y de planeamiento y control de la producción.

En el capítulo anterior se identificaron las principales causas raíces que limitan a la empresa obtener resultados deseados en sus indicadores de desempeño productivo. Para facilitar el análisis y planteamiento de estrategias de solución a los problemas encontrados, se realizará una ponderación y un análisis de Pareto, lo cual permitirá saber qué causas son las que afectan de una manera más directa a los objetivos de la empresa en el proceso de producción.

Para ello se empleará la Matriz de Selección de Problema Principal donde se van a listar las principales causas raíz, luego se calificará cada una asignándole un valor de acuerdo al impacto en los criterios indicados. Con dicho puntaje multiplicado por la ponderación preestablecida se podrá seleccionar las principales causas para luego proceder a plantear soluciones para dichas causas. En la tabla 4.1 se muestran los pesos de criterios y escalas de calificación.

Tabla 4.1

Pesos de criterios y escalas de calificación.

\begin{tabular}{|l|c|}
\hline \multicolumn{1}{|c|}{ Criterios } & Peso \\
\hline Impacto en la satisfacción del cliente & $20 \%$ \\
\hline Impacto en los costos de la empresa & $30 \%$ \\
\hline Complejidad, puede ser resuelto por equipos & $15 \%$ \\
\hline Alineamiento del problema con los objetivos y estrategias de la organización & $35 \%$ \\
\cline { 2 - 4 } & $100 \%$ \\
\cline { 2 - 4 } &
\end{tabular}

Elaboración Propia 
Tabla 4.2

Matriz de selección de causas principales

\begin{tabular}{|c|c|c|c|c|c|}
\hline \multirow{2}{*}{ Causas } & \multicolumn{5}{|c|}{ Crite rios a Evaluar } \\
\cline { 2 - 6 } & $\begin{array}{c}\text { Impacto en la } \\
\text { satisfacción del } \\
\text { cliente (20\%) }\end{array}$ & $\begin{array}{c}\text { Impacto en los } \\
\text { costos(30\%) }\end{array}$ & $\begin{array}{c}\text { Complejidad, puede } \\
\text { ser resuelto por el } \\
\text { equipo (15\%) }\end{array}$ & $\begin{array}{c}\text { Alineamiento del } \\
\text { problema con los objetivos } \\
\text { y estrategias de la } \\
\text { organización (35\%) }\end{array}$ & $\begin{array}{c}\text { PUNTAJE } \\
\text { TOTAL }\end{array}$ \\
\hline $\begin{array}{c}\text { C1. Inexistencia de una envasadora } \\
\text { automática para cada línea de producción } \\
\text { (Mayonesa, Ketchup, Mostaza) }\end{array}$ & 10 & 90 & 30 & 90 & $\mathbf{6 5}$ \\
\hline $\begin{array}{c}\text { C2. No existe un programa de planeamiento } \\
\text { y control de la producción adecuado }\end{array}$ & 30 & 90 & 30 & 30 & $\mathbf{6 9}$ \\
\hline C3. Falta de capacidad de tanques pulmón & 0 & 30 & 90 & 30 & $\mathbf{3 3}$ \\
\hline $\begin{array}{c}\text { C.4 Inexistencia de un programa de } \\
\text { mantenimiento preventivo }\end{array}$ & 10 & 90 & 30 & $\mathbf{6 5}$ \\
\hline
\end{tabular}

Elaboración propia

Realizada la ponderación en la tabla 4.2, se procederá a realizar un ranking en la tabla 4.3.

Tabla 4.3

Ranking de causas

\begin{tabular}{|c|c|c|c|c|}
\hline Causas & Puntaje Total & $\begin{array}{c}\text { Puntaje } \\
\text { Acumulado }\end{array}$ & $\%$ & $\begin{array}{c}\% \\
\text { Acumulado }\end{array}$ \\
\hline $\begin{array}{c}\text { C2. No existe un programa de } \\
\text { planeamiento y control de la } \\
\text { producción adecuado }\end{array}$ & $\mathbf{6 9}$ & 69 & $30 \%$ & $30 \%$ \\
\hline $\begin{array}{c}\text { C1. Inexistencia de una } \\
\text { envasadora automática para } \\
\text { cada línea de producción } \\
\text { (Mayonesa, Ketchup, Mostaza) }\end{array}$ & $\mathbf{6 5}$ & 134 & $28 \%$ & $58 \%$ \\
\hline $\begin{array}{c}\text { C.4 Inexistencia de un programa } \\
\text { de mantenimiento preventivo }\end{array}$ & $\mathbf{6 5}$ & 199 & $28 \%$ & $86 \%$ \\
\hline $\begin{array}{c}\text { C3. Falta de capacidad de } \\
\text { tanques pulmón }\end{array}$ & $\mathbf{3 3}$ & 232 & $14 \%$ & $100 \%$ \\
\hline
\end{tabular}

Elaboración propia

En la figura 4.1 se puede apreciar que 3 causas representan el $\mathbf{8 6 \%}$ de los principales problemas del proceso de producción y sobre las cuales se plantearán soluciones. 
Figura 4.1

Diagrama de Pareto - Causas de problemas en el proceso de producción

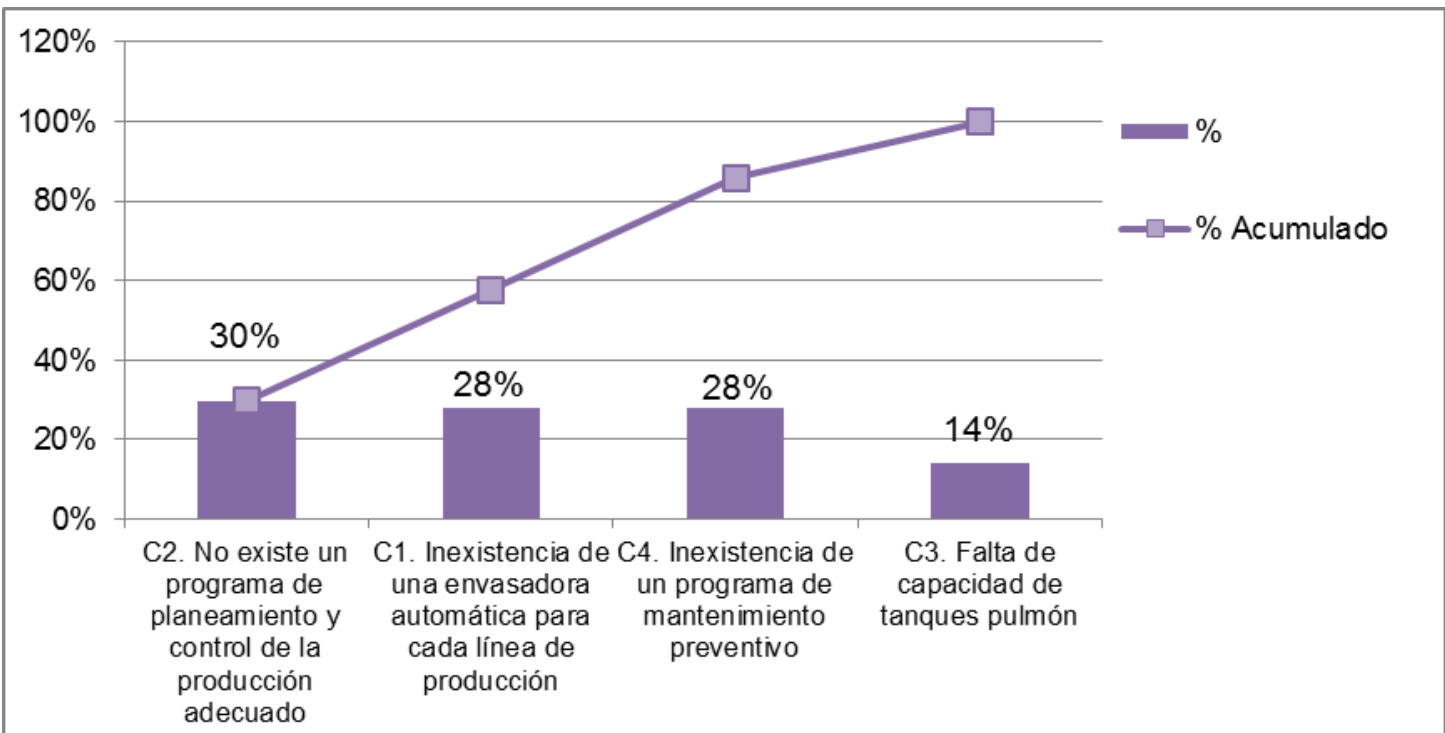

Elaboración propia

Después de haber determinado las 3 causas más importantes, se detallarán las posibles soluciones a los problemas que limitan el cumplimiento deseado de los indicadores de producción.

Causa 2: No existe un programa de planeamiento y control de la producción adecuado. El área de producción no realiza la planificación de insumos de la manera óptima o deseada pues en varias ocasiones ha habido paradas de producción por la falta de los mismos. A continuación se detallan algunas soluciones al problema identificado.

- Solución A: Implementar un MRP I (Material Requirement Planning)

El MRP I es un sistema de información para la planificación de las operaciones. Son sistemas de empuje de la producción (push). Básicamente se utiliza para la planificación de los requerimientos de materiales y tiene como objetivo asegurar la disponibilidad (en cantidad y momento preciso) de materias primas e insumos para cumplir con los planes de programación del área productiva. Esto trae consigo la disminución de los tiempos de espera en la producción y entrega de productos, la reducción de materiales faltantes así como una mejor gestión de los niveles de inventario. Así pues, el MRP I consiste en un cálculo de necesidades netas de artículos (productos terminados, insumos, materia prima) introduciendo un factor nuevo no considerado en los métodos tradicionales de gestión de stock, 
que es el plazo de fabricación o de compra de cada insumo, lo que conduce a modular a lo largo del tiempo las necesidades ya que indica la oportunidad de aprovisionar los materiales con el debido tiempo respecto a su utilización en la fase siguiente de producción.

- Solución B: Mantener un alto nivel de stock de seguridad Plantear y establecer un adecuado nivel de stock de seguridad que se debe mantener en el almacén de productos terminados para lograr satisfacer la demanda proyectada, implementando un turno adicional para la línea. De esta manera el problema del hecho que en ocasiones no se cuente con producto en el área de envasado no afectará el cumplimiento de la demanda, pues se contará con productos disponibles ante cualquier eventualidad.

Causa 1: Inexistencia de una envasadora automática para cada línea de producción (Mayonesa, Ketchup, Mostaza). Dicha situación genera un gran inconveniente ya que el hecho de compartir una máquina envasadora automática con las 3 líneas productivas genera paradas prolongadas ( 3 horas en promedio) por tener que cambiar el producto y formato, además de la limpieza exhaustiva que debe realizarse. A continuación detallamos las posibles soluciones para este problema:

- Solución A: Adquisición de una nueva máquina envasadora

En este sentido el envasado de mayonesa contaría con su propia envasadora automática y no existirían paradas prolongadas por tener que cambiar el producto, formato y por no tener que hacer limpiezas exhaustivas.

- Solución B: Adquisición de una máquina envasadora usada

Otra solución es la adquisición de una máquina sachetera usada lo cual implicaría una menor inversión al ser una envasadora de segunda mano. Tener en cuenta que dicha máquina debe mantener la misma capacidad de producción o mayor, y el mismo nivel de tecnología que la máquina actual, pues se pretende compartir la cantidad de procesamiento para aumentar la producción. De igual manera, se espera aumentar la productividad y reducir los costos de producción al disminuir los tiempos. 
Causa 4: Inexistencia de un programa de mantenimiento preventivo. Actualmente ALIEX aplica mantenimientos correctivos a las máquinas, es decir, los mantenimientos son realizados cuando la maquinaria sufre alguna avería durante su operación en la planta de la empresa. De esta manera no existen mantenimientos preventivos programados. A causa de ello, frecuentemente, durante el proceso de producción de mayonesa, existen paradas prolongadas en las batidas y en el llenado, lo cual retrasa y disminuye los $\mathrm{Kg}$. planificados para el día evitando cumplir con el programa de producción. Se pudo identificar tal problema ya que, en los reportes de producción diarios, se evidencia pocas horas hombres utilizadas en ciertos días debido a que se tuvo que realizar mantenimientos correctivos a las máquinas averiadas.

- Solución A: Implementar un programa de mantenimiento preventivo.

Establecer la práctica de mantenimiento preventivo en el área de mantenimiento dentro de la empresa, en la cual se incluya un plan periódico y planificado de mantenimiento preventivo en el cual se redacte claramente los objetivos y necesidades de la empresa, el programa a seguir, las normas y estándares, los métodos y técnicas de mantenimiento. Esto minimizará las paradas imprevistas y largas de producción. El éxito de esta actividad dependerá en gran parte de las habilidades y características del personal responsable de dicha labor.

- Solución B: Tercerizar la labor de mantenimiento preventivo Tercerizar una empresa de mantenimiento especialista en mantenimiento preventivo para que realice la labor periódica.

\subsection{Selección d alternativas de solución}

\subsubsection{Determinación y ponderación de criterios evaluación de las alternativas}

Para la selección de la mejor solución aplicable a cada problema se utilizará como apoyo el libro de consulta 'Mejora continua de los procesos', en el cual plantean se debe establecer criterios para evaluar cada alternativa de propuesta y así determinar la mejor solución. Para ello se establecieron los siguientes criterios y sus pesos mostrados en la tabla 4.4. 
Tabla 4.4

Escala de calificación y pesos de criterios para la elección de soluciones

\begin{tabular}{|c|c|}
\hline Escala de complejidad & Puntaje \\
\hline Alta & 10 \\
\hline Media & 30 \\
\hline Alta & 50 \\
\hline Tiempo de imple mentación & Puntaje \\
\hline 1 - 15 dias & 50 \\
\hline 16 - 30 dias & 30 \\
\hline 30 a más & 10 \\
\hline Inversión & Puntaje \\
\hline Baja & 50 \\
\hline Media & 30 \\
\hline Alta & 10 \\
\hline Impacto en el problema & Puntaje \\
\hline 7 a más semanas & 10 \\
\hline 4 - 6 semanas & 20 \\
\hline 2 - 3 semanas & 30 \\
\hline 1 semana & 40 \\
\hline
\end{tabular}

\begin{tabular}{|l|c|}
\hline \multicolumn{1}{|c|}{ Criterios } & Peso \\
\hline Escala de complejidad & $15 \%$ \\
\hline Tiempo de implementación & $20 \%$ \\
\hline Inversión & $30 \%$ \\
\hline Impacto en el problema & $35 \%$ \\
\hline \multirow{2}{*}{$100 \%$} \\
\hline
\end{tabular}

Fuente: Bonilla, E., Diaz, B., Kleeberg, F., Noriega, M.. T. (2010).

\subsubsection{Evaluación cualitativa y cuantitativa de las alternativas de solución}

A continuación detallaremos la evaluación de cada alternativa en base a los criterios definidos en el punto anterior.

Causa 2: No existe un programa de planeamiento y control de la producción adecuado

Tabla 4.5

Alternativas de solución para la causa 2

\begin{tabular}{|c|c|c|c|c|c|}
\hline \multirow[b]{2}{*}{ Alternativas de solución } & $15 \%$ & $20 \%$ & $30 \%$ & $35 \%$ & \multirow[b]{2}{*}{ Total } \\
\hline & $\begin{array}{c}\text { Escala de } \\
\text { Complejidad }\end{array}$ & $\begin{array}{c}\text { Tiempo de } \\
\text { Implementación }\end{array}$ & Inversión & $\begin{array}{c}\text { Impacto en } \\
\text { Problema } \\
\end{array}$ & \\
\hline $\begin{array}{l}\text { Implementar un MRP I (Material } \\
\text { Requirement Planning) }\end{array}$ & 30 & 10 & 30 & 20 & 23 \\
\hline $\begin{array}{c}\text { Mantener un alto nivel de stock } \\
\text { de seguridad }\end{array}$ & 30 & 10 & 30 & 10 & 19 \\
\hline
\end{tabular}

Elaboración Propia

Se eligió implementar un MRP I pues obtuvo la mayor calificación (23) como se muestra en la tabla 4.5. Enseguida, se identifican 3 tipos de posibles herramientas que cumplen la función de un MRP I. 
- Uso de una hoja de calculo

$\checkmark$ Ventajas:

Costo bajo

$>$ Tiempo de implementación bajo

$>$ De Fácil manejo y adaptación

Desventajas:

$>$ Inexistencia de métodos que aseguren la consistencia y correcta información en la herramienta

Es un trabajo operativo más y no se logra obtener un proceso más automatizado y estandarizado.

- Desarrollo de un software adaptado a las necesidades de la empresa

$\checkmark$ Ventajas:

$>$ No hay necesidad de adaptar un sistema a la empresa pues esta herramienta encajará perfectamente

Desventajas:

D El tiempo de implementación será mucho mayor pues además de instalarlo en la empresa existe toda una etapa previa de diseño y desarrollo de la herramienta.

Se debe considerar el costo no solo de implementación sino también de diseño y desarrollo por la inversión humana que se requiere.

- Adquisición de una herramienta existente del mercado

$\checkmark$ Ventajas:

El tiempo de implementación es menor que el de un software desarrollado a medida ya que se tendría que considerar el tiempo de diseño.

$>$ Es de implementación gradual ya que se realiza por módulos por lo que no es necesario efectuar todos los módulos si aún no se requieren.

Existe una constante actualización de versiones de la herramienta conforme la tecnología vaya desarrollando gracias a las licencias anuales. 
Se tiene un alto nivel de seguridad de la información.

$>$ Herramienta con trayectoria en el mercado.

Desventajas:

El costo es mayor pues son herramientas con prestigio y trayectoria en el mercado.

Se requiere un alto nivel de capacitación de quienes manipularán la herramienta.

$>$ Se debe analizar si la empresa cumple con los requisitos técnicos para que la herramienta pueda adaptarse.

A continuación se muestran los factores que serán tomados en cuenta para elegir la mejor alternativa y mediante un ranking de factores que se muestra en la tabla 4.6 se le dará un peso a cada uno en base al criterio del autor:

- $\operatorname{Costo}(1)$

- Tiempo de Implementación (2)

- Adaptación a la empresa (3)

- Seguridad y consistencia de la información (4)

- Prestigio (5)

Tabla 4.6

Matriz de enfrentamiento

\begin{tabular}{|c|c|c|c|c|c|c|c|}
\hline Factor & $\mathbf{1}$ & $\mathbf{2}$ & $\mathbf{3}$ & $\mathbf{4}$ & $\mathbf{5}$ & Conteo & Ponderación \\
\hline $\mathbf{1}$ & & 1 & 0 & 0 & 1 & 2 & $20 \%$ \\
\hline $\mathbf{2}$ & 0 & & 0 & 0 & 1 & 1 & $10 \%$ \\
\hline $\mathbf{3}$ & 1 & 1 & & 0 & 1 & 3 & $30 \%$ \\
\hline $\mathbf{4}$ & 1 & 1 & 1 & & 1 & 4 & $40 \%$ \\
\hline $\mathbf{5}$ & 0 & 0 & 0 & 0 & & 0 & $0 \%$ \\
\cline { 5 - 7 }
\end{tabular}

Elaboración propia

Luego de haber establecido un peso a cada factor, se decidirá cuál es la mejor alternativa en base a una matriz de selección que se muestra en la tabla 4.7, en donde cada factor se calificará con una escala del 1 al 3, siendo 1 malo, 2 bueno y 3 excelente. 
Tabla 4.7

Valoración de alternativas

\begin{tabular}{|c|c|c|c|c|c|c|c|}
\cline { 3 - 8 } \multicolumn{2}{c|}{} & \multicolumn{2}{c|}{ Opción 1 } & \multicolumn{2}{c|}{ Opción 2 } & \multicolumn{2}{c|}{ Opción 3 } \\
\hline Factor & Peso & Valoración & Puntaje & Valoración & Puntaje & Valoración & Puntaje \\
\hline 1 & $20 \%$ & 3 & 0.6 & 1 & 0.2 & 2 & 0.4 \\
\hline 2 & $10 \%$ & 3 & 0.3 & 1 & 0.1 & 2 & 0.2 \\
\hline 3 & $30 \%$ & 1 & 0.3 & 3 & 0.9 & 2 & 0.6 \\
\hline 4 & $40 \%$ & 1 & 0.4 & 2 & 0.8 & 3 & 1.2 \\
\hline
\end{tabular}

Elaboración propia

Se concluye que la mejor alternativa es adquirir una herramienta existente del mercado pues obtiene el mayor puntaje (2.4).

Causa 1: Inexistencia de una envasadora automática para cada línea de producción (Mayonesa, Ketchup, Mostaza).

Se eligió adquirir una nueva máquina sachetera envasadora pues obtuvo la mayor calificación (30.5) como se muestra en la tabla 4.8 .

\section{Tabla 4.8}

Alternativas de solución para causa 1

\begin{tabular}{|c|c|c|c|c|c|}
\hline \multirow[b]{2}{*}{ Alternativas de solución } & $15 \%$ & $20 \%$ & $30 \%$ & $35 \%$ & \multirow[b]{2}{*}{ Total } \\
\hline & $\begin{array}{c}\text { Escala de } \\
\text { Complejidad }\end{array}$ & $\begin{array}{c}\text { Tiempo de } \\
\text { Implementación } \\
\end{array}$ & Inversión & $\begin{array}{c}\text { Impacto en } \\
\text { Problema } \\
\end{array}$ & \\
\hline $\begin{array}{l}\text { Adquisición de una nueva } \\
\text { máquina sachetera envasadora }\end{array}$ & 50 & 30 & 10 & 40 & 30.5 \\
\hline $\begin{array}{l}\text { Adquisición de una máquina } \\
\text { sachetera envasadora usada }\end{array}$ & 50 & 30 & 30 & 20 & 29.5 \\
\hline
\end{tabular}

Elaboración propia

Causa 4: Inexistencia de un programa de mantenimiento preventivo

Se eligió implementar un nuevo programa de mantenimiento preventivo pues obtuvo la mayor calificación (28.5) como se muestra en la tabla 4.9. 
Tabla 4.9

Alternativas de solución para causa 4

\begin{tabular}{|c|c|c|c|c|c|}
\hline \multirow[b]{2}{*}{ Alternativas de solución } & $15 \%$ & $20 \%$ & $30 \%$ & $35 \%$ & \multirow[b]{2}{*}{ Total } \\
\hline & $\begin{array}{c}\text { Escala de } \\
\text { Complejidad } \\
\end{array}$ & $\begin{array}{c}\text { Tiempo de } \\
\text { Implementación }\end{array}$ & Inversión & $\begin{array}{c}\text { Impacto en } \\
\text { Problema } \\
\end{array}$ & \\
\hline $\begin{array}{l}\text { Implementar un nuevo programa } \\
\text { de mantenimiento preventivo }\end{array}$ & 30 & 10 & 50 & 20 & 28.5 \\
\hline $\begin{array}{c}\text { Tercerizar labor de } \\
\text { mantenimiento preventivo }\end{array}$ & 50 & 30 & 10 & 20 & 23.5 \\
\hline
\end{tabular}

Elaboración propia

Después de haber evaluado cada alternativa y de haber elegido las propuestas de solución, se mostrará el análisis de las ventajas y desventajas de cada una de ellas.

- Solución 1: Implementar un MRP I (Material Requirement Planning)

Ventajas:

Se tendrá una eficiente gestión de aprovisionamiento de materia prima e insumos.

Se tendrá mejor respuestas ante la demanda del mercado

- Se reducirán los tiempos de espera toda la cadena del proceso de producción ya que los insumos siempre se encontrarán disponibles en el momento deseado y en la cantidad deseada.

Se podrá cambiar el plan maestro en caso de pedidos no programados.

El manejo de inventarios será más eficiente

Se logrará una mayor satisfacción de los clientes

Rapidez de detección de dificultades en el cumplimiento de la programación

Desventajas:

Requiere de información precisa

$>$ No es una herramienta autónoma por lo cual depende en gran manera de la correcta organización de la empresa y sobre todo de su gerencia. Asimismo requiere un alto nivel de capacitación de los usuarios. 
- Solución 2: Adquisición de una nueva máquina sachetera envasadora para la línea de mayonesa

$\checkmark$ Ventajas:

Se aumentará la capacidad productiva de la línea de mayonesa ya que no existirán paradas prolongadas por tener que cambiar los formatos o por limpieza de la máquina para el envasado de otros productos.

> Se reducirán los tiempos de espera durante el proceso.

$>$ Disminución de los costos de producción.

$>$ Se obtendrá una optimización del recurso humano, tanto en tiempo como en el desarrollo de sus habilidades.

\section{Desventajas:}

No existe gran oferta de la maquinaria en el mercado nacional, lo cual obliga a importar la envasadora.

- Solución 3: Implementar nuevo programa de mantenimiento preventivo

$\checkmark$ Ventajas:

Se logrará minimizar las paradas imprevistas durante la producción por falta de mantenimiento.

Se mantendrá la infraestructura y los equipos en buenas condiciones de tal manera que no interfiera con el proceso productivo.

$\checkmark$ Desventajas:

$>$ Se requiere personal altamente capacitado para la ejecución del programa de mantenimiento.

$>$ Existirán paradas programadas lo cual podría retrasar la producción semanal y mensual.

Pérdida de horas hombre en la producción de la mayonesa por paradas de máquina durante el mantenimiento. 


\subsubsection{Priorización y programación de soluciones seleccionadas}

A continuación, se someten las 3 soluciones principales a una matriz de enfrentamiento en la tabla 4.10 donde se determinará el peso de cada una en base al criterio del gerente y jefe de producción de ALIEX para determinar el orden de implementación de las soluciones propuestas. De la tabla 4.10 se concluye que la primera solución a implementar será "Implementación de un MRP I", seguida de "Implementación de un programa de mantenimiento preventivo" y finalmente "Adquisición de una máquina sacheteadora automática".

Tabla 4.10

Matriz de enfrentamiento - Soluciones propuestas

\begin{tabular}{|c|c|c|c|c|c|}
\hline Solución & $\mathbf{1}$ & $\mathbf{2}$ & $\mathbf{3}$ & Conteo & Ponderación \\
\hline $\mathbf{1}$ & & 1 & 1 & 2 & $67 \%$ \\
\hline $\mathbf{2}$ & 0 & & 0 & 0 & $0 \%$ \\
\hline $\mathbf{3}$ & 0 & 1 & & 1 & $33 \%$ \\
\hline
\end{tabular}

Elaboración propia

En el presente trabajo de investigación desarrollaremos la primera y tercera solución. La razón por la que no se desarrollará la segunda solución es porque con una adecuada organización y planificación de la producción de todos los tipos de salsas de mesa (que se logrará implementando el software y el programa de mantenimiento preventivo) se puede cumplir con la demanda proyectada en la tabla 5.12 ya que la capacidad de producción de la máquina envasadora lo permite.

Actualmente, la capacidad de producción de dicha máquina es de 1487.5 $\mathrm{kg}$ /turno y la planta programa 2 turnos al mes para cumplir con la demanda actual. Considerando que la demanda proyectada para el mes 12 será de $10410 \mathrm{~kg}$ (véase tabla 5.12), ALIEX deberá programar 7 turnos al mes para cumplirla. De esta manera, la empresa se evitará realizar la gran inversión que implica adquirir una nueva máquina. 


\section{CAPÍTULO V. DESARROLLO Y PLANIFICACION DE LAS SOLUCIONES}

\subsection{Ingeniería de la solución}

Solución 1: Implementación de un MRP I (Material Requirement Planning). A continuación, se describirán las actividades para la implementación de la solución priorizada. Se utilizó el modelo PMI (Project management institute), específicamente el modelo PMBOK (Project Management Body of Knowledge) como se ve en la figura 5.1, el cual nos permitirá iniciar, planificar y ejecutar el proyecto descrito.

Figura 5.1

Metodología PMBOK (Project Management Body of Knowledge) para implementar un MRP I (Planeamiento de requerimiento de materiales)

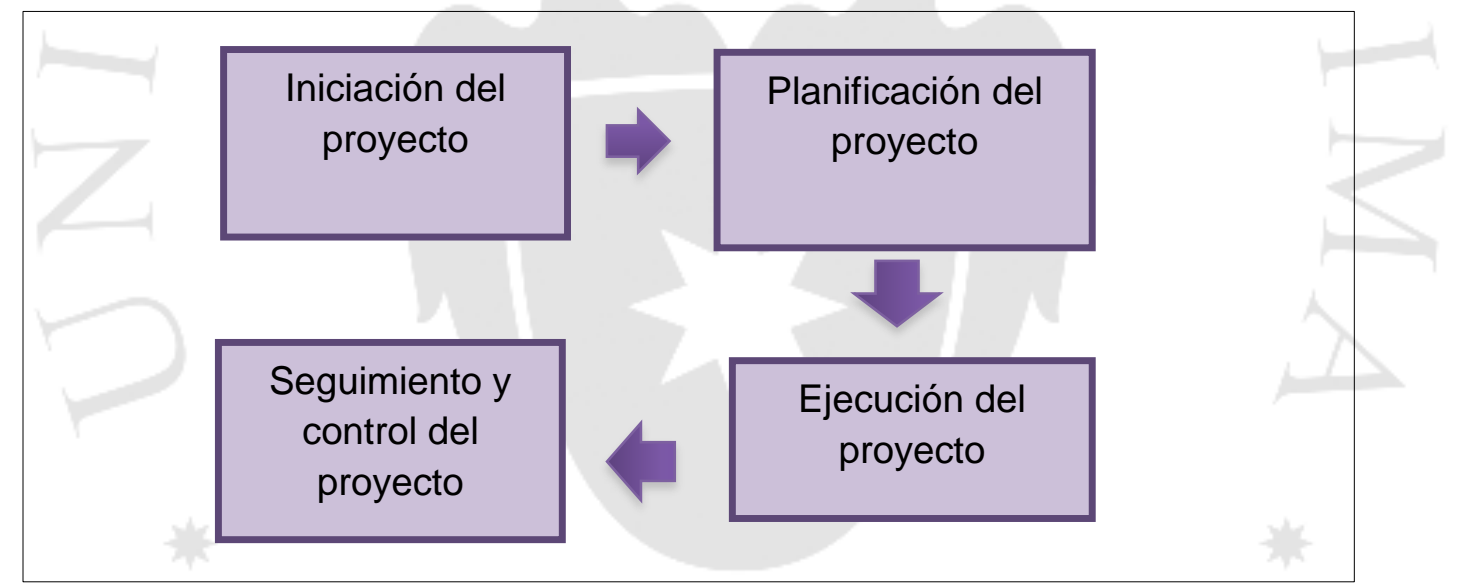

Fuente: Project Management Institute, (2008)

La iniciación del proyecto incluye generar compromiso de la gerencia y definir el objetivo del proyecto. La planificación del proyecto incluye definir las políticas (objetivo y alcance) para el uso que se le dará al MRP y definir los procedimientos necesarios para el correcto funcionamiento de la herramienta. Por último, la ejecución del proyecto incluye la definición de los recursos humanos y tecnológicos necesarios para implementar la solución. 


\section{- Iniciación del proyecto}

A continuación, se detallarán los pasos necesarios para dar inicio a la implementación de la nueva herramienta:

$\checkmark$ Compromiso de la gerencia: En esta etapa la gerencia brinda la autorización formal para comenzar con la implementación de este nuevo proyecto. La gerencia tiene un rol muy importante en la implementación de esta solución, principalmente porque son los responsables de decidir si se implementa o no y sobre todo deciden el nivel de inversión. Asimismo, son los encargados de designar al responsable del proyecto, así como trasmitirles la solución propuesta de implementación y generar en ellos un sentido de compromiso. Esta situación se tangibilizará en capacitaciones de planeamiento y control de la producción para los jefes de producción junto con sus analistas, pues el hecho de implementar un software no soluciona el problema, sino que va de la mano con la gestión humana.

Objetivos: El objetivo de la implementación de un MRP I es lograr contar con los insumos necesarios para el proceso productivo, en el momento deseado y en las cantidades requeridas, con el fin de evitar retrasos en la producción de mayonesa.

\section{- Planificación del proyecto}

En esta etapa, se detallarán las políticas y procedimientos necesarios para la implementación de la herramienta.

$\checkmark$ Definir y detallar las políticas, su objetivo y alcance para el funcionamiento del MRP I

Objetivo de las políticas

- El objetivo de definir claramente las políticas del uso del MRP I es guiar al personal responsable con el uso de la herramienta, y asegurarse del buen funcionamiento de la misma.

$>$ Alcance de las políticas: Las políticas a detallar son de uso y aplicación de las siguientes áreas:

- Gerencia de producción / planeamiento y control de la producción 
- Logística: compras y almacén

Políticas

- Sobre el MPS: el analista encargado de generar el MPS (programa maestro de producción) debe revisarlo semestral y semanalmente junto con el gerente de producción, y de presentarse algún cambio y/o variación en el documento, debe comunicarlo con la debida anticipación (2 semanas como mínimo) al analista de planeamiento responsable de manipular la herramienta MRP I.

- Sobre el MRP I (Plan de requerimiento de materiales): el analista de planeamiento debe revisar el MRP I semanalmente, y de presentarse algún cambio y/o variación en las órdenes de aprovisionamiento, debe informarlo con la debida anticipación (2 semanas como mínimo) al departamento de logística/compras.

- Sobre el listado de materiales (BOM): debe revisarse semestralmente por el jefe de producción.

- Sobre el estado de inventarios: el jefe de almacén debe mantener actualizado el nivel de inventarios de la empresa diariamente.

- Sobre el lead time: el analista de compras debe revisar el leadtime acordado con cada proveedor semestralmente.

- Sobre el control de la producción: se establecerán indicadores de cumplimiento / del programa de producción y se monitorearan semanalmente en los comités de producción. Asimismo, habrán bonos por buen desempeño.

\section{Procedimientos}

A continuación, se describe los inputs que necesita la herramienta para su funcionamiento, así como los outputs como se observa en la figura 5.2. Los principales inputs de un MRP I son los siguientes: 
MPS (Programa maestro de producción): es un plan detallado que establece qué y cuántos productos finales se tienen que producir y en qué plazos deben tenerse terminados. En la tabla 5.1 se muestra el MPS de cajas por 252 sachets de mayonesa de 10 gr para los próximos 12 meses. Cabe recalcar que el presente pronóstico se calculó en base a una regresión potencial que se muestra en la tabla 5.8 en base a las ventas históricas del 2015.

\section{Tabla 5.1}

Pronóstico de ventas en cajas x 252 sachets de 10 gr

\begin{tabular}{|c|c|c|c|c|c|c|c|c|c|c|c|}
\hline $\mathbf{1}$ & $\mathbf{2}$ & $\mathbf{3}$ & $\mathbf{4}$ & $\mathbf{5}$ & $\mathbf{6}$ & $\mathbf{7}$ & $\mathbf{8}$ & $\mathbf{9}$ & $\mathbf{1 0}$ & $\mathbf{1 1}$ & $\mathbf{1 2}$ \\
\hline 3404 & 3484 & 3561 & 3634 & 3705 & 3772 & 3837 & 3900 & 3960 & 4019 & 4075 & 4131 \\
\hline
\end{tabular}

Nota: Demanda calculada en base a una regresión potencial

Elaboración propia

Lista de materiales (BOM): es un listado que detalla la estructura del producto final mostrando los insumos que lo integran, cantidades y secuencia de fabricación. Éste puede contener varios niveles. En la tabla 5.2 se muestra el listado de materiales para obtener $100 \mathrm{Kg}$ de semielaborado de mayonesa. Asimismo en la tabla 5.3 se muestra el listado de materiales para obtener el producto terminado que es 1 caja de 252 sachets de mayonesa se 10 gr. 
Tabla 5.2

Lista de materiales (BOM) para semielaborado de $100 \mathrm{Kg}$ de Mayonesa

\begin{tabular}{|c|c|c|}
\hline Materia Prima & Cantidad x 100 kg & $\%$ Peso \\
\hline Ac. Acetico $(\mathrm{kg})$ & 0.089 & $0.09 \%$ \\
\hline Ac. Fosforico & 0.190 & $0.19 \%$ \\
\hline Aceite $(\mathrm{kg})$ & 59.173 & $59.17 \%$ \\
\hline Agua $(\mathrm{kg})$ & 33.327 & $33.33 \%$ \\
\hline Almidón Mirathik (kg) & 2.158 & $2.16 \%$ \\
\hline Benzoato $(\mathrm{kg})$ & 0.050 & $0.05 \%$ \\
\hline BHA & 0.005 & $0.01 \%$ \\
\hline Color Biocon atos $6(\mathrm{~kg})$ & 0.079 & $0.08 \%$ \\
\hline EDTA $(\mathrm{kg})$ & 0.005 & $0.01 \%$ \\
\hline Glutamato & 0.003 & $0.00 \%$ \\
\hline Goma Xantan $(\mathrm{kg})$ & 0.186 & $0.19 \%$ \\
\hline Sabor limon especiado & 0.100 & $0.10 \%$ \\
\hline Sabor Queso Cheddar & 0.050 & $0.05 \%$ \\
\hline Sal $(\mathrm{kg})$ & 1.319 & $1.32 \%$ \\
\hline Sorbato de Potasio $(\mathrm{kg})$ & 0.050 & $0.05 \%$ \\
\hline Yema de huevo $(\mathrm{kg})$ & 3.216 & $3.22 \%$ \\
\hline & 100.000 & $100 \%$ \\
\hline
\end{tabular}

Fuente: ALIEX, (2016)

Tabla 5.3

Listado de materiales (BOM) del Producto terminado (Cajas de 252 sachets)

\begin{tabular}{|l|c|}
\hline \multicolumn{1}{|c|}{ Materia Prima } & Kg y/o Unidad \\
\hline Semielaborado $(\mathrm{Kg})$ & 2.52 \\
\hline Bolsa $(\mathrm{U})$ & 252 \\
\hline Caja $(\mathrm{U})$ & 1 \\
\hline Etiqueta $(\mathrm{U})$ & 1 \\
\hline
\end{tabular}

Fuente: ALIEX, (2016)

Estado del inventario: permite conocer las cantidades disponibles de cada producto $\mathrm{y}$ por diferencia las cantidades que deben comprarse $\mathrm{o}$ aprovisionarse.

Lead Time: Tiempo de reposición de materiales o insumos.

Tamaño de lote de los proveedores: Mínima cantidad que se puede adquirir de un proveedor. 
El output de la herramienta es la plantilla MRP I (plan de requerimiento de materiales) el cual mantiene a la organización informada sobre los niveles de inventario y las necesidades de reabastecimiento de todos los materiales con el detalle de cantidad de los mismos y fechas en que se requieren. El plan está conformado por 6 módulos:

Requerimientos brutos del producto final y de los materiales que conforman el producto final. Para el primero es la demanda del producto proveniente el MPS (productos de demanda independiente) y el segundo resulta de la explosión mediante la lista de materiales (productos de demanda dependiente)

Recepciones programadas: Cantidades a recibir previstas por órdenes (de aprovisionamiento o fabricación) ya lanzadas en los periodos anteriores y que se esperan que lleguen y estén disponibles. Aparece en el mismo intervalo que las necesidades netas, pero su tamaño estará modificado según la lotificación establecida.

Inventario disponible: Es la cantidad de inventario disponible al final de cada periodo. Solo deberá reflejarse lo disponible restando, en su caso, lo reservado, o bien alternativamente habrá que añadir filas al estadillo para incluir las reservas y obtener por diferencia lo disponible.

Requerimiento neto: Es la cantidad de producto requerida sin considerar el nivel de defectuosos de los proveedores o los requisitos de compra o producción por lotes. Asimismo, debe considerar los niveles de stock de seguridad requeridos por la organización, si fuera el caso.

Plan de pedidos: Es la cantidad del producto que debe ser solicitado al proveedor (en caso de ser comprado) o a producción (en caso de ser fabricado). Dicho de otra manera, es el requerimiento neto ajustado a las variables \% de defectuosos del proveedor o del proceso y el modelo de compra por lotes o LxL (unitaria) 
Emisión de órdenes planificadas: Pedidos situados en el intervalo de tiempo en que deben lanzarse o emitirse para que los materiales estén disponibles cuando los necesite su superior. Generalmente se calcula considerando el Lead Time de los materiales

A continuación, en la tabla 5.4 se muestra una plantilla de cómo quedará la planificación de materiales. Cabe recalcar que cada material/producto contará con su propia plantilla.

\section{Tabla 5.4}

Plantilla de un MRP I (Plan de requerimiento de materiales)

\begin{tabular}{|l|c|c|c|c|}
\cline { 2 - 5 } \multicolumn{1}{c|}{} & \multicolumn{5}{c|}{ Periodo mensual } \\
\hline Material/Producto XXX & $\mathbf{1}$ & $\mathbf{2}$ & $\mathbf{3}$ & $\mathbf{4}$ \\
\hline Requerimientos Brutos & & & & \\
\hline Recepciones programadas & & & & \\
\hline Inventario disponible & & & & \\
\hline Requerimientos Netos & & & & \\
\hline Plan de pedidos & & & & \\
\hline Emisión de órdenes planificadas & & & & \\
\hline
\end{tabular}

Fuente: Company, Ramón., Fonollosa, J. (1999) 
Figura 5.2

Flujo de Inputs y Outputs de un MRP I (Planeamiento de requerimiento de materiales)

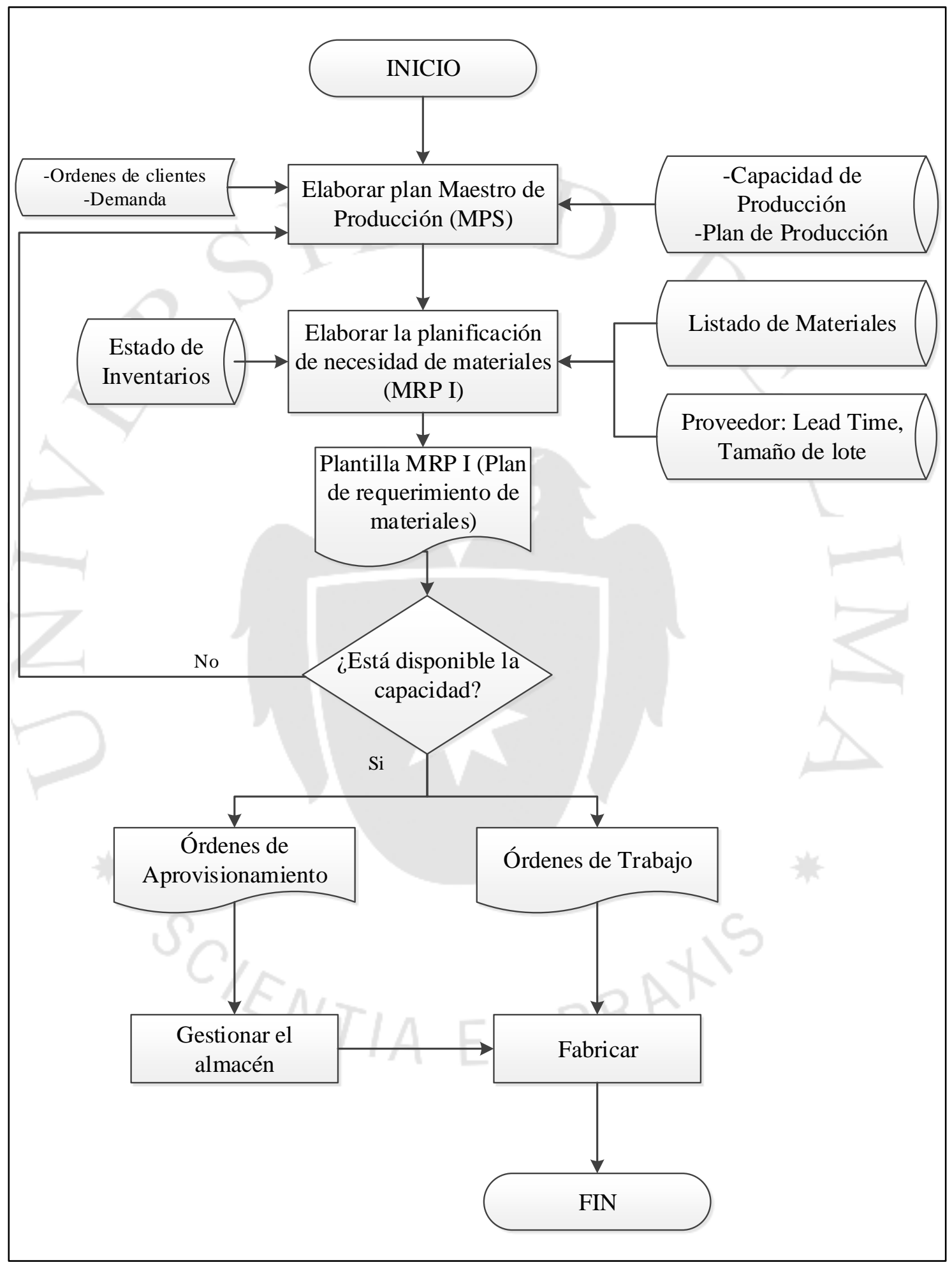

Elaboración propia 
- Ejecución del proyecto

A continuación se detallarán los recursos humanos y tecnológicos necesarios para implementar la herramienta.

$\checkmark$ Definir y detallar los recursos necesarios

Recurso humano: Analista que trabajará en el área de planeamiento y control de la producción y será el responsable de manipular el MRP. Para este recurso se ha definido el siguiente perfil:

- Bachiller en Ingeniería Industrial, perteneciente al tercio superior. Debe contar con conocimientos de inglés y excel avanzado.

- Debe contar con experiencia en empresas de consumo masivo, de preferencia en el área productiva

- Debe presentar habilidades interpersonales y capacidad para trabajar bajo presión.

- Disponibilidad para trabajar en Lurín de 9 a 6 pm

En la figura 5.3 se muestra el diagrama de flujo para disponer de los recursos humanos que se necesitan. 


\section{Figura 5.3}

Diagrama de Flujo para la implementación de un MRP I (Planeamiento de requerimiento de materiales) - Contratación del analista PCP

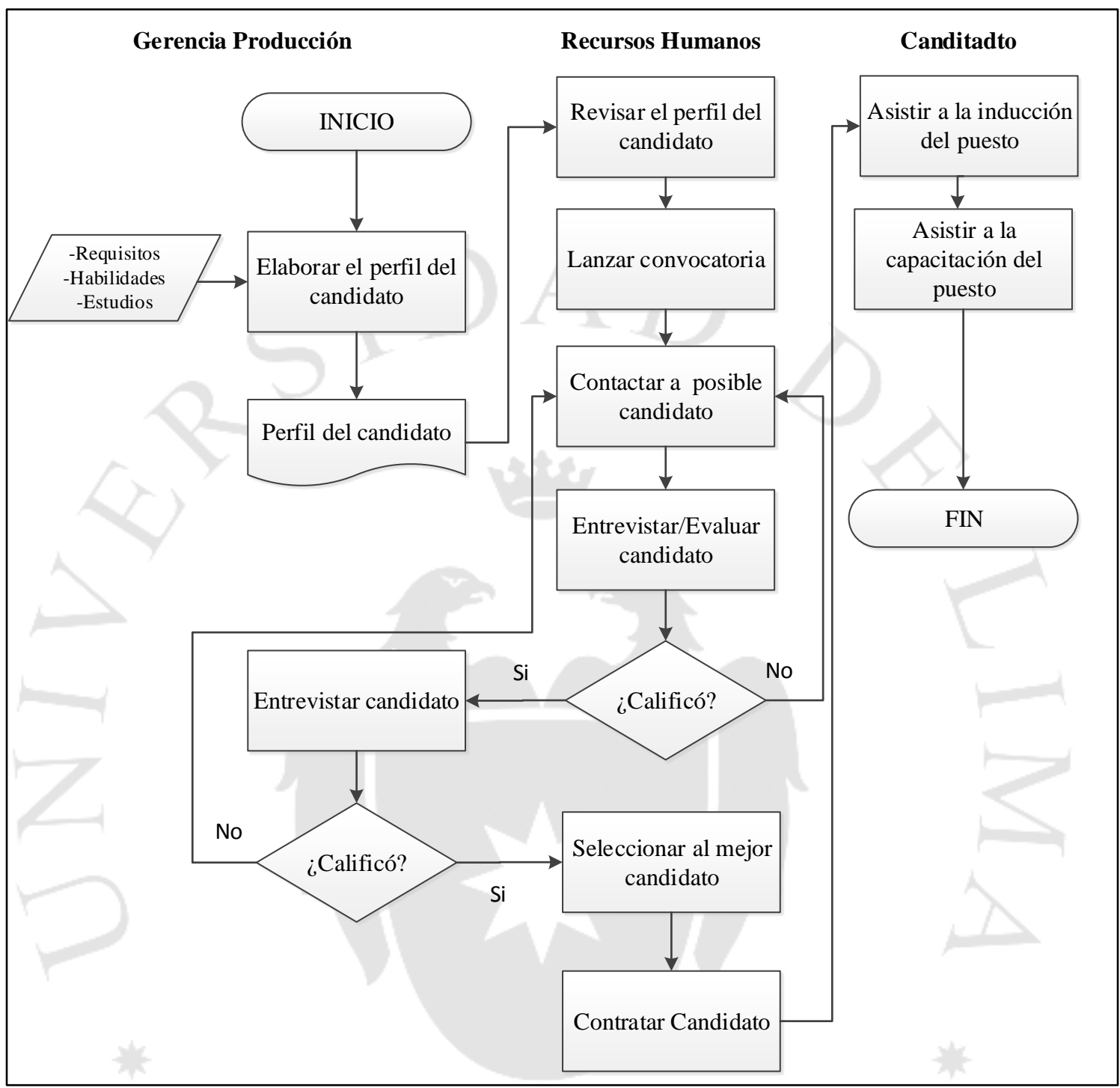

Elaboración propia 
Recurso tecnológico: Es el software que se utilizará para la implementación del MRP I. Se ha decidido que se buscará una solución en el mercado de acuerdo a las necesidades de la empresa. Para ello se deberán evaluar herramientas y proveedores según el diagrama de flujo que se muestra en la figura 5.5.

A continuación, en la figura 5.4 se muestra el esquema tecnológico actual de ALIEX. Se trata del software "Consistat", el cual es proporcionado por el outsourcing contable de ALIEX. Este le proporciona un data ware house (DWH) el cual está almacenado en los servidores de la empresa contable outsourcing y tiene conexión remota. Dicho software no presenta funcionalidades para gestionar un MRP I, pues actualmente el proceso se realiza de manera manual mediante hojas de excel.

Figura 5.4

Esquema software de ALIEX actual

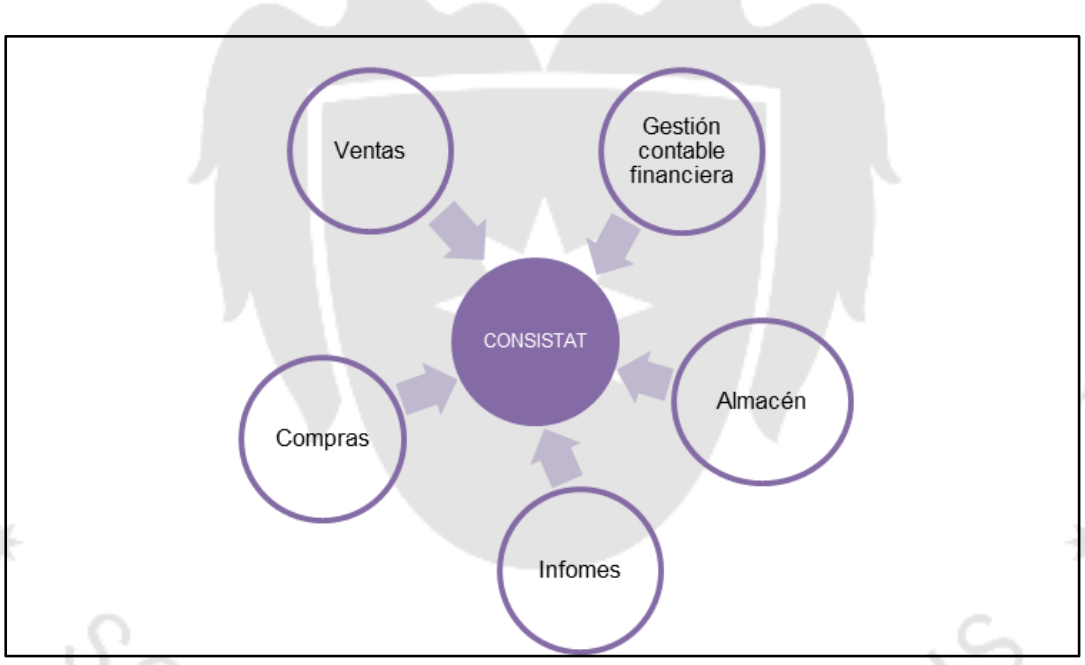

Fuente: ALIEX, (2016)

Dado que no existe un programa de planeamiento de la producción en ALIEX, en la figura 5.5 se muestra el flujograma para adquirir una herramienta que cuente con dicha funcionalidad y que mejor se adapte a las necesidades de ALIEX. 
Figura 5.5

Diagrama de Flujo para la implementación de un software MRP I (Planeamiento de requerimiento de materiales)

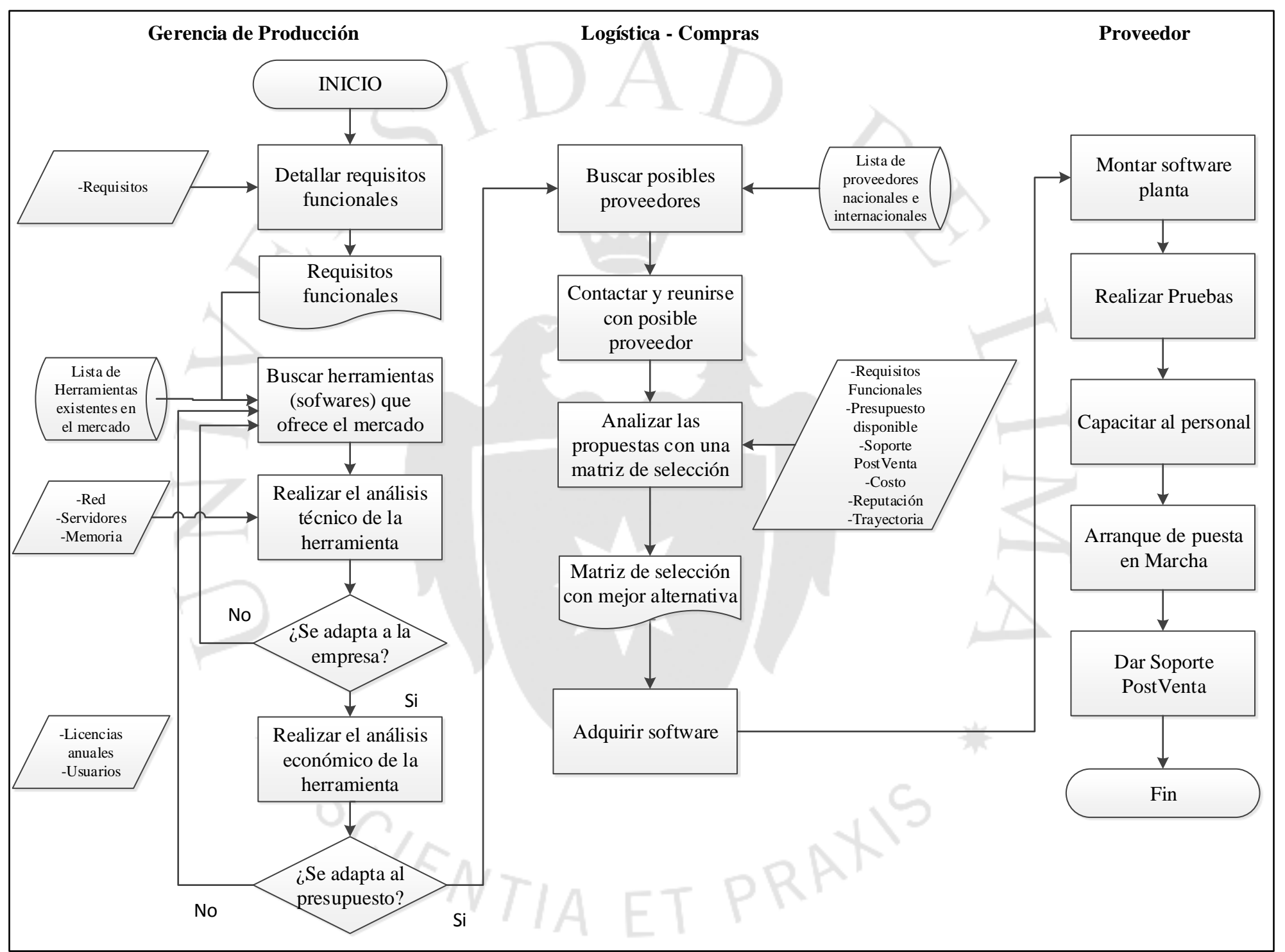

Elaboración propia 
Después de haber buscado softwares que cumplan con los requisitos funcionales y con los requisitos técnicos se identificaron 2 posibles alternativas: Capataz Flex y SAP.

A continuación se muestran los factores que serán tomados en cuenta para elegir la mejor alternativa y mediante un ranking de factores que se muestra en la tabla 5.5 se le dará un peso a cada uno en base al criterio del gerente general de la empresa:

- Costo

- Flexibilidad de la herramienta para adaptarse a las necesidades de ALIEX

- Solución de las necesidades de ALIEX

- Reputación de la herramienta

Tabla 5.5

Matriz de enfrentamiento

\begin{tabular}{|c|c|c|c|c|c|c|}
\hline Factor & Costo & Flexibilidad & Solución & Reputación & Conteo & Ponderación \\
\hline Costo & & 0 & 0 & 1 & 1 & $17 \%$ \\
\hline Flexibilidad & 1 & & 0 & 1 & 2 & $33 \%$ \\
\hline Solución & 1 & 1 & & 1 & 3 & $50 \%$ \\
\hline Reputación & 0 & 0 & 0 & & 0 & $0 \%$ \\
\hline \multicolumn{7}{l}{}
\end{tabular}

Elaboración propia

Luego de haber establecido un peso a cada factor, se decidirá cuál es la mejor alternativa en base a una matriz de selección que se muestra en la tabla 5.6, en donde cada factor se calificará con una escala del 1 al 3, siendo 1 malo, 2 bueno y 3 excelente.

Tabla 5.6

Matriz de selección para la Valoración de alternativas

\begin{tabular}{|c|c|c|c|c|c|}
\cline { 3 - 6 } \multicolumn{2}{c|}{} & \multicolumn{2}{c|}{ SAP } & \multicolumn{2}{c|}{ Capataz Flex } \\
\hline Factor & Peso & Valoración & Puntaje & Valoración & Puntaje \\
\hline Costo & $17 \%$ & 1 & 0.2 & 2 & 0.3 \\
\hline Flexibilidad & $33 \%$ & 1 & 0.3 & 3 & 1 \\
\hline Solución & $50 \%$ & 3 & 1.5 & 3 & 1.5 \\
\cline { 6 - 6 } & & 2 & \multicolumn{2}{c}{} & 2.8 \\
\hline
\end{tabular}

Elaboración propia 
Se concluye que la mejor alternativa es adquirir la herramienta Capatax Flex pues obtuvo el puntaje más alto (2.8).

Se observa el software argentino Capataz flex en la figura 5.6. Dicho Software cuenta con distintos módulos y consiste en una edición diseñada para empresas que necesitan una solución reducida a la medida de sus necesidades. Es ideal para empresas que requieren funcionalidades bien definidas, sin tener que invertir en un Capataz Empresarial. La ventaja de Capataz flex es que se puede ir implementando gradualmente los distintos módulos que ofrece. Este producto es muy "flexible" (de ahí su denominación), ya que el usuario arma su Capataz según las necesidades de su empresa. Dicho software se adapta a las necesidades de ALIEX pues la empresa ya cuenta con un software ERP descrito anteriormente, y lo que se necesita principalmente es repotenciar la gestión de planeamiento y control de la producción. A continuación se muestran los distintos módulos con los que cuenta esta herramienta.

Figura 5.6

Esquema software propuesto

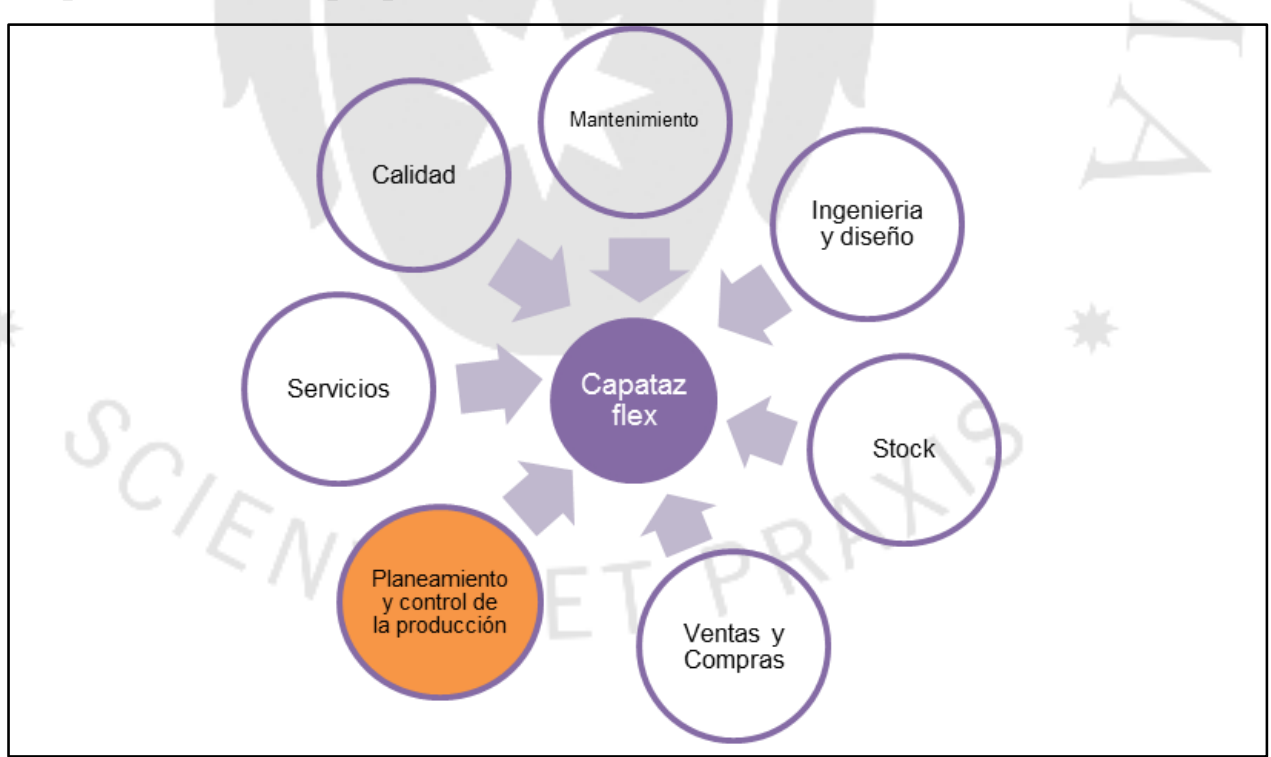

Fuente: Capataz Software, (2016)

Para el caso de ALIEX, cuyo objetivo es repotenciar la gestión de planeamiento y control de la producción, se implementarán los siguientes módulos de Capataz Flex: 
- Planeamiento y control de la producción:

- Generará informes de programa de fabricación, programa de compras. Nos indicará principalmente qué falta fabricar internamente, y qué falta comprar y en cuánta cantidad como se muestra en la figura 5.7

- Generará informes de presupuestos de fabricación y presupuesto de compras y posteriormente las órdenes de compra.

Figura 5.7

Outputs del módulo PCP (Planeamiento Y control de la producción) de Capataz Flex

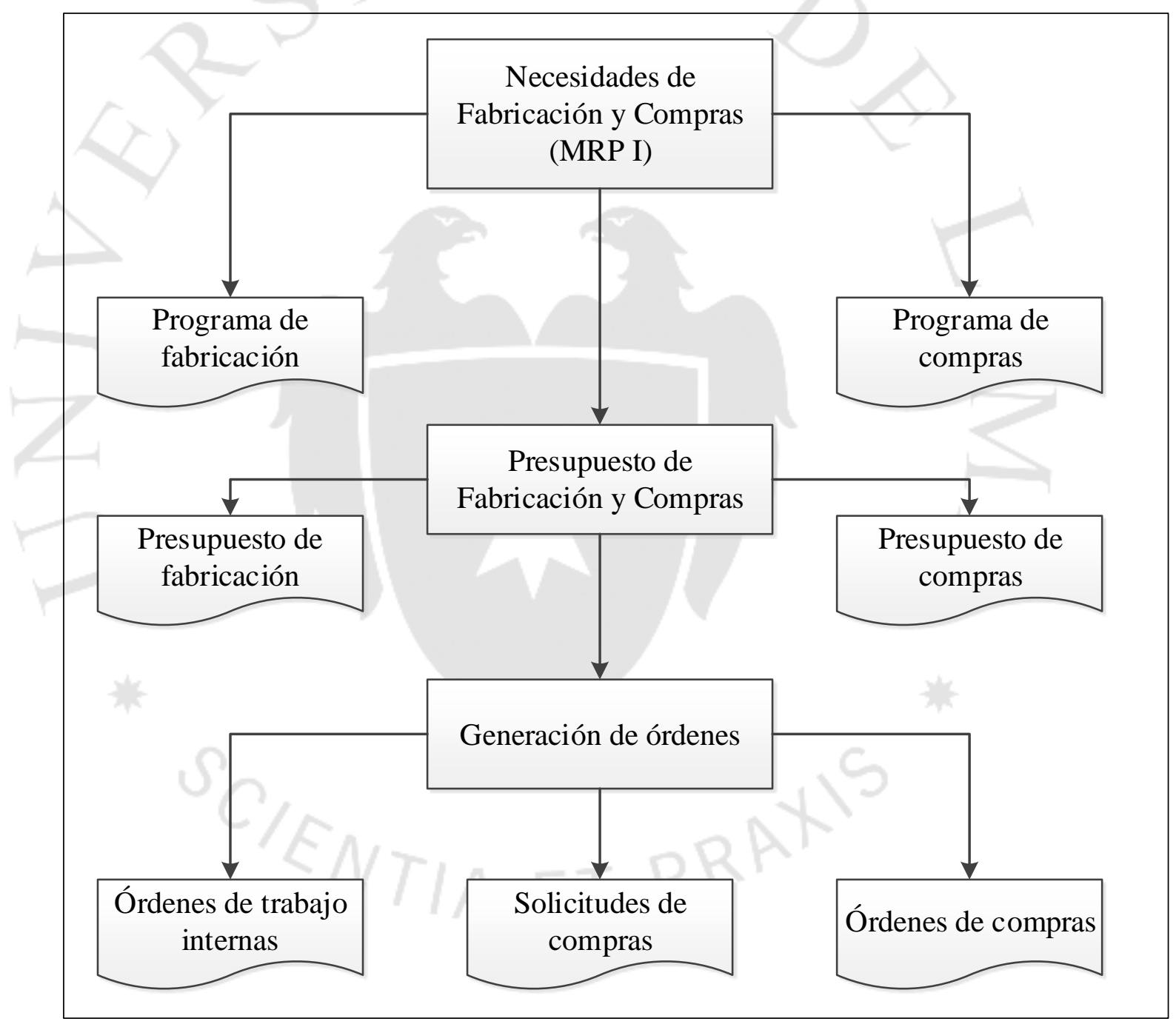

Fuente: Capataz Software, (2016)

- Ingeniería y diseño:

- Registra la configuración de los productos, es decir la lista de materiales/insumos jerárquicos $(\mathrm{BOM})$ 
- Contiene hojas de ruta donde se detallan los datos de las operaciones (tiempos, costos, máquinas etc)

- Stock:

- Monitorea/trazabilidad el flujo de materiales dentro y fuera de la empresa.

○ Numera automáticamente las series y lotes de fabricación/adquisición

- Agiliza la recepción a proveedores

- Controla inventarios mínimos y máximos calculándose automáticamente

○ Genera lotes económicos de compra y fabricación

\section{- Compras}

- Gestiona las órdenes de compra

- Emite informes de órdenes de compra pendientes de recepción para alimentar el stock proyectado

El input principal del MRP I es el programa maestro de producción (MPS), el cual se puede y se cargará en forma manual mediante la importación de datos a través de un archivo Excel, documento donde se almacenan los pronósticos de ventas.

Para la implementación de la herramienta descrita se requiere adquirir un hardware (una PC personal) que será usada por el ingeniero responsable de utilizar el software MRP I, es decir el que estará a cargo del planeamiento y control de la producción (PCP).

Solución 3: Implementación de un programa de mantenimiento preventivo

\section{- Iniciación del proyecto}

A continuación, se detallarán los pasos necesarios para dar inicio a la implementación del programa de mantenimiento preventivo

$\checkmark$ Compromiso de la gerencia: En esta etapa la gerencia brinda la autorización formal para comenzar con la implementación de este nuevo proyecto. Como ya se mencionó, la gerencia tiene un rol muy importante en la implementación de esta solución, principalmente porque son los 
responsables de decidir si se implementa o no y sobre todo deciden el nivel de inversión.

$\checkmark$ Objetivos: El objetivo de la implementación de un programa de mantenimiento preventivo es minimizar las paralizaciones imprevistas y largas de la maquinaria con el fin de aumentar la disponibilidad de activos y lograr cumplir con el programa de producción de mayonesa que la planta establece.

\section{- Planificación del proyecto y ejecución del proyecto}

En esta etapa, se detallarán las políticas y procedimientos necesarios para la implementación del programa

$\checkmark$ Definir y detallar las políticas, objetivo y alcance para el funcionamiento del programa

Objetivo de las políticas:

- El objetivo de definir claramente las políticas del programa es guiar al personal responsable, y asegurarse del buen funcionamiento del mismo

Alcance de las políticas: Las políticas a detallar son de uso y aplicación de las siguientes áreas:

- Gerencia de producción / mantenimiento

Políticas

- Se implementará un mantenimiento planificado (preventivo), el cual será ejecutado con recursos propios de la empresa (personal y herramientas).

- Las intervenciones del programa de mantenimiento se realizarán con una frecuencia "F" la cual será establecida en base a la experiencia del jefe de mantenimiento de la planta.

- El programa de mantenimiento debe ser flexible, es decir debe ser revisado semestralmente pues siempre existe la necesidad de realizar cambios. 
- Para llevar un adecuado control del programa y asegurase del éxito del mismo, se deberá contar con órdenes de trabajo con 15 días de anticipación. De esta manera, se harán los pedidos de materiales y/o herramientas que se necesitarán.

- El jefe de mantenimiento asignará las labores de mantenimiento al personal de acuerdo a la necesidad que se presente.

- Las labores de mantenimiento preventivo se realizarán los días en que la planta no produce, es decir los días sábados.

- La gerencia debe asegurarse que el personal de mantenimiento se encuentre capacitado para dichas labores.

\section{Procedimientos}

A continuación, se describen los procedimientos necesarios para implementar el programa. En la figura 5.8 se muestran los 2 grandes procesos para la implementación del mismo. Cabe recalcar que las actividades del bloque A se realizarán solo 1 vez sin embargo las actividades del bloque B se repetirán cada vez que se ejecute el mantenimiento preventivo a las máquinas.

\section{Figura 5.8}

Flujo para la implementación del programa de mantenimiento preventivo

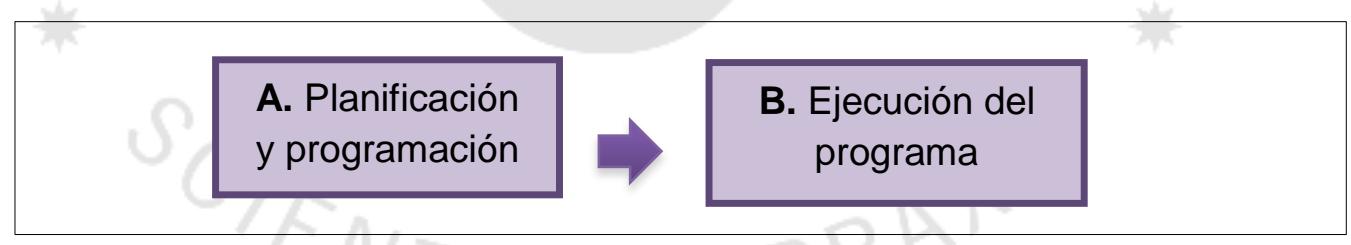

Elaboración propia

En la figura 5.9 se detalla el diagrama de flujo para el bloque A, el cual involucra las siguientes actividades:

Se debe listar la relación de máquinas del área de mayonesa. En la tabla 5.7 se indica el código y descripción de cada máquina. 
Tabla 5.7

Relación de máquinas del área de mavonesa

\begin{tabular}{|c|c|c|}
\hline Máquina & Código & Descripción \\
\hline \multirow{3}{*}{$\begin{array}{l}\text { Licuadora industrial } \\
\text { de mayonesa }\end{array}$} & \multirow{3}{*}{0000120} & $\begin{array}{l}\text { Licuadora de acero inoxidable, } \\
\text { tratamiento anticorrisivo para } \\
\text { aumentar resistencia }\end{array}$ \\
\hline & & Cuchillas de acero inoxidable \\
\hline & & Vaso con diseño cónico \\
\hline \multirow{3}{*}{$\begin{array}{c}\text { Envasadora } \\
\text { Sacheteadora }\end{array}$} & \multirow{3}{*}{0000061} & Acero inoxidable \\
\hline & & 10 boquillas de llenado \\
\hline & & $\begin{array}{l}\text { Envasado de sachets de } 10 \mathrm{gr}, 50 \mathrm{gr} \\
\text { y } 100 \mathrm{gr}\end{array}$ \\
\hline
\end{tabular}

Elaboración propia

Se debe elaborar un plan de trabajo de mantenimiento para cada máquina, documento que contiene la relación de actividades preventivas que deben realizarse junto con los recursos necesarios, tiempos y costos en caso existan. El plan cuenta con un encabezado donde se incorporan los datos generales del plan y con un pie de página donde se muestra información de control. Los inputs principales para elaborar el plan son los manuales de las máquinas donde se detallan las actividades preventivas recomendadas y los registros históricos con los que el departamento de mantenimiento cuenta donde figuran las principales fallas que ha presentado la máquina. En el anexo 3 y 4 se muestran los planes de mantenimiento para ambas máquinas.

Se debe elaborar un programa de mantenimiento preventivo que contenga un resumen de toda la planificación de la aplicación de los distintos planes de trabajo de mantenimiento a cada uno de los equipos listados. En el anexo 5 se muestra el programa. Cabe recalcar que la frecuencia para la ejecución de los planes de trabajo de mantenimiento se fijó en base a la experiencia del departamento de mantenimiento de la planta. 
Figura 5.9

Diagrama de flujo del bloque A

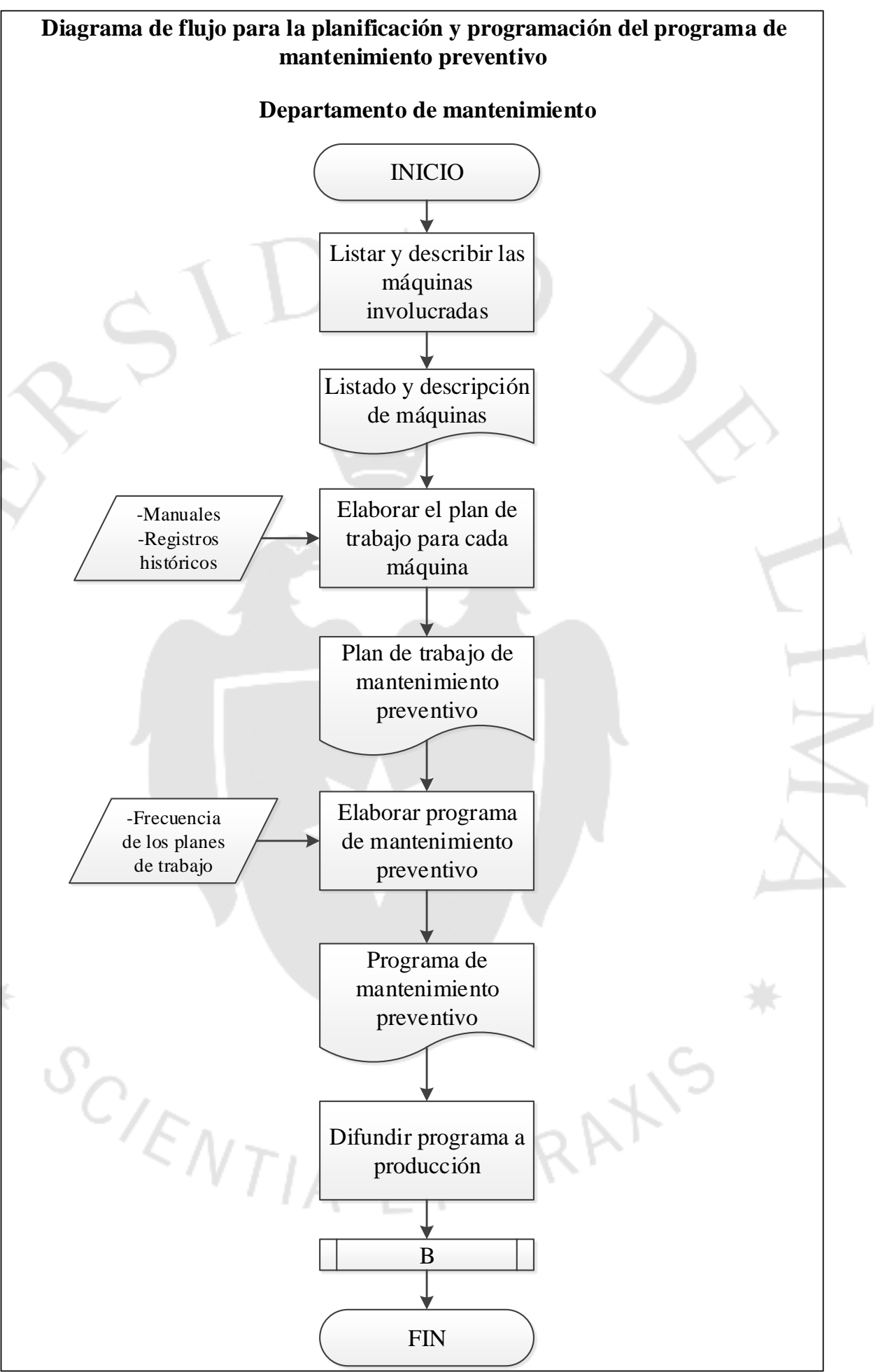

Elaboración propia 
En la figura 5.10 se detalla el diagrama de flujo para el proceso B, el cual involucra las siguientes actividades:

Cuando llegue el momento de ejecutar un plan de trabajo, se debe elaborar y lanzar una única orden de trabajo, la detalla los recursos necesarios para ejecutar el plan de mantenimiento. En la tabla 5.8 se muestra la plantilla de una orden de trabajo.

\section{Tabla 5.8}

Plantilla de una orden de trabajo de mantenimiento

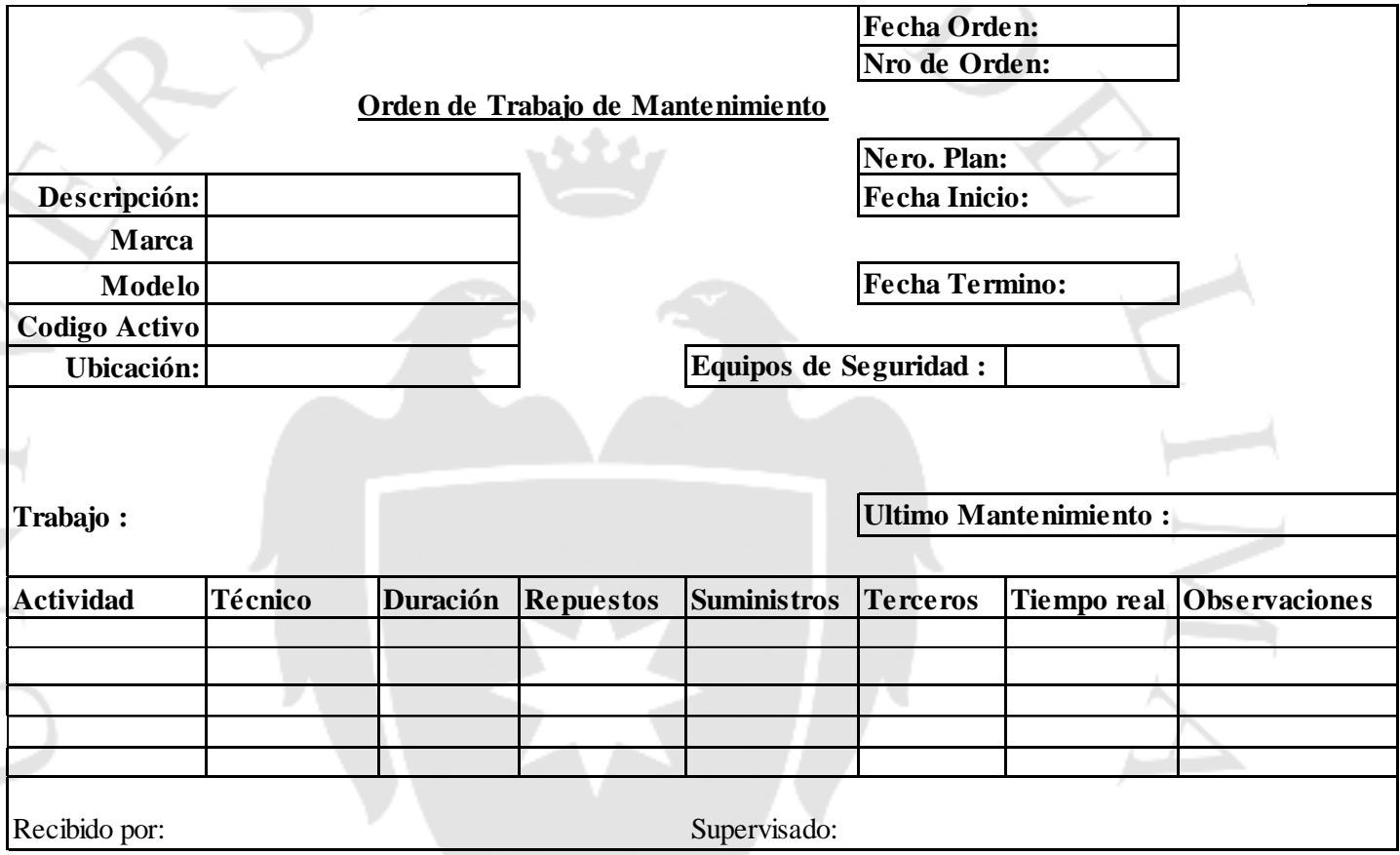

Elaboración Propia

El jefe de mantenimiento debe controlar la ejecución del programa, haciéndole seguimiento a los avances y realizando reajustes/actualizaciones del programa en caso sea necesario. Asimismo, debe asegurarse del correcto funcionamiento del programa, es decir contrastar realidad vs. lo planificado y tomar medidas correctivas para la planificación.

Por último del jefe de producción debe firmar la orden de trabajo en señal de que tiene conocimiento de la ejecución de las labores de mantenimiento de las máquinas. 
Figura 5.10

Diagrama de flujo del bloque B

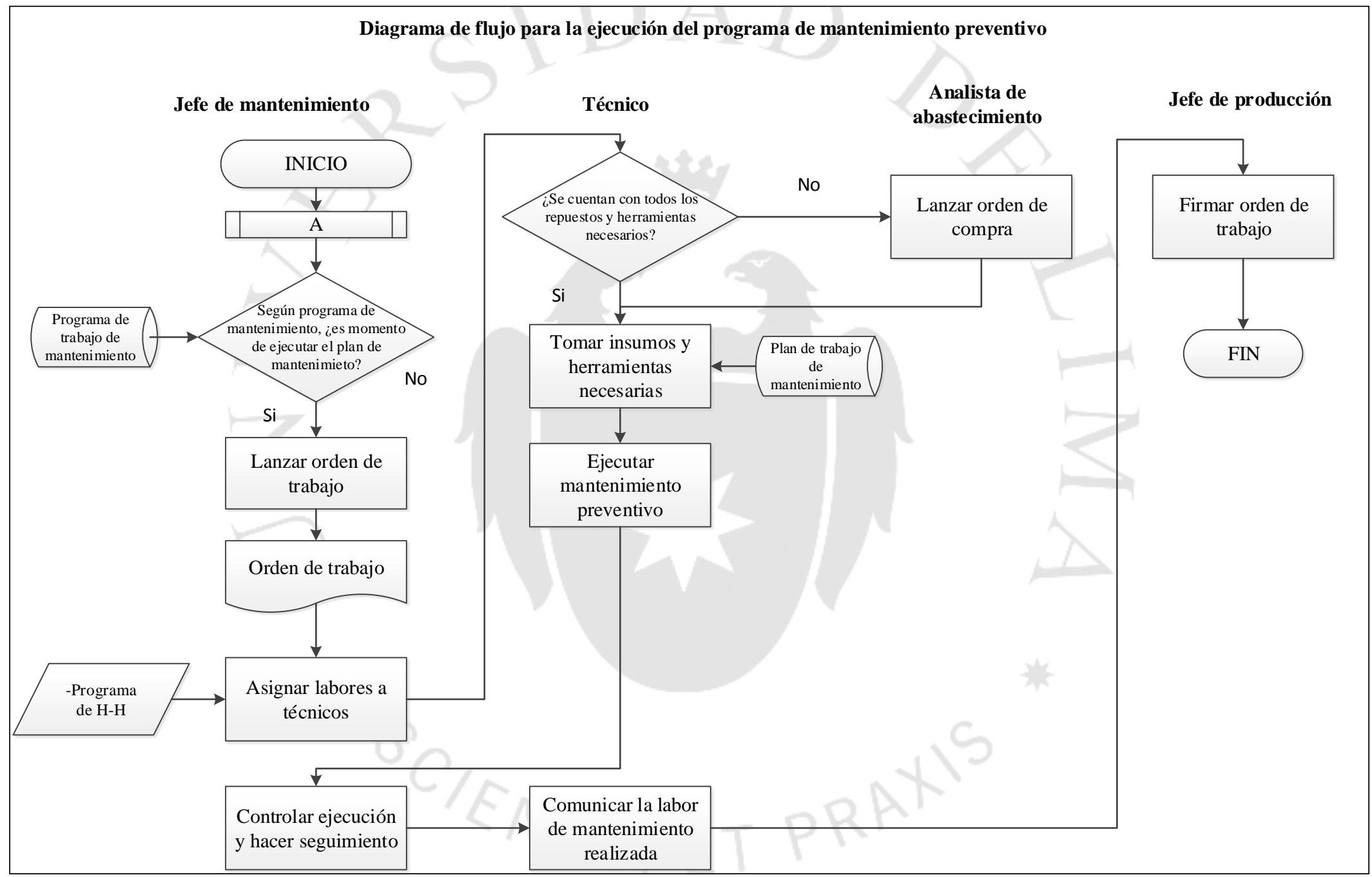

Elaboración propia 


\subsection{Planificación de la implementación de la solución}

\subsubsection{Determinación de objetivos y metas}

Después de implementar las mejoras desarrolladas, se espera que el \% de utilización de la licuadora sea de $100 \%$. Cabe recalcar que en dicho objetivo ya se descontaron las horas de limpieza y almuerzo de los operarios. Por otro lado también se cumplirá con el $\%$ de utilización deseado para la máquina envasadora de 10 gr.

- Escenario actual

Actualmente se tiene una utilización promedio del $88 \%$, como se observa en la figura 5.11. Es por ello que no se logra cumplir con el programa de producción lo cual provoca que ALIEX no cumpla con la demanda del mercado.

\section{Figura 5.11}

Evolutivo del indicador de utilización de licuadora en porcentaje (HNP/NBP) Escenario actual

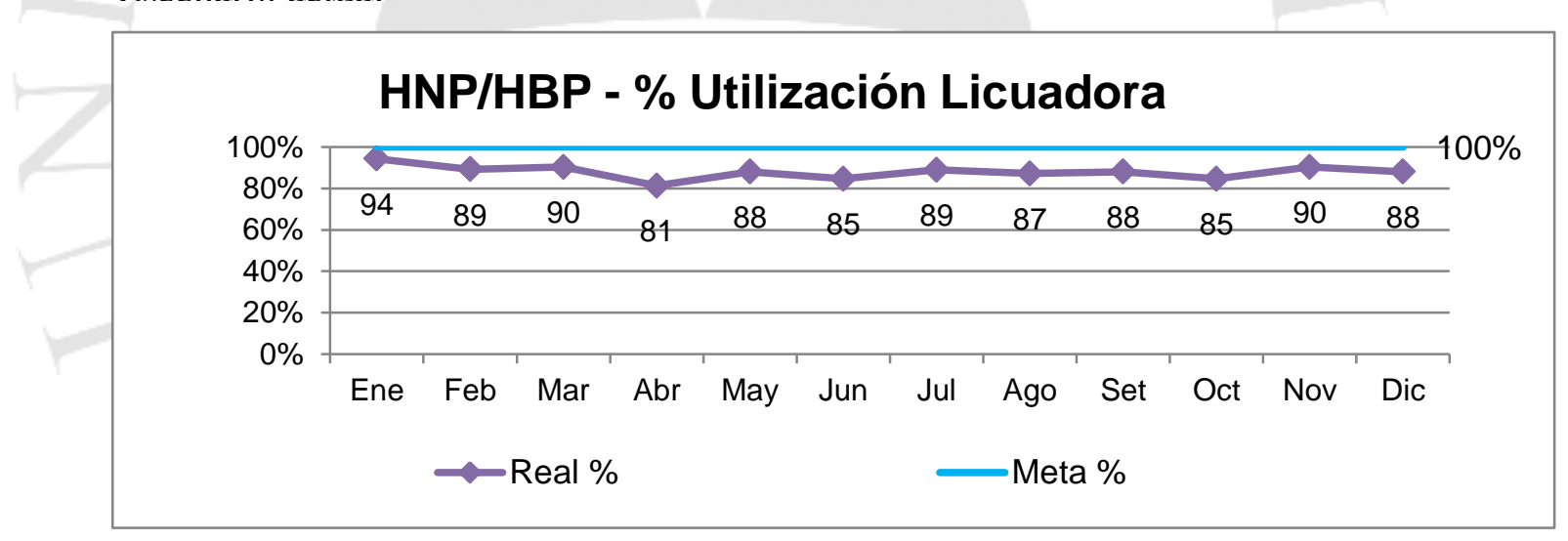

Elaboración propia

- Escenario meta

Con el fin de cumplir el programa de producción, se aspira lograr una utilización de la licuadora del $100 \%$ como se observa en la figura 5.12. De esta manera contará con el producto suficiente para cumplir con la demanda del mercado. 
Figura 5.12

Pronóstico del indicador utilización de licuadora en porcentaje (HNP/NBP) Escenario meta

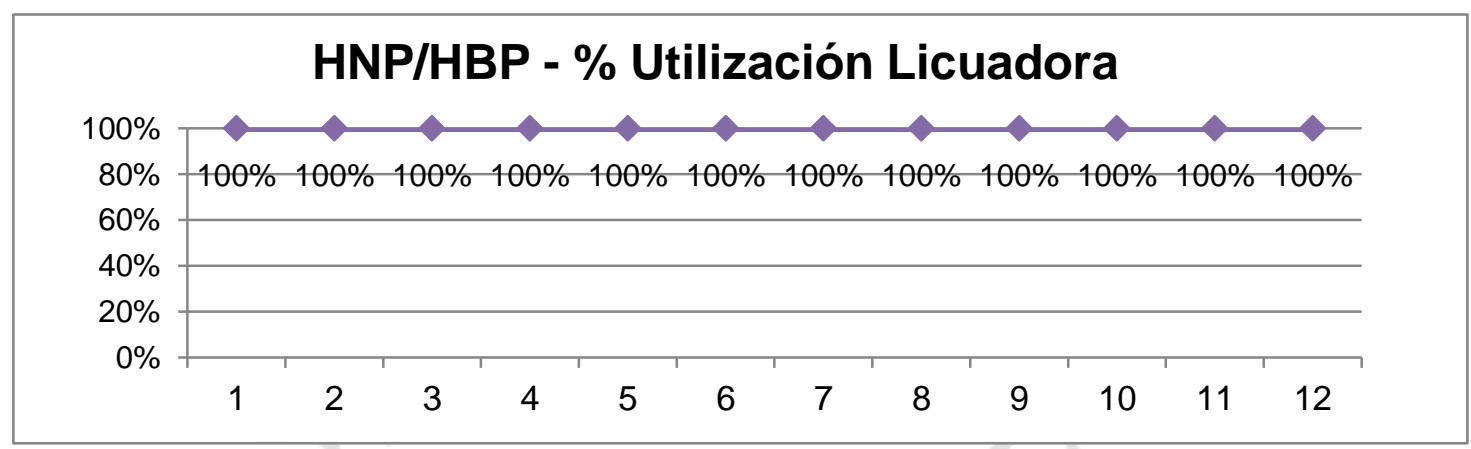

Elaboración propia

Debido a que en el 2015 hubo un crecimiento del 57\% de las ventas en el formato de 10 gr de mayonesa como se muestra en la tabla 5.9, se espera que para el 2016 las ventas presenten el mismo comportamiento.

Tabla 5.9

Histórico de Venta en soles de Mayonesa

\begin{tabular}{|l|c|c|}
\cline { 2 - 3 } \multicolumn{1}{c|}{} & $\begin{array}{c}\text { Venta Mayonesa } \\
\mathbf{1 0} \text { gr }\end{array}$ & $\begin{array}{c}\text { \% } \\
\text { Crecimiento }\end{array}$ \\
\hline 2011 & S/. 299,874 & \\
\hline 2012 & S/. 429,978 & $43 \%$ \\
\hline 2013 & S/. 499,170 & $16 \%$ \\
\hline 2014 & S/. 565,856 & $13 \%$ \\
\hline 2015 & S/. 887,236 & $57 \%$ \\
\hline
\end{tabular}

Elaboración propia

Tabla 5.10

Venta en Cajas por 252 sachets de 10gr de mayonesa del 2015

\begin{tabular}{|c|c|c|c|c|c|c|c|c|c|c|c|c|}
\cline { 2 - 10 } \multicolumn{1}{c|}{} & Ene & Feb & Mar & Abr & May & Jun & Jul & Ago & Set & Oct & Nov & Dic \\
\hline $\begin{array}{c}\text { Venta 2015 } \\
\text { en cajas }\end{array}$ & 1354 & 2214 & 2369 & 2392 & 2481 & 2525 & 2586 & 2610 & 2642 & 3357 & 3111 & 4046 \\
\hline
\end{tabular}

Elaboración propia

Al analizar la tabla 5.10, se comprobó que el comportamiento de ventas del 2015 se ajusta mejor a una regresión potencial debido a que muestra un mayor coeficiente de determinación, como se muestra en la tabla 5.11, lo que 
quiere decir que existe mayor relación entre las variables dependientes e independientes que en este caso son la cantidad de venta y los meses.

Tabla 5.11

Tipo de regresiones

\begin{tabular}{|l|c|}
\hline \multicolumn{1}{|c|}{$\begin{array}{c}\text { Tipo de } \\
\text { Regresión }\end{array}$} & $\mathbf{R}^{\mathbf{2}}$ \\
\hline Potencial & 0.82 \\
\hline Polinómica & 0.80 \\
\hline Lineal & 0.79 \\
\hline Exponencial & 0.76 \\
\hline Logarítmica & 0.74 \\
\hline
\end{tabular}

Elaboración propia

Es por ello que en la tabla 5.12 se muestra el pronóstico de ventas para los siguientes 12 meses bajo la siguiente ecuación de la regresión potencial:

$$
y=1515 x^{0.3156}
$$

Tabla 5.12

Pronóstico de Venta en cajas de 252 sachets de 10 gr para los próximos 12 meses

\begin{tabular}{|c|c|c|c|c|c|c|c|c|c|c|c|c|}
\hline $\begin{array}{l}\text { Pronostico de } \\
\text { Venta en cajas }\end{array}$ & 3404 & 3484 & 3561 & 3634 & 3705 & 3772 & 3837 & 3900 & 3960 & 4019 & 4075 & 4131 \\
\hline
\end{tabular}

Fuente: ALIEX (2016)

Ahora se calcularán las cajas adicionales que se venderán en los próximos 12 meses al tener un \% de utilización de la maquinaria del $100 \%$ lo que quiere decir que se cumplirá el plan de producción al $100 \%$ y al $88 \%$, por lo que tendremos producto terminado suficiente para cumplir con la demanda pronosticada. En la tabla 5.13 se muestra las cajas de ventas adicionales a vender en los próximos 12 meses después de implementar las 2 soluciones. Cabe recalcar que las HM que sobran son utilizadas para envasar otras salsas como kétchup y mostaza. 
Tabla 5.13

Cajas de 252 sachets de 10 gr. adicionales a vender

\begin{tabular}{|c|c|c|c|c|c|c|c|c|c|c|c|c|}
\cline { 2 - 11 } \multicolumn{1}{c|}{} & $\mathbf{1}$ & $\mathbf{2}$ & $\mathbf{3}$ & $\mathbf{4}$ & $\mathbf{5}$ & $\mathbf{6}$ & $\mathbf{7}$ & $\mathbf{8}$ & $\mathbf{9}$ & $\mathbf{1 0}$ & $\mathbf{1 1}$ & $\mathbf{1 2}$ \\
\hline $\begin{array}{c}\text { Venta Real con } \\
\mathbf{8 8 \%} \text { de utilización }\end{array}$ & 2995 & 3066 & 3134 & 3198 & 3260 & 3319 & 3377 & 3432 & 3485 & 3536 & 3586 & 3635 \\
\hline $\begin{array}{c}\text { Venta adicional en } \\
\text { cajas con 100\% de } \\
\text { utilización }\end{array}$ & 408 & 418 & 427 & 436 & 445 & 453 & 460 & 468 & 475 & 482 & 489 & 496 \\
\hline
\end{tabular}

Elaboración propia

\subsubsection{Elaboración del presupuesto general requerido para la ejecución de la}

\section{solución}

En la tabla 5.14 se detalla la inversión inicial en la que se incurrirá por implementar la solución de adquirir un software en donde se obtiene un total de S/. 47300.

Tabla 5.14

Presupuesto en soles de las soluciones propuestas

\begin{tabular}{|l|c|c|c|}
\hline \multicolumn{1}{|c|}{ Actividad } & $\begin{array}{c}\text { Horas } \\
\text { Totales }\end{array}$ & $\begin{array}{c}\text { Costo por } \\
\text { hora s/. }\end{array}$ & Total S/. \\
\hline 1. Capacitaciones para el personal & 10 & 100 & S/.1,000 \\
\hline 2.Contratación e inducción de un analista para PCP & 10 & 15 & S/.150 \\
\hline 3.Búsqueda de software & 10 & 15 & S/.150 \\
\hline 4.Adquisición/instalación del software en el mercado. & & & S/.44,000 \\
\hline 4.1 Lincencias Capatax Flex (2 users) & & & S/.20,000 \\
\hline 4.2 Licencias SQL, base de datos & & & S/. 5,000 \\
\hline 4.3 Servicios de implementación y capacitación & & & S/. 15,000 \\
\hline \multicolumn{1}{|c|}{ 4.4 Servicios de mantenimiento anual 2016 } & & & $\mathrm{S} / .2,000$ \\
\hline 5. Infraestructura ( 1 Computadora de escritorio) & & & $\mathrm{S} / .2,000$ \\
\hline Total Inversión Inicial & & & S/.47,300 \\
\hline
\end{tabular}

Elaboración propia

Existen 3 costos más asociados a la implementación de ambas soluciones: el primero es el sueldo del analista PCP de S/.2800 mensuales y el segundo y tercero son los costos del mantenimiento preventivo de la licuadora y envasadora de S/.301.09 cada 60 días y S/. 1599.50 cada 90 días respectivamente (en el anexo 4 y 5 se encuentra el detalle de dichos costos). En la evaluación económica se visualizarán tales flujos. 


\subsubsection{Cronograma de implementación de las soluciones}

De la tabla 5.15 se concluye que después de 9 semanas, el software Capataz Flex estará implementado en ALIEX.

Asimismo en la semana 1 se ejecutará el primer plan de trabajo de mantenimiento preventivo de ambas máquinas. En el anexo 5 se muestra el programa de mantenimiento preventivo completo para los próximos 12 meses.

Tabla 5.15

Cronograma de implementación de las soluciones propuestas

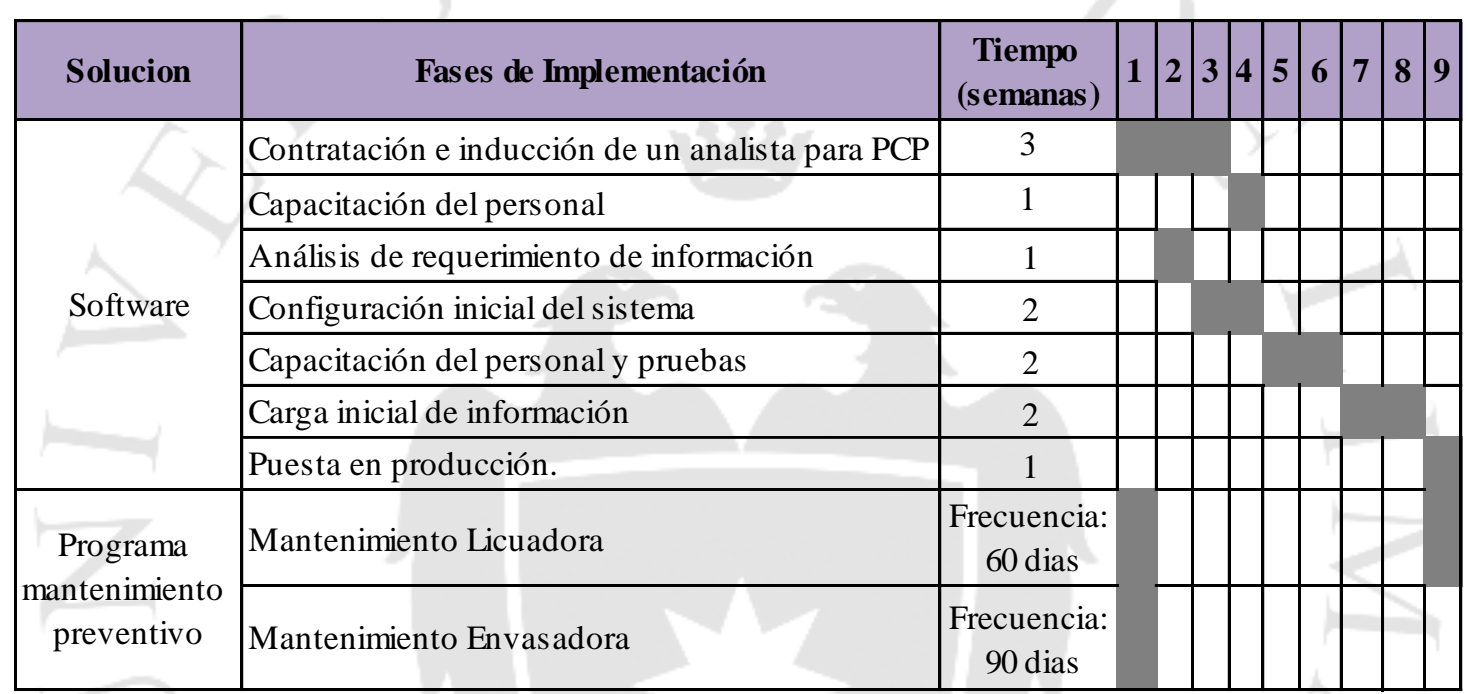

Elaboración propia 


\section{CAPÍTULO VI. EVALUACIÓN DE LA SOLUCIÓN Y BENEFICIOS ESPERADOS}

\subsection{Evaluación económica financiera de la solución}

En el presente punto analizaremos si el proyecto es económicamente viable.

El ingreso por ventas se calculó en base a las ventas adicionales que la empresa tendrá por cumplir con el programa de producción y poder cumplir con la demanda proyectada. Por otro lado, se utilizó un cok (costo del accionista del capital) del 22\% el cual se obtiene al dividir la Utilidad Neta del 2015 entre el total patrimonio de la empresa. En la tabla 6.1 se muestra el flujo económico

\section{Tabla 6.1}

Flujo económico de la solución

\begin{tabular}{|c|c|c|c|c|c|c|c|c|c|c|c|c|c|}
\hline & 0 & 1 & 2 & 3 & 4 & 5 & 6 & 7 & 8 & 9 & 10 & 11 & 12 \\
\hline Inversión Inicial S/. & S/. 47,300 & & & 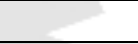 & & & & & & & & & \\
\hline$(+)$ Ingreso por ventas & & S/. 17,972 & S/. 18,398 & S/. 18,803 & S/. 19,190 & S/. 19,560 & S/. 19,916 & S/. 20,259 & S/. 20,590 & S/. 20,909 & S/. 21,219 & S/. 21,518 & S/. 21,809 \\
\hline (-) Sueldo del analista PCP & Y & S/. 2,800 & S/. 2,800 & S/. 2,800 & S/. 2,800 & S/. 2,800 & S/. 2,800 & S/. 2,800 & S/. 2,800 & S/. 2,800 & S/. 2,800 & S/. 2,800 & S/. 2,800 \\
\hline (-) Mantenimiento preventivo licuadora & & S/. 301 & & S/. 301 & & S/. 301 & & S/. 301 & & S/. 301 & & S/. 301 & \\
\hline (-) Mantenimiento preventivo envasadora & & S/. 1,599.50 & & & S/. 1,599.50 & & & S/. 1,599.50 & & & S/. 1,599.50 & & \\
\hline Flujo Neto de Fondos económicos & S/. 47,300 & S/. 13,272 & S/. 15,598 & S/. 15,702 & S/. 14,790 & S/. 16,459 & S/. 17,116 & S/. 15,559 & S/. 17,790 & S/. 17,808 & S/. 16,819 & S/. 18,417 & S/. 19,009 \\
\hline
\end{tabular}

Elaboración propia

Se obtiene un VAN mayor a 0 y una TIR mayor a la tasa (22\%) por lo que el proyecto es económicamente viable.

\begin{tabular}{|c|c|}
\hline VAN & S/. 17,247 \\
\hline TIR & $31 \%$ \\
\hline
\end{tabular}




\subsection{Determinación de escenarios que afectarían la solución}

El evento que afectaría a la solución propuesta es que no exista demanda en el mercado para la venta de cajas de 252 sachets de 10 gr, lo que ocasionaría no lograr el VAN ni TIR deseado. A continuación se hará un análisis de sensibilidad, el cual permitirá hallar la probabilidad de tener un escenario optimista y otro pesimista., asi como el VAN y TIR esperado al ponderar tales escenarios.

En la figura 6.1 se muestra la regresión potencial de las ventas del producto en el 2015.

Figura 6.1

Evolutivo ventas en soles 2015 - Cajas de 252 sachets de 10 gr

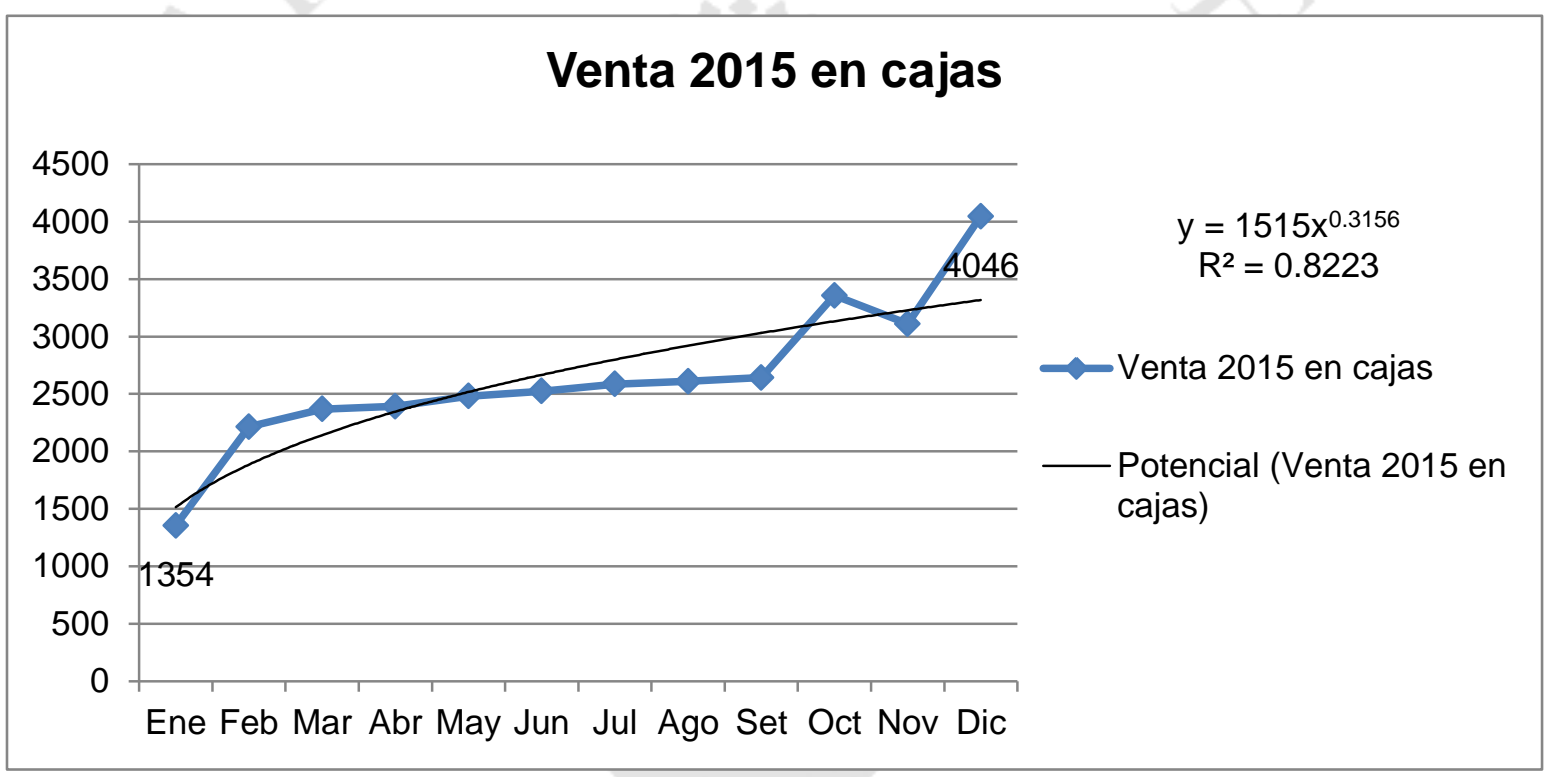

Elaboración propia

Son 12 puntos en total, de los cuales 5 están por encima de la línea de tendencia y 7 por debajo, por ende la probabilidad de tener un escenario optimista y pesimista es de $42 \%$ y $58 \%$ respectivamente.

Ahora se determinará qué tan bueno o qué tan malo sería cada escenario, es decir cuanto más o cuanto menos se podría vender. Para ello se calculará el porcentaje de diferencia que existe entre el mes con mayor venta vs la línea de regresión y el porcentaje de diferencia entre el mes de menor venta vs la línea de regresión.

En la tabla 6.2 se detalla que en un escenario Optimista se vendería 22\% más y en uno pesimista se vendería $11 \%$ menos. Con esta información se calcularán los 
nuevos ingresos de ventas para calcular el VAN y TIR esperado según las probabilidades. Para ello se muestran los análisis económicos para cada escenario en la tabla 6.3 y 6.4 .

Tabla 6.2

Características de cada escenario

\begin{tabular}{|c|c|c|c|c|}
\hline $\begin{array}{c}\text { Tipo de } \\
\text { escenario }\end{array}$ & Probabilidad & $\mathbf{y}=\mathbf{1 5 1 5 \mathbf { x } ^ { \mathbf { 0 . 3 1 5 6 } }}$ & $\begin{array}{c}\text { Punto más } \\
\text { alto } \mathbf{y} \text { bajo }\end{array}$ & $\begin{array}{c}\text { \% de } \\
\text { diferencia }\end{array}$ \\
\hline Optimista & $42 \%$ & 3319 & 4046 & $22 \%$ \\
\hline Pesimista & $58 \%$ & 1515 & 1354 & $-11 \%$ \\
\hline
\end{tabular}

Elaboración propia 


\section{Escenario Optimista}

\section{Tabla 6.3}

Flujo económico del escenario optimista de la solución

\begin{tabular}{|c|c|c|c|c|c|c|c|c|c|c|c|c|c|}
\hline & 0 & 1 & 2 & 3 & 4 & 5 & 6 & 7 & 8 & 9 & 10 & 11 & 12 \\
\hline Inversión Inicial S/. & S/. 47,300 & 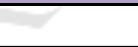 & & & & & & +2 & & & & & \\
\hline$(+)$ Ingreso por ventas & 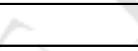 & S/. 21,909 & S/. 22,428 & S/. 22,922 & S/. 23,393 & S/. 23,845 & S/. 24,279 & S/. 24,697 & S/. 25,100 & S/. 25,490 & S/. 25,867 & S/. 26,232 & S/. 26,587 \\
\hline (-) Sueldo del analista PCP & 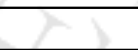 & S/. 2,800 & S/. 2,800 & S/. 2,800 & S/. 2,800 & S/. 2,800 & S/. 2,800 & $\mathrm{S} / .2,800$ & $\mathrm{~S} / .2,800$ & S/. 2,800 & S/. 2,800 & S/. 2,800 & S/. 2,800 \\
\hline (-) Mantenimiento preventivo licuadora & +2 & S/. 301 & & S/. 301 & & S/. 301 & & S/. 301 & & S/. 301 & & S/. 301 & \\
\hline (-) Mantenimiento preventivo envasadora & & S/. $1,599.50$ & & & S/. 1,599.50 & & & S/. $1,599.50$ & A & & S/. $1,599.50$ & & \\
\hline Flujo Neto de Fondos económicos & S/. 47,300 & S/. 17,209 & S/. 19,628 & S/. 19,820 & S/. 18,994 & S/. 20,744 & S/. 21,479 & S/. 19,996 & S/. 22,300 & S/. 22,388 & S/. 21,467 & S/. 23,131 & S/. 23,787 \\
\hline
\end{tabular}

Elaboración propia

Escenario Pesimista

Tabla 6.4

Flujo económico del escenario pesimista

\begin{tabular}{|c|c|c|c|c|c|c|c|c|c|c|c|c|c|}
\hline & $\mathbf{0}$ & 1 & 2 & 3 & 4 & 5 & 6 & 7 & 8 & 9 & 10 & 11 & 12 \\
\hline Inversión Inicial S/. & S/. 47,300 & & & 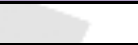 & & & & & & & & & \\
\hline (+) Ingreso por ventas & +2 & S/. 16,062 & S/. 16,443 & S/. 16,805 & S/. 17,150 & S/. 17,482 & S/. 17,800 & S/. 18,106 & S/. 18,402 & S/. 18,687 & S/. 18,964 & S/. 19,232 & S/. 19,492 \\
\hline (-) Sueldo del analista PCP & & S/. 2,800 & S/. 2,800 & S/. 2,800 & S/. 2,800 & S/. 2,800 & S/. 2,800 & S/. 2,800 & S/. 2,800 & S/. 2,800 & S/. 2,800 & S/. 2,800 & S/. 2,800 \\
\hline (-) Mantenimiento preventivo licuadora & & S/. 301 & & S/. 301 & & S/. 301 & & S/. 301 & & S/. 301 & & S/. 301 & \\
\hline (-) Mantenimiento preventivo envasadora & & S/. $1,599.50$ & & & S/. 1,599.50 & & & S/. $1,599.50$ & & & S/. 1,599.50 & & \\
\hline Flujo Neto de Fondos económicos & S/. 47,300 & S/. 11,362 & S/. 13,643 & S/. 13,703 & S/. 12,751 & S/. 14,381 & S/. 15,000 & S/. 13,406 & S/. 15,602 & S/. 15,586 & S/. 14,564 & S/. 16,130 & S/. 16,692 \\
\hline
\end{tabular}

Elaboración propia

En la tabla 6.5 se obtiene el VAN y TIR esperado de S/. 19,659 y 32\%. Tales resultados se obtuvieron al ponderar la probabilidad de que suceda cada escenario con su respectivo VAN y TIR. Se concluye que a pesar de que hayan cambios en la demanda, el proyecto sigue siendo viable pues el VAN esperado es mayor a 0 y la TIR mayor al COK de $22 \%$. 
Tabla 6.5

Resultados ponderados de escenarios que afectarían la solución

\begin{tabular}{|c|c|c|c|}
\cline { 2 - 4 } \multicolumn{1}{c|}{} & Optimista & Pesimista & Esperado \\
\hline VAN & S/.34,648 & S/. 8,805 & S/. 19,659 \\
\hline TIR & $40 \%$ & $27 \%$ & $32 \%$ \\
\hline
\end{tabular}

Elaboración propia

\subsection{Análisis del impacto social y ambiental de la solución}

Impacto Social: A continuación calcularemos indicadores e índices de interés social.

- Valor Agregado: En la presente investigación se obtiene un valor agregado de S./ 20579 al haber sumado lo que se le pagará al analista PCP en los próximos 12 meses (se calculó su VAN) y la inversión inicial para adquirir el software, reclutar al personal y capacitar.

- Densidad de Capital: Indica la relación de la inversión del capital versus los empleos generados. La densidad del proyecto es de 47300 pues por 1 empleo generado se invierte dicha cantidad.

$$
\text { Densidad de capital }=\frac{\text { Inversión del proyecto }}{\# \text { de empleos generados }}
$$

- Intensidad de Capital: Indica la relación de la inversión total versus el valor agregado del proyecto, nos permite medir cual es el grado de aporte del proyecto a través del nivel de la inversión, para generar valor agregado sobre los insumos. Se concluye que se invierte 2.30 nuevos soles al generar 1 nuevo sol de valor agregado.

$$
\text { Intensidad de capital }=\frac{\text { Inversión del proyecto }}{\text { Valor agregado }}
$$

- Productividad Mano de Obra: Es un índice que nos permite analizar cuál es la capacidad de la mano de obra empleada para generar producción para el 
proyecto. Se concluye que se generan 79436 nuevos soles al generar 1 empleo en este proyecto. Dicho resultado es muy bueno pues no se necesita mucha mano de obra para vender.

$$
\text { Producción M.O }=\frac{\text { Producción }(\text { Ventas })}{\# \text { de empleos generados }}
$$

- Relación Producto - Capital: Es el llamado coeficiente de Capital, mide la relación entre el valor agregado generado en el proyecto, versus el monto de la inversión total. Se concluye que se genera 1.37 nuevos soles de valor agregado al invertir 1 nuevo sol. Este resultado es positivo pues se genera más de lo que se invierte.

$$
\text { Produto }- \text { Capital }=\frac{\text { Valor agregado }}{\text { Inversión del proyecto }}
$$

Impacto Ambiental: A continuación se muestran, en la tabla 6.6, los posibles impactos ambientales que se podrían generar al implementar la solución propuesta, de donde no se observa ningún impacto crítico pues todos los niveles son medios o bajos

\section{Tabla 6.6}

Análisis ambiental de la solución propuesta

\begin{tabular}{|c|l|c|c|}
\hline \multicolumn{1}{|c|}{ Procesos } & \multicolumn{1}{c|}{ Aspecto ambiental } & Impacto ambiental & $\begin{array}{c}\text { Nivel de } \\
\text { impacto }\end{array}$ \\
\hline \multirow{2}{*}{$\begin{array}{c}\text { Licuado - Mayor utilización de la } \\
\text { máquina }\end{array}$} & Mayor consumo de energia & $\begin{array}{c}\text { Recurso propenso a } \\
\text { agotarse }\end{array}$ & Bajo \\
\cline { 2 - 4 } & Mayor ruido generado & Afección al oído (sordera) & Medio \\
\hline \multirow{2}{*}{$\begin{array}{c}\text { Envasado - Mayor utilización de la } \\
\text { máquina }\end{array}$} & $\begin{array}{c}\text { Recurso propenso a } \\
\text { agotarse }\end{array}$ & Bajo \\
\cline { 2 - 4 } & Mayor consumo de energia & Afección al oído (sordera) & Medio \\
\hline Distribución y venta de productos & Emisión de CO2 a causa de camiones & Cambio climático & Medio \\
\hline Implementación de Software & Mayor consumo de energia & $\begin{array}{c}\text { Recurso propenso a } \\
\text { agotarse }\end{array}$ & Bajo \\
\hline
\end{tabular}

Elaboración propia 


\section{CONCLUSIONES}

- Gracias al uso de las diversas herramientas de ingeniería y de mejora continua, se logró determinar que el proceso productivo de ALIEX es el proceso con mayores oportunidades de mejora, al cual se plantearon alternativas de solución para eliminar los factores que ocasionaban una disminución en la eficiencia de los procesos.

- Tras haber evaluado las diferentes causas que limitan obtener los resultados deseados en el desempeño del proceso productivo de mayonesa, se concluye que la principal causa raíz es no manejar una planificación adecuada para el abastecimiento de insumos y materia prima.

- Después de haber propuesto diversas alternativas de solución para la principal causa raíz, se optó por adquirir un software MRP I en el mercado, el cual ayudará a ALIEX a contar con los insumos y materia prima en el momento deseado y en la cantidad requerida. Esto contribuirá a eliminar las paradas prolongadas del proceso de producción de mayonesa y a cumplir con el programa de producción semanal, maximizando así la producción y los recursos disponibles. Como consecuencia de ello, se contará con producto disponible para cubrir la demanda proyectada.

- Implementar la mejora aplicada al proceso de producción de mayonesa es económicamente viable pues se obtiene un VAN positivo y una TIR mayor al costo del capital del accionista, incluso para los escenarios que podrían afectar el resultado de la solución. 


\section{RECOMENDACIONES}

- Para la implementación de las soluciones propuestas se recomienda generar compromiso tanto por parte de la gerencia quienes brindarán los recursos necesarios para cumplir con los objetivos planteados, así como compromiso por parte de los trabajadores quienes aportarán sus habilidades y destrezas para el desarrollo de las soluciones.

- Realizar un análisis a los indicadores de producción luego de haber implementado las mejoras propuestas con el fin de medir el impacto de la mejora. Asimismo, se les deberían realizar un seguimiento constante al comportamiento de los indicadores e identificar posibles desvíos.

- Es necesario evaluar y elegir minuciosamente al proveedor del software a adquirir, así como realizar las pruebas necesarias durante su instalación, todo esto con el fin de no tener problemas posteriormente. Por otro lado, el analista PCP debe estar bien capacitado para manipular el software. 


\section{REFERENCIAS}

ALIEX. (2000). Alimentos de exportación SAC. Visitado: 2016, 23 de Enero. Recuperado de: www.aliexperu.com

Bonilla, E., Diaz, B., Kleeberg, F., Noriega, M.T. (2010). Mejora Continua de los Procesos. Lima: Universidad de Lima

Capataz Software. (1994). Capataz Software Flex. Visitado: 2016, 22 de Julio. Recuperado de: www.capatazsoft.com.ar

Carmelo Oria, Jose Junor. Wai Lee Wong, Danny Chun. (2012). Mejora aplicada en el área de producción en una empresa panificadora. (Seminario de investigación). Lima: Universidad de Lima

Chiggo Gino Giovanni, Parra Alfaro Nadia Eliana. (2012). Mejora en el área de producción de la empresa Tecno Carne Perú SAC. (Seminario de investigación). Lima: Universidad de Lima

Company, Ramón., Fonollosa, J. (1999). Nuevas Técnicas de gestión de stock: MRP Y JIT. México.

Pallete Herrera, Agustin Manuel (2009). Estudio para la mejora de la productividad de una Planta de concentrado de cobre en la empresa Enproyec. (Seminario de investigación). Lima: Universidad de Lima

Pietrapiana, F. (2007) Mejora de la productividad en el sistema de producción en una empresa vinícola, (Trabajo de investigación para optar por el título profesional de Ingeniería Industrial). Lima: Universidad de Lima

Project Management Institute. (2008). Guía de los fundamentos para la dirección de proyectos: guía del PMBOK. Pennsylvania. 


\section{BIBLIOGRAFIA}

ALIEX. (2000). Alimentos de exportación SAC. Visitado: 2016, 23 de Enero.

Recuperado de: www.aliexperu.com 


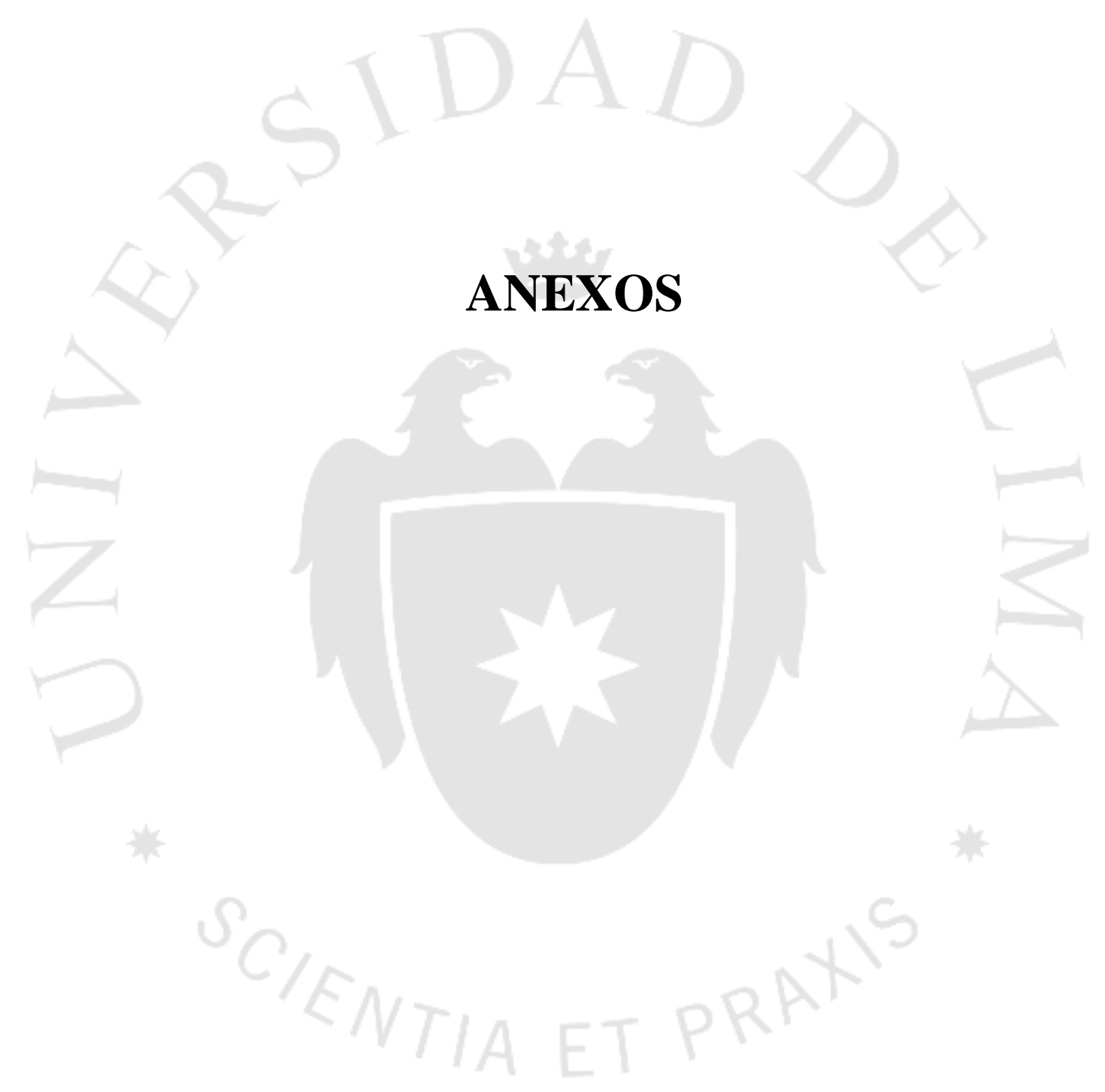


ANEXO 1: Formato de encuesta virtual para la definición de las estrategias genéricas de ALIEX

Te pedimos otorgues una puntuación a cada una de las siguientes fortalezas que podría tener la empresa. Marca 0 si no la tiene en absoluto, o 10 si la tiene plenamente.

Area en la que laboras *

1. Alta capacidad de producción de productos sofisticados *

\begin{tabular}{|l|l|l|l|l|l|l|l|l|l|}
1 & 2 & 3 & 4 & 5 & 6 & 7 & 8 & 9 & 10 \\
\hline & & & & & & & & & \\
\hline
\end{tabular}

2. Alta capacidad de producción de productos tradicionales *

\begin{tabular}{|l|l|l|l|l|l|l|l|l|l|}
1 & 2 & 3 & 4 & 5 & 6 & 7 & 8 & 9 & 10 \\
\hline & & & & & & & & & \\
\hline
\end{tabular}

3. Bajos costos de producción *

\begin{tabular}{|l|l|l|l|l|l|l|l|l|l|l|}
1 & 2 & 3 & 4 & 5 & 6 & 7 & 8 & 9 & 10 \\
\hline & & & & & & & & & \\
\hline
\end{tabular}

4. Poder de negociación con clientes industriales *

\begin{tabular}{|l|l|l|l|l|l|l|l|l|l|}
1 & 2 & 3 & 4 & 5 & 6 & 7 & 8 & 9 & 10 \\
\hline & & & & & & & & & \\
\hline
\end{tabular}

5. Capacidad para desarrollar productos personalizados *

\begin{tabular}{|l|l|l|l|l|l|l|l|l|l|l|}
1 & 2 & 3 & 4 & 5 & 6 & 7 & 8 & 9 & 10 \\
\hline & & & & & & & & & \\
\hline
\end{tabular}

6. Certificaciones de calidad *

\begin{tabular}{|l|l|l|l|l|l|l|l|l|l|}
1 & 2 & 3 & 4 & 5 & 6 & 7 & 8 & 9 & 10 \\
\hline & & & & & & & & & \\
\hline
\end{tabular}

7. Cultivo de relaciones personales con los clientes finales *

\begin{tabular}{|l|l|l|l|l|l|l|l|l|l|}
1 & 2 & 3 & 4 & 5 & 6 & 7 & 8 & 9 & 10 \\
\hline & & & & & & & & & \\
\hline
\end{tabular}


8. Empaques y envases simples *

\begin{tabular}{|l|l|l|l|l|l|l|l|l|l|}
1 & 2 & 3 & 4 & 5 & 6 & 7 & 8 & 9 & 10 \\
\hline & & & & & & & & & \\
\hline
\end{tabular}

9. Empaques y envases sofisticados. *

\begin{tabular}{|l|l|l|l|l|l|l|l|l|l|}
1 & 2 & 3 & 4 & 5 & 6 & 7 & 8 & 9 & 10 \\
\hline & & & & & & & & & \\
\hline
\end{tabular}

10. Especialización en producir productos de alto valor agregado *

\begin{tabular}{|l|l|l|l|l|l|l|l|l|l|}
1 & 2 & 3 & 4 & 5 & 6 & 7 & 8 & 9 & 10 \\
\hline & & & & & & & & & \\
\hline
\end{tabular}

11. Fuerza de ventas en autoservicios y bodegas *

\begin{tabular}{|l|l|l|l|l|l|l|l|l|l|}
1 & 2 & 3 & 4 & 5 & 6 & 7 & 8 & 9 & 10 \\
\hline & & & & & & & & & \\
\hline
\end{tabular}

12. Fuerza de ventas en mercados tradicionales (Mayoristas) *

\begin{tabular}{|l|l|l|l|l|l|l|l|l|l|}
1 & 2 & 3 & 4 & 5 & 6 & 7 & 8 & 9 & 10 \\
\hline & & & & & & & & & \\
\hline
\end{tabular}

13. Fuerza de ventas en negocios de comida *

\begin{tabular}{|l|l|l|l|l|l|l|l|l|l|l|l|}
1 & 2 & 3 & 4 & 5 & 6 & 7 & 8 & 9 & 10 \\
\hline & & & & & & & & & \\
\hline
\end{tabular}

14. Inversión en publicidad masiva *

\begin{tabular}{|l|l|l|l|l|l|l|l|l|l|}
1 & 2 & 3 & 4 & 5 & 6 & 7 & 8 & 9 & 10 \\
\hline & & & & & & & & & \\
\hline
\end{tabular}

15. Poder de negociación con autoservicios y bodegas *

\begin{tabular}{|l|l|l|l|l|l|l|l|l|l|}
1 & 2 & 3 & 4 & 5 & 6 & 7 & 8 & 9 & 10 \\
\hline & & & & & & & & & \\
\hline
\end{tabular}

16. Poder de negociación en mercados tradicionales (mayoristas) *

\begin{tabular}{|l|l|l|l|l|l|l|l|l|l|}
1 & 2 & 3 & 4 & 5 & 6 & 7 & 8 & 9 & 10 \\
\hline & & & & & & & & & \\
\hline
\end{tabular}


17. Posicionamiento por bajo precio de productos *

\begin{tabular}{|l|l|l|l|l|l|l|l|l|l|l|}
1 & 2 & 3 & 4 & 5 & 6 & 7 & 8 & 9 & 10 \\
\hline & & & & & & & & & \\
\hline
\end{tabular}

18. Posicionamiento por calidad de productos *

\begin{tabular}{|l|l|l|l|l|l|l|l|l|l|}
1 & 2 & 3 & 4 & 5 & 6 & 7 & 8 & 9 & 10 \\
\hline & & & & & & & & & \\
\hline
\end{tabular}

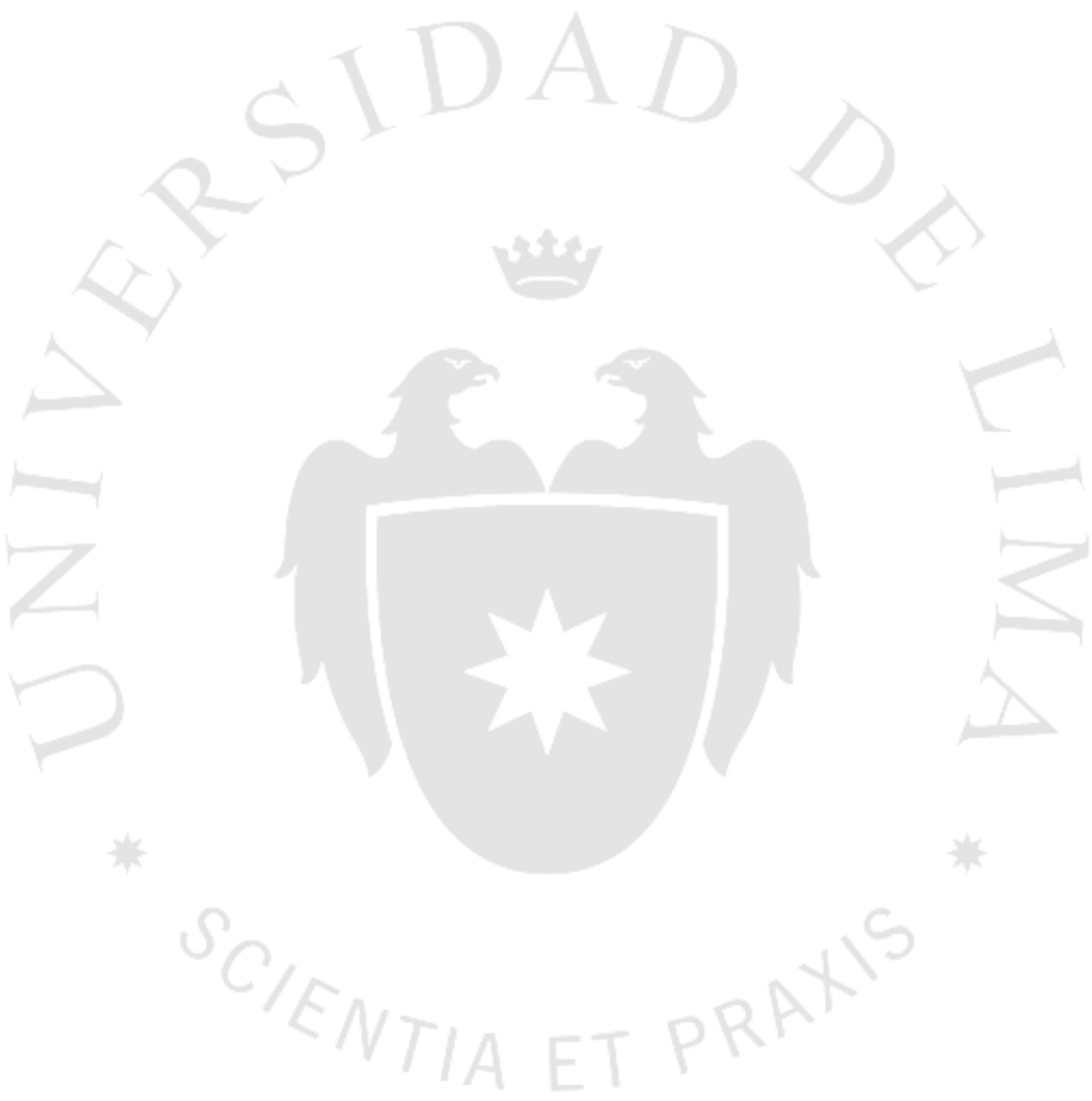




\section{ANEXO 2: Puntuación obtenida en la encuesta sobre ventajas competitivas}

\begin{tabular}{|c|c|c|c|c|c|c|c|c|c|c|c|c|c|c|c|c|c|c|c|}
\hline Nombre de usuario & $\begin{array}{l}\text { Área en la que } \\
\text { laboras }\end{array}$ & 1 & 2 & 3 & 4 & 5 & 6 & 7 & 8 & 9 & 10 & 11 & 12 & 13 & 14 & 15 & 16 & 17 & 18 \\
\hline Imanrique@aliexperu.com & Contabilidad & 5 & 9 & 5 & 6 & 6 & 6 & 6 & 5 & 3 & 5 & 3 & 8 & 3 & 3 & 4 & 8 & 7 & 7 \\
\hline mbustamante@aliexperu.com & Ventas & 3 & 6 & 1 & 4 & 5 & 8 & 6 & 5 & 1 & 1 & 7 & 8 & 4 & 4 & 5 & 8 & 5 & 5 \\
\hline mmeza@aliexperu.com & Comercial & 3 & 8 & 7 & 7 & 9 & 6 & 4 & 5 & 1 & 3 & 1 & 8 & 4 & 1 & 1 & 9 & 8 & 8 \\
\hline ssilva@aliexperu.com & C. Calidad & 6 & 9 & 7 & 9 & 8 & 6 & 4 & 9 & 4 & 6 & 5 & 9 & 5 & 3 & 5 & 9 & 7 & 7 \\
\hline gcacho@aliexperu.com & Administración & 2 & 9 & 9 & 7 & 8 & 9 & 6 & 9 & 2 & 3 & 1 & 9 & 6 & 1 & 2 & 9 & 9 & 1 \\
\hline lmezones@aliexperu.com & Luis Mezones & 3 & 7 & 5 & 6 & 6 & 4 & 6 & 8 & 1 & 5 & 1 & 8 & 5 & 1 & 1 & 8 & 7 & 6 \\
\hline rmeza@aliexperu.com & Tesorería & 2 & 6 & 4 & 4 & 2 & 5 & 4 & 5 & 5 & 3 & 1 & 8 & 2 & 1 & 1 & 8 & 3 & 8 \\
\hline dclemente@aliexperu.com & Producción & 7 & 8 & 5 & 8 & 7 & 7 & 8 & 5 & 8 & 7 & 5 & 6 & 6 & 2 & 2 & 3 & 6 & 3 \\
\hline mmostacero@aliexperu.com & Logística & 1 & 7 & 4 & 4 & 2 & 5 & 4 & 7 & 5 & 1 & 1 & 9 & 4 & 4 & 1 & 8 & 7 & 8 \\
\hline fpimentel@aliexperu.com & $\begin{array}{l}\text { Aseguramiento } \\
\text { de Calidad }\end{array}$ & 7 & 9 & 5 & 7 & 6 & 7 & 7 & 7 & 5 & 4 & 2 & 9 & 4 & 5 & 2 & 8 & 9 & 6 \\
\hline jzucconi@aliexperu.com & Producción & 3 & 8 & 3 & 5 & 4 & 5 & 2 & 8 & 2 & 3 & 1 & 7 & 1 & 1 & 1 & 7 & 6 & 6 \\
\hline jmeza@aliexperu.com & $\begin{array}{l}\text { Gerencia } \\
\text { General }\end{array}$ & 6 & 7 & 4 & 6 & 6 & 3 & 5 & 4 & 5 & 2 & 2 & 10 & 7 & 1 & 1 & 5 & 5 & 5 \\
\hline & $\begin{array}{c}\text { Promedio } \\
\text { simple }\end{array}$ & 4.0 & 7.8 & 4.9 & 6.1 & 5.8 & 5.9 & 5.2 & 6.4 & 3.5 & 3.6 & 2.5 & 8.3 & 4.3 & 2.3 & 2.2 & 7.5 & 6.6 & 5.8 \\
\hline \multicolumn{3}{|c|}{$\begin{array}{l}\text { 1. Alta capacidad de producción de productos } \\
\text { sofisticados }\end{array}$} & \multicolumn{8}{|c|}{$\begin{array}{l}\text { 7. Cultivo de relaciones personales con los clientes } \\
\text { finales }\end{array}$} & \multicolumn{9}{|c|}{ 13. Fuerza de ventas en negocios de comida } \\
\hline \multicolumn{3}{|c|}{$\begin{array}{l}\text { 2. Alta capacidad de producción de productos } \\
\text { tradicionales }\end{array}$} & \multicolumn{8}{|c|}{ 8. Empaques y emvases simples } & \multicolumn{9}{|c|}{ 14. Inversión en publicidad masiva } \\
\hline \multicolumn{3}{|c|}{ 3. Bajos costos de producción } & \multicolumn{8}{|c|}{ 9. Empaques y emvases sofisticados } & \multicolumn{9}{|c|}{$\begin{array}{l}\text { 15. Poder de negociación con autoservicios y } \\
\text { bodegas }\end{array}$} \\
\hline \multicolumn{3}{|c|}{ 4. Poder de negociación con clientes industriales } & \multicolumn{8}{|c|}{$\begin{array}{l}10 \text { Especialización en producir productos de alto } \\
\text { valor agregado }\end{array}$} & \multicolumn{9}{|c|}{ 16. Poder de negociación en mercados tradicionales } \\
\hline \multirow{2}{*}{\multicolumn{3}{|c|}{$\begin{array}{ll}5 . & \text { Capacidad para desarrollar productos } \\
& \text { personalizados } \\
6 . & \text { Certificaciones de calidad }\end{array}$}} & \multicolumn{8}{|c|}{11 Fuerzas en ventas en autoservicios y bodegas } & \multicolumn{9}{|c|}{ 17. Posicionamiento por bajo precio de productos } \\
\hline & & & \multicolumn{8}{|c|}{$\begin{array}{l}12 \text { Fuerzas de ventas en mercados tradicionales } \\
\text { (Mayoristas) }\end{array}$} & \multicolumn{9}{|c|}{ 18. Posicionamiento por calidad de productos } \\
\hline
\end{tabular}

Fuente: ALIEX, (2015) 
ANEXO 3: Plan de trabajo de mantenimiento preventivo para la licuadora de mayonesa

\begin{tabular}{|c|c|c|c|c|c|c|}
\hline \multicolumn{7}{|c|}{$\begin{array}{l}\text { Manual: } \\
\text { Frecuencia: } 60 \text { Dias }\end{array}$} \\
\hline Actividad Preventiva & Componente & $\frac{\text { Duración }}{\text { (h) }}$ & Herramientas & Repuestos & $\begin{array}{l}\text { Costo de M.O. } \\
(\mathrm{S} / .)\end{array}$ & $\begin{array}{r}\text { Costo de } \\
\text { Repuestos } \\
\text { (S/.) }\end{array}$ \\
\hline $\begin{array}{c}\text { Revisión de cuchillas y bastidor } \\
\text { del raspador }\end{array}$ & Componente mecánico & $0.5 \mathrm{~h}$ & Llave francesa $15 "$ & $\begin{array}{l}\text { Jebe sanitario blanco de } \\
5 \mathrm{~mm}\end{array}$ & 5.18 & 50 \\
\hline $\begin{array}{l}\text { Revisión de retenes de la linea } \\
\text { de vacio, tapa, jebe de la tapa }\end{array}$ & Componente mecánico & $1 \mathrm{~h}$ & Llave francesa $15^{\prime \prime}$ & $\begin{array}{c}2 \text { retenes sanitario } \\
\text { blanco } 32-50-10 \\
\end{array}$ & 10.37 & 100 \\
\hline Revisión del motor eléctrico & Componente mecánico & $1.5 \mathrm{~h}$ & $\begin{array}{c}\text { Martillo de goma, llave } \\
\text { mixta } 14, \text { destornillador } \\
\text { punta plana y estrella, } \\
\text { llaves allen. }\end{array}$ & $\begin{array}{c}\text { Rodajes , retenes, barniz } \\
\text { electrico (si fuera } \\
\text { necesario) }\end{array}$ & 15.54 & 120 \\
\hline \multicolumn{7}{|c|}{ 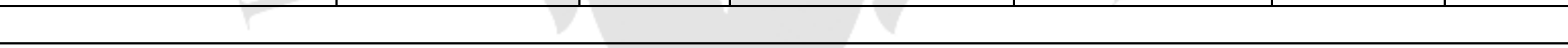 } \\
\hline & & & & TOTALES & 31.09 & 270 \\
\hline Fecha: & $21 / 11 / 2016$ & & & $\begin{array}{r}\text { Costo Total } \\
\text { Tiempo Total } \\
\text { Hecho por : } \\
\text { Aprobado por : }\end{array}$ & $\begin{array}{l}\quad \text { S/. } 301.09 \\
\quad 3 \mathrm{~h} \\
\text { Arturo Rivas } \\
\text { Jean Piero } \\
\text { Zucconi }\end{array}$ & \\
\hline
\end{tabular}


ANEXO 4: Plan de trabajo de mantenimiento preventivo para la envasadora sacheteadora

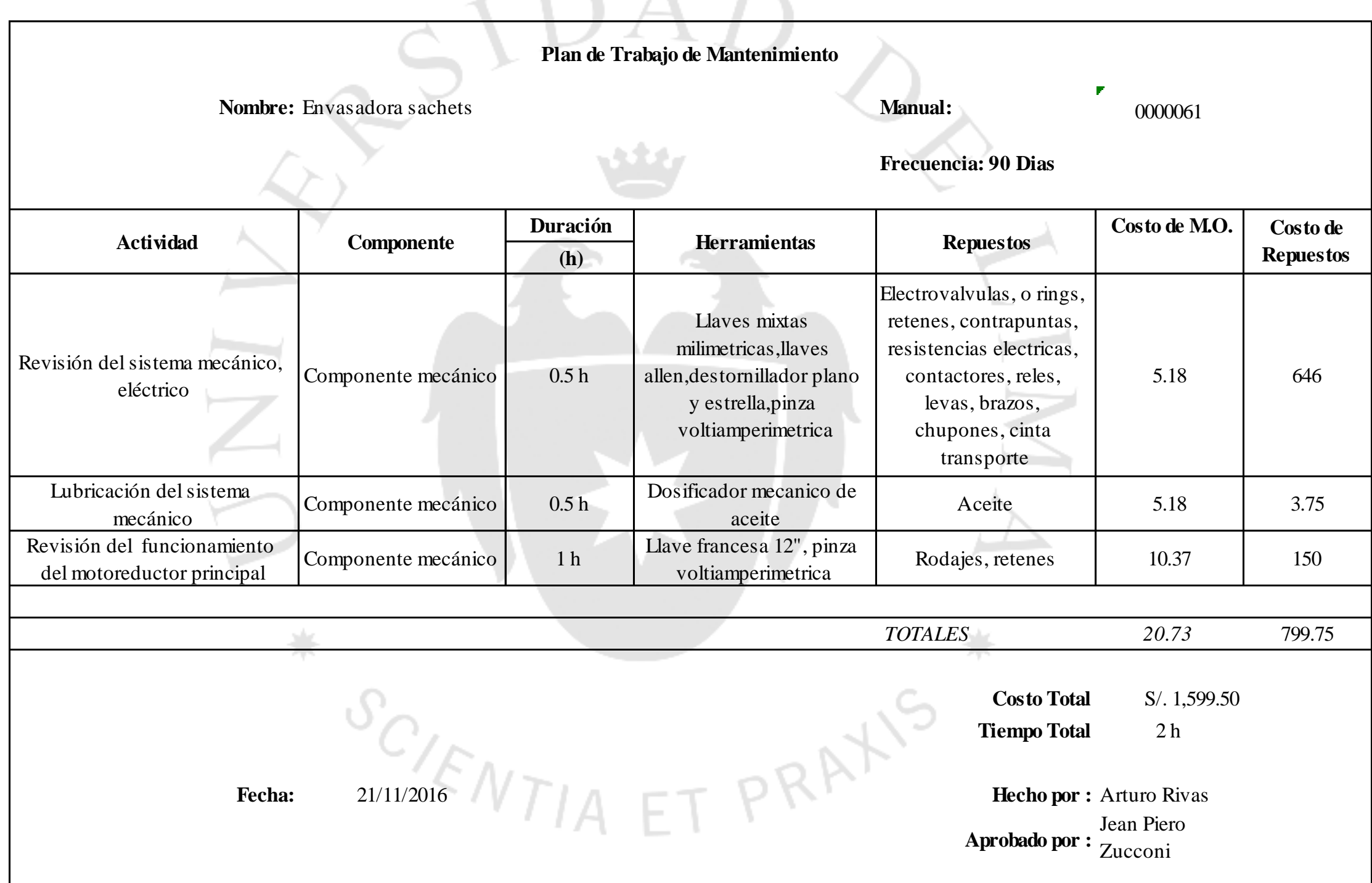


ANEXO 5: Programa de mantenimiento preventivo

\begin{tabular}{|c|c|c|c|c|c|c|c|c|c|c|c|c|}
\hline Maquina & $\mathbf{1}$ & $\mathbf{2}$ & $\mathbf{3}$ & $\mathbf{4}$ & $\mathbf{5}$ & $\mathbf{6}$ & $\mathbf{7}$ & $\mathbf{8}$ & $\mathbf{9}$ & $\mathbf{1 0}$ & $\mathbf{1 1}$ & $\mathbf{1 2}$ \\
\hline Licuadora & P/T 000120 & & P/T 000120 & & P/T 000120 & & P/T 000120 & & P/T 000120 & & P/T 000120 & \\
\hline $\begin{array}{c}\text { Envasadora } \\
\text { sacheteadora }\end{array}$ & P/T 000061 & & & P/T 000061 & & & P/T 000061 & & & P/T 000061 & \\
\hline
\end{tabular}

Elaboración propia 


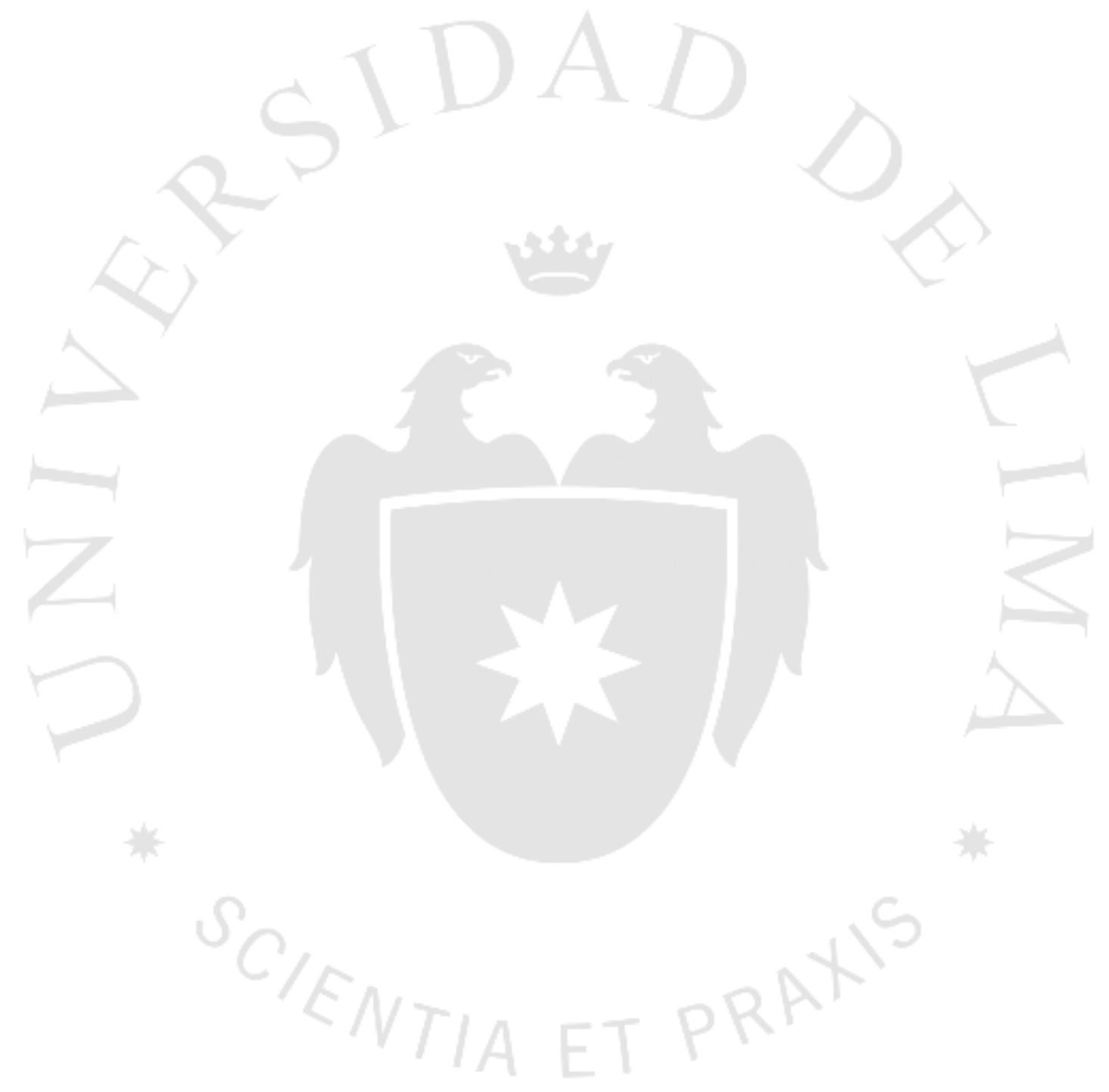

